MARCIA REGINA ECHES PERUGINI

\title{
Avaliação do impacto de medidas de intervenção no controle de Enterococcus spp. resistente a vancomicina em unidade de terapia intensiva
}

Tese apresentada à Faculdade de Medicina da Universidade de São Paulo para obtenção do título de Doutor em Ciências

Área de concentração: Doenças Infecciosas e Parasitárias

Orientadora: Profa. Dra. Silvia Figueiredo Costa

São Paulo

2008 
Agradeço a Deus por sempre me fazer enxergar que com muito esforço, amor e dedicação tudo é possível. 


\section{AGRADECIMENTOS ESPECIAIS}

À minha família

Ao meu marido, Carlos e Aos nossos filhos,

Bruna, Maria Eduarda e Carlos Henrique Em primeiro lugar peço perdão! Perdão pelas horas roubadas, perdão pela ausência, perdão pela falta de carinho. Carlos, eu quero que você saiba que a sua presença em minha vida me faz segura, você é o meu Norte. Divido com todos vocês mais esta vitória e quero dividir ainda o resto da minha vida. Com vocês acredito que vencer é real. Sou feliz por vocês existirem na minha vida. Eu AMO MUITO vocês!!!

Aos meus pais Hélio e Elza Se hoje estou onde estou, devo a vocês, por todo exemplo, todo empenho, todo carinho e por todo Amor. Me perdoem pela ausência e obrigada pelos ensinamentos. Nunca vou me esquecer:

"Se você for o melhor sempre terá um lugar para você". Amo Vocês. 
À minha orientadora

Silvia

Nem tenho palavras para te agadecer! Mas muito obrigada por todo seu ensinamento, por todo seu apoio e por toda sua preocupação. Eu sei que você sempre quis o melhor.

Que Deus te abençoe!!!

Às minhas grandes amigas

Darly

"amigo é um irmão que a gente escolhe", A você minha querida amiga irmã agradeço de todo meu coração pelo carinho, pelo aconchego do seu lar, pelo seu amor e de sua família. Que

Deus os abençoe.

Marsileni, Regina e Vera

É muito difícil conciliar vida profissional

com pós-graduação. Sem vocês eu jamais teria conseguido. Obrigada pela força intelectual e incentivadora. Obrigada pelo apoio e pelas orações.

Vocês são minha família. Esta vitória é nossa. Que Deus dê a vocês em dobro tudo que fizeram por mim.

Neuza e Renata Vocês foram peças chave deste quebra-cabeça. Muito obrigada pelo apoio, pela compreensão e por todo carinho. 


\section{Agradecimentos}

Aos colegas do Laboratório de Investigação médica - LIM 54: Inneke, Anna Karina, Renata, Alexei, Robson, Liang e Elthon pelo apoio técnico e convívio harmonioso. Nunca vou esquecer tudo o que me ensinaram e que fizeram por mim. Muito obrigada é pouco.

Queridos colegas do Setor de Microbiologia do Laboratório de Análises Clínicas do HU. Como é bom ter amigos e poder contar com vocês. Sinto falta de todos.

A todos os meus queridos estagiários os quais não ouso nominar para não correr o risco de esquecer nenhum. Vocês todos foram a base deste trabalho, sem vocês eu jamais teria conseguido. Espero que eu tenha plantado uma sementinha no coração de cada um, que ainda quero ver florescer. Eu me realizo em vocês!!!

Aos meus orientandos dos cursos de Especialização em Controle de Infecção em Serviços de Saúde e Análises Clínicas, pelo auxílo e carinho.

À toda equipe de profissionais das Unidades de Terapia Intensiva do HU, pelas inconvenientes observações, pela paciência conosco e principalmente por terem acreditado no nosso trabalho. A vocês dedico o mérito dos resultados alcançados. Vocês fizeram a diferença. Continuem assim!!

A todos aqueles que participaram da intervenção educacional e colocaram em prática as orientações recebidas. Controle de Infecção é você que faz.

Pessoal da Comissão de Controle de Infecção Hospitalar do HU: Claúdia, Joseani, Emerson, Nick, Regina, Jaqueline, Marsileni, Renata, Neuza, Néia e Fábio obrigada pelo apoio e incentivo.

Á coordenação do Programa de Pós-graduação em Doenças Infecciosas e Parasitárias pelo auxílio e compreensão.

Às secretarias do Programa de Pós-graduação em Doenças Infecciosas e Parasitárias pela Roseli e Rose pela acolhida, apoio e carinho.

Aos colegas do Departamento de Patologia, Análises Clínicas e Toxicológicas da Universidade Estadual de Londrina e à secretária Marina pelo incentivo e apoio dispensados.

A Direção Clinica e Chefia do Laboratório de Análises Clínicas do HU pela liberação durante a realização deste trabalho.

A você que de alguma forma me apoiou, me incentivou, me auxiliou em qualquer etapa deste trabalho, Muito obrigada. 


\section{SUMÁRIO}

Lista de Figuras

Lista de Tabelas

Resumo

Summary

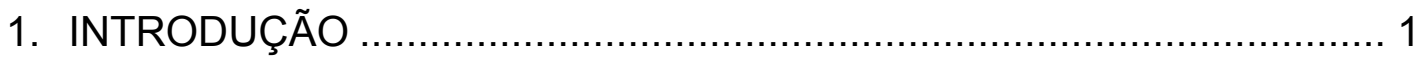

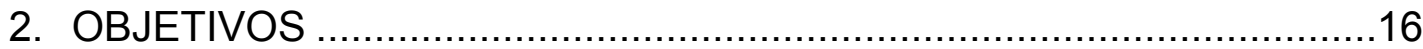

2.1 Objetivo Geral ............................................................ 17

2.2 Objetivos Específicos ................................................... 17

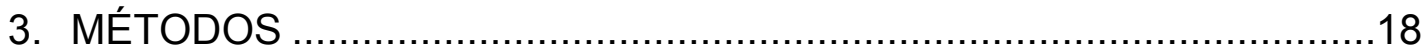

3.1 Local do Estudo............................................................... 19

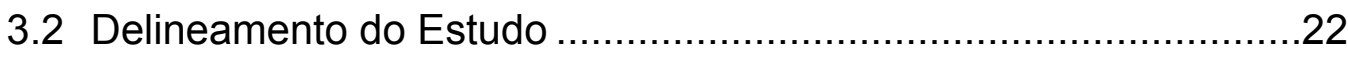

3.3 Períodos Pré-Intervenção..................................................23

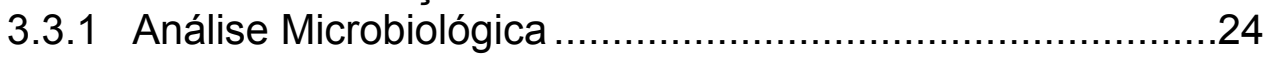

3.3.2 Determinação da densidade de incidência .......................28

3.4 Avaliação dos Dados Demográficos dos Pacientes ......................29

3.4.1 Análise Molecular .......................................................30

3.4.2 Avaliação da Adesão dos Profissionais da Saúde às Medidas de Controle de VRE .........................................32

3.4.3 Avaliação dos Profissionais da Limpeza..........................33

3.4.4 Determinação do Consumo de Glicopeptídeos ..................34

3.5 Período de Intervenção ..........................................................35

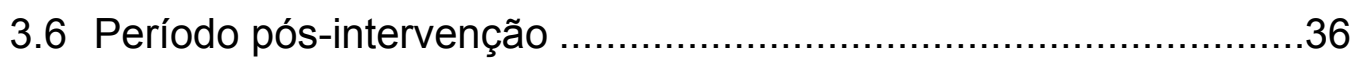

3.7 Análise Estatística .................................................................

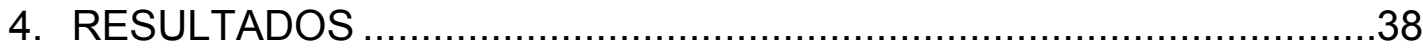

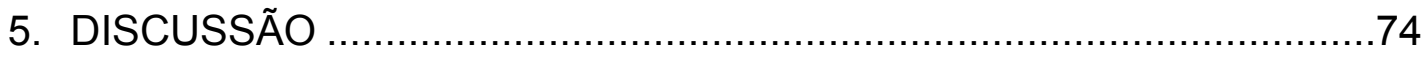

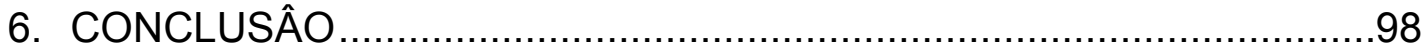

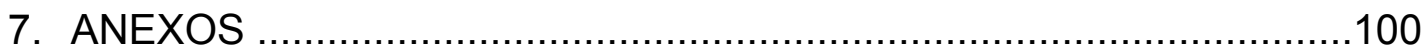

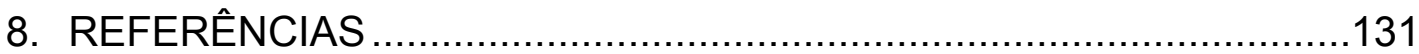




\section{Lista de Figuras}

Figura 1 - Unidade de Terapia Intensiva (UTI I) do Hospital Universitário da Universidade Estadual de Londrina

Figura 2 - Unidade de Terapia Intensiva (UTI II) do Hospital Universitário da Universidade Estadual de Londrina ................20

Figura 3 - Freqüência de VRE em culturas de vigilância realizadas no HU de maio de 2002 a dezembro de 2006, por ano.

Figura 4 - Freqüência de espécies identificadas entre 516 VRE, obtidos de pacientes colonizados e infectados do $\mathrm{HU}$, por ano, no período de maio de 2002 a dezembro de 2007.

Figura 5 - Freqüência de espécies identificadas entre 516 VRE, obtidos de pacientes colonizados e infectados do HU, por ano, no período de maio de 2002 a dezembro de 2007.

Figura 6 - Densidade de Incidência de colonização por VRE por 1.000 pacientes-dia nos anos de 2002 a 2006.

Figura 7 - Densidade de incidência de colonização por VRE por 1.000 pacientes-dia, nas UTIs Gerais do HU de maio de 2002 a dezembro de 2007.

Figura 8 - Densidade de incidência de infecção por VRE por 1.000 pacientes-dia, nas UTIs Gerais do HU dos períodos préintervenção, janeiro de 2006 a março de 2007, intervenção, abril de 2007 e pós-intervenção, de maio a dezembro de 2007.

Figura 9 - Densidade de incidência de colonização por VRE por 1.000 pacientes-dia, nas UTIs Gerais do HU de janeiro de 2005 a dezembro de 2007, mês a mês, nas fases pré e pósintervenção.

Figura 10 - Distribuição de 36 materiais biológicos obtidos de infecções causadas por VRE, no período de julho de 2005 a dezembro de 2007.

Figura 11 - Alguns pontos de coleta de ambiente e equipamentos por box.

Figura 12 - Percentual de VRE de 135 culturas positivas, isolados de 1063 culturas do ambiente e equipamentos próximos a pacientes, realizadas entre maio de 2002 a dezembro de 2007.

Figura 13 - Percentual de positividade de VRE entre 160 culturas de ambiente próximo a pacientes realizadas de abril de 2006 a março de 2007 (período pré-intervenção) e de 252 realizadas de maio a dezembro de 2007 (período pósintervenção). 
Figura 14 - Distribuição de materiais ambientais e equipamentos positivos para VRE de acordo com o Box da UTI I, no momento I de coleta (abril de 2006) do período préintervenção.

Figura 15 - Distribuição de materiais ambientais e equipamentos positivos para VRE de acordo com o Box da UTI III, no momento I de coleta (abril de 2006), período pré-intervenção. ...53

Figura 16 - Distribuição de materiais positivos para VRE de acordo com a localização na UTI I, e Posto de Enfermagem, momento IV (novembro de 2007) do período pós-intervenção.

Figura 17 - Distribuição de materiais positivos para VRE de acordo com a localização na UTI II, momento IV (novembro de 2007) do período pós-intervenção.

Figura 18 - Comparação da freqüência de culturas positivas de ambiente, densidade de colonização e densidade de infecção por 1000 pacientes-dia, dos períodos em que foram realizadas culuras ambientais e de equipamentos.

Figura 19 - Padrão de Restrição de 15 cepas de E. faecium e 2 de E.faecalis obtidas de materiais biológicos, de colonização e de contaminação ambiental dos anos 2002 e 2003.

Figura 20 - Padrões de restrição de isolados de E. faecium e E.faecalis...61

Figura 21 - Padrões de restrição de isolados de E. faecium de 2007 .......62

Figura 22 - Padrões de restrição de isolados de $E$. faecium e $E$. faecalis obtidos de materiais biológicos em 2007 de pacientes internados nas UTIs, Pronto Socorro e Enfermarias.

Figura 23 - Padrões de restrição de isolados de E. faecium de 2004 a 2007.

Figura 24 - Dendrograma contendo padrões moleculares de PFGE de 27 amostras de VRE entre E. faecium e de E. faecalis que paresentaram perfis moleculares diferentes.

Figura 25 - Reação de Cadeia em polimerase (PCR) de 12 amostras E.faecium e E. faecalis isoladas de infecção e de ambiente....66

Figura 26 - Média da Dose Diária Definida de Vancomicina (DDD) nos anos de 2002 a 2007.

Figura 27 - DDD de vancomicina e teicoplanina dos períodos pré e pósintervenção por mês. 


\section{Lista de Tabelas}

Tabela 1 - Critérios interpretativos para análise de tipagem molecular.....30

Tabela 2 - Características clínicas e demográficas de 36 pacientes com infecção por VRE identificadas de junho de 2005 a dezembro de 2007 .............................................................4

Tabela 3 - Percentual de culturas de ambiente positivas nos momentos I e II do período pré-intervenção e nos momento III e momento IV do período pós-intervenção, por material de isolamento.

Tabela 4 - Percentual de perfis de sensibilidade a antimicrobianos de $E$. faecium de 189 amostras obtidas no período pré-intervenção e de 143 do período pós-intervenção

Tabela 5 - Concentração inibitória mínima de antimicrobianos de 77 isolados de E.faecuim e 34 de E. faecalis

Tabela 6 - Distribuição dos 12 perfis moleculares de 30 amostras de $E$. faecium anos 2002 a 2004, de 14 perfis de 144 amostras dos anos 2005 a 2007, e de 4 perfis de $E$. faecalis identificados nos e 2005 a 2007, de acordo com os critérios de Tenover et al. (1997).

Tabela 7 - Proporção de adesão a precauções de contato e padrão por profissionais da saúde durante os períodos pré e pósintervenção, nas UTIs do HU 


\section{RESUMO}

Perugini MRE. Avaliação do impacto de medidas de intervenção no controle de Enterococcus spp. resistente a vancomicina em unidade de terapia intensiva [tese]. São Paulo: Faculdade de Medicina, Universidade de São Paulo; 2008. 168p.

Durante os anos 90 um aumento dramático no isolamento de VRE foi reportado nos estados Unidos, principalmente em unidades de terapia intensiva, esta tendência continua até hoje. No Brasil o primeiro caso de VRE foi documentado em 1996 e desde então muitos casos têm sido descritos em todo país. Uma variedade de medidas tem sido usada para reduzir taxas de VRE, mas a melhor estratégia para o controle e prevenção deste patógeno ainda não está totalmente definida. O Objetivo deste estudo foi avaliar o impacto de um processo multidisciplinar para monitorar a adesão de profissionais às precauções padrão e de contato e o papel do meio ambiente e de equipamentos na transmissão de VRE. Este estudo consistiu de três períodos: um período basal, um período de intervenção e outro de pós-intervenção. $O$ teste $\chi^{2}$ foi usado para comparar os dados dos períodos pré e pós-intervenção e o teste de $\chi^{2}$ para tendência linear foi usado para avaliar a distribuição de VRE e o uso de glicopeptídeos durante o período de estudo, o nível de $p<0.05$ foi significante. As amostars foram avaliadas pela técnica de PFGE. PCR para detecção do gene de resistência foi realizada para as amostras clínicas. $E$. faecium foi a espécie mais freqüente tendo sido responsável por $71 \%$ das culturas positivas. Foram documentadas 36 infecções e aquelas da corrente sangüínea foram as mais frequentes $17(47 \%)$ A intervenção educacional foi realizada com 136 profissionais. Foram avaliadas 706 oportunidades de precauções padrão e de contato. A adesão às precauções padrão e de contato não aumentou comparando os períodos pré e pós-intervenção. Entretanto, a proporção de culturas ambientais e de equipamentos diminuiu significativamente comparando os períodos pré $(23.2 \%)$ and pós-intervenção $(2.4 \%)(p<0.001)$ e foram associadas a diminuição das Infecções por VRE por 1.000 pacientes-dia $(p=0.004)$. O uso de vancomicina (DDD) não mudou significativamente ao longo do estudo $(p=0.97)$ e o uso de teicoplanina aumentou principalmente nos últimos meses de $2007(p<0.001)$. O mesmo clone de E. faecium foi encontrado em $90 \%$ das amostras. No presente estudo, redução da proporção de contaminação ambiental e de equipamentos esteve associada com diminuição das taxas de infecção por VRE.

Descritores: 1.Enterococcus 2.Resistência a vancomicina 3.Infecção hospitalar 4.Controle de infecções 5.Adesão a diretivas antecipadas 6. Unidade de terapia intensiva 


\section{SUMMARY}

Perugini MRE. Evaluation of impact of intervention measures on the control of Enterococcus spp. vancomycin resistant in intensive care unit. [thesis]. São Paulo: "Faculdade de Medicina, Universidade de São Paulo"; 2008. 168p.

During the 1990s a dramatic increase of VRE isolation was reported mostly in the Intensive Care Units $(\mathrm{UCl})$ in the USA and the trend continues. In Brazil, the first VRE isolated occurred in 1996 and many cases have been described thereafter. A variety of measures have been used to reduce VRE rates, the optimal approach however to control and prevent this pathogen, is not well defined. The aim of this study was to evaluate the impact of a multidisciplinary process to monitor improve healthcare work (HCW) compliance with standard and contact precautions and the role of environment and equipments on the transmission of VRE. This study consisted of three period baseline, intervention and pos-intervention period. $\chi^{2}$ test was used to compared data pre and pos intervention and $\chi^{2}$ test for linear trend was used to evaluate the distribution VRE and use of glycopeptides during the study period, the level of $p<0.05$ was significant. PFGE was performed. Detection of genes of resistance of VRE isolated from clinical samples was performed by PCR E. faecium was the most frequent species isolated being responsible for $71 \%$ of positives cultures. Thirty-six infection were documented, bloodstream infection $17(47 \%)$ was the most frequent site. The educational intervention was given to $136 \mathrm{HCW} .706$ opportunities were evaluated, the compliance with standard and contact precautions did not improve comparing pre and pos-intervention period. However, the proportion of environmental and equipments positive cultures decreased significantly comparing pre $(23.2 \%)$ and pos-intervention $(2.4 \%)$ period $(p<0.001)$ and was associated with decrease of VRE infection per 1.000 pts-day $(p=0.004)$. The use of vancomycin (DDD) did not change significantly over the study period $(p=0.97)$ and the use of teicoplanin increased $(p<0.001)$. Ninety percent of $E$. faecium belong to the same type. In the present study, reduction of proportion of positive environmental and equipments cultures was associated with decreased of rates of VRE infections.

Descriptors: 1.Enterococcus 2.Vancomycin-resistant 3.Cross infection 4.Infection control 5.Advance directive adherence 6.Intensive care units 
1. INTRODUÇÃO 
Embora Enterococcus spp. participa da microbiota normal do intestino e tenha sido considerado relativamente inócuo até o final da década de 70 , recentemente, este agente apresentou um aumento crescente de resistência a vários antimicrobianos, e emergiu como importante patógeno de endocardites, infecções da corrente sanguínea, infecções urinárias, e de feridas cirúrgicas. Os pacientes que geralmente desenvolvem infecções por esse agente são pacientes imunocomprometidos, sob antibioticoterapia prolongada com antimicrobianos tais como cefalosporinas e pacientes internados em unidades de terapia intensiva. Geralmente a colonização do trato gastrintestinal precede o desenvolvimento da infecção (Murray, 2000; Centikawa; Falk; Mayhal, 2000; Oprea et al., 2004).

Historicamente, 90\% das infecções enterocócicas são causadas pelo Enterococcus faecalis (E. faecalis) (Mutnick et al., 2003). Entretanto, a aquisição de resistência a vancomicina por cepas de Enterococcus faecium (E. faecium) multiresistentes resultou na emergência desta espécie de VRE como agente particularmente de infecções hospitalares (Chavers et al., 2003). Assim em hospitais americanos, europeus e de várias outras partes do mundo $E$. faecium é a espécie resistente a vancomicina mais comum (Low; Barth; Jones, 2001; NNIS, 2004; Siegel et al., 2007). 
Infecções enterocócicas também têm sido associadas a maior morbidade e mortalidade, especialmente em pacientes com diversos fatores de risco como alta prevalência de doenças infecciosas, e em hospitais com superlotação e infra-estrutura inadequada. Este agente tem número reduzido de opções terapêuticas além da maior patogenicidade pela aquisição de genes de virulência, entre eles esp, purK e hyl (Willems et al., 2001; Leavis et al., 2003; Rice et al., 2004;). Alguns pesquisadores relataram que infecções hospitalares por E. faecium freqüentemente são causadas por uma linhagem amplamente disseminada ao redor do mundo que contem um complexo clonal epidêmico-virulento chamado (CC)-17 (Klare et al., 2005; Willems et al., 2005).

Nos anos 80, depois da emergência de resistência a beta-lactâmicos e a aminoglicosídeos de alto nível, vancomicina passou a ser um dos poucos antimicrobianos disponíveis para tratar infecções enterocócicas por $E$. faecium. Em 1986, entretanto, Enterococcus resistente a vancomicina (VRE) foi identificado pela primeira vez na Europa (Leclerq et al., 1988; Utley et al., 1988) e em seguida, em 1999 nos Estados Unidos onde rapidamente disseminou-se (Moellering, 2000).

A ocorrência de VRE aumentou progressivamente, nos últimos 10 anos, em diversas partes do mundo este agente tem sido isolado em quase todos os continentes incluindo países da Ásia, Europa, América do Sul e África (Dalla Costa et al., 1998; Marin et al., 1998; Murray, 2000; Kawalec et al., 2001; DeLisle, 2003, Koh, Chiu, Lin, 2006; Kolar et al., 2006; Werner et al., 2007). 
Dados do SENTRY Antimicrobial Surveillance Program mostraram que em 1999 Enterococos era 17\% mais resistentes a vancomicina nos Estados Unidos do que em outras regiões (Mutnick et al., 2003). De acordo com o NNIS (2004) 28,5\% das infecções enterocócicas em Unidades de Terapia Intensiva (UTI) foram causadas por VRE, um aumento de $12 \%$ em relação ao período anterior de 1998 a 2002. Recentemente o Programa SENTRY (2007) apontou este microrganismo como o quarto colocado $(10,2 \%)$ entre os agentes etiológicos das infecções sanguíneas nos Estados Unidos, o quinto $(7,2 \%)$ na Europa enquanto na América Latina este percentual é bem mais baixo (3,3\%) (Biendenbach al., 2004).

$\mathrm{Na}$ Europa a maioria dos países apresenta níveis baixos de colonização como 1,5 a 14,9\%, na Holanda (van Den Bogard et al., 1997, van Den Braak, 2000), 5\% na França (Boisivon, Thibault, Leclerq, 1997), (Mascini et al., 2006), 1,5\%.

Na América latina os índices aumentaram nos últimos anos, tendo variado de 12 a 28\% na Argentina (Togneri, et al., 2005, Littivik et al., 2006) e no Brasil I após a descrição do primeiro caso em 1996, na cidade de Curitiba (Dalla Costa, 1998), VRE tem sido isolado por vários pesquisadores com incidência de colonização variando de 0 a 30\% (Zanella et al, 1999; Reis et al, 2001; Cereda et al, 2002, Caiaffa Filho et al, 2003; Moretti et al, 2004; Furtado et al, 2005b; Camargo et al, 2005; Tresoldi et al., 2006, Vilela et al. 2006).

Uma das maiores razões para que este microrganismo tenha sobrevivido no ambiente hospitalar é sua elevada resistência intrínseca a 
antimicrobianos como beta-lactâmicos aminoglicosídeos em baixos níveis, macrolídeos e sulfametoxazol-trimetoprim, o que parece ter contribuído para sua seleção, como patógeno hospitalar, após a introdução de cefalosporinas (Murray, 1990; DeLisle, Perl, 2003).

A resistência ao glicopeptídeo vancomicina tem sido considerada um dos exemplos mais críticos de resistência. Até o momento, seis mecanismos de resistência a glicopeptideos, VanA, VanB, VanC, VanD, VanE e VanG, têm sido descritos (Fines et al., 1999; Carias et al., 1998: Mevius et al., 1998; Navarro, Courvalin, 1994; Rippere et al, 1998, Murray, 2000; Mckessar et al., 2000).

Os fenótipos VanA, B, D, E e VanG são mediados por grupos de genes adquiridos, ao contrário dos genes que codificam para o fenótipo VanC, que são endógenos, sendo que o mecanismo mais comum é devido à presença do gene vanA. O gene vanB é menos prevalente, ambos localizados em transposons e encontrados em E. faecalis e E. faecium. Em contraste vanC está localizado no cromossomo e ocorre em espécie menos virulentas com E. gallinarum e E. casseliflavus. VanD, VanE e VanG tem sido relatados apenas esporadicamente (Bontem, Willems, Weinstein, 2001, Depardieu, Perichon, Courvalin, 2004, Naas et al., 2005; Boyd et al., 2006).

As bases genéticas para resistência a vancomicina são bastante complexas. Os fenótipos VanA e B são produzidos por um produto de 2 genes com ação reguladora que tornam a resistência induzível e por outro grupo que capacita Enterococcus a sintetizar pentapeptídeos precursores da parede celular (Arthur et al, 1998). 
O fenótipo VanA apresenta altos níveis de resistência a vancomicina níveis moderados a teicoplanina. Embora Enterococcus com fenótipo VanB tenham sido caracterizados, originalmente, como moderadamente resistente a vancomicina e sensíveis a teicoplanina, recentemente relatos têm sido feitos de que este cluster de genes vanB pode conferir uma ampla variação nos níveis de resistência a vancomicina e teicoplanina (Arthur, Courvalin, 1993; Hayden et al.,1993).

A localização dos genes responsáveis pelos fenótipos VanA e VanB em transposons e plasmídios facilita fortemente a disseminação horizontal entre espécies de Enterococos e atribuem relevância clínica aos Enterococos que apresentam fenótipos vanA e vanB. O fenótipo Van $A$ é induzível e determinado por um cluster de genes três dos quais van $\mathrm{H}$, vanA, e vanX são determinantes críticos de resistência e outros dois genes regulatórios, vanR e vanS. Juntos com dois genes regulatórios, vanR e vanS, eles formam a maior região conservada vanRSHAX do transposon Tn1546 (Arthur, Courvalin, 1993).

Infecções enterocócicas graves requerem tratamento com combinação de antimicrobianos bactericidas que incluem uma penicilina (penicilina ou ampicilina) com um aminoglicosídeo (gentamicina ou estreptomicina) para aquelas cepas sensíveis (Herman, Gerding, 1991). Vancomicina em combinação com aminoglicosídeos de alto nível também apresentam ação sinérgica contra Enterococcus sensíveis a ambas as classes (Westenfelder et al., 1973). 
O tratamento de infecções devido a VRE, entretanto, especialmente por E. faecium, é extremamente problemático, por que estes microrganismos são resistentes a múltiplos antimicrobianos. Ampicilina ou penicilina com ou sem sinergismo com aminoglicosídeos de alto nível são drogas de escolha para tratar infecções causadas por E. faecalis resistentes a vancomicina em pacientes não alérgicos, pois a maioria delas, é pelo menos, moderadamente sensível a estas drogas (Centikawa, Falk, Mayhall, 2000).

Nitrofurantoína também parece ser uma escolha razoável para o tratamento deste agente em infecções urinárias baixas. Outro agente terapêutico ativo contra Enterococcus é o cloranfenicol, que permanece ativo contra E. faecium, porém durante seu uso no tratamento pode desencadear resistência (Palmer, Rybak, 1996).

Quinopristin-dalfopristin é uma estreptogramina que tem atividade bacteriostática contra E. faecium, mas é inativa contra E. faecalis (Wade et al., 1992). Além do mais já foi reportada resistência a esta classe em E. faecium (Chow, Donabedian, Zervos, 1997).

Fosfomicina e nitrofurantoína têm sido efetivos em pacientes que em pacientes com infecção do trato urinário baixo. Porém, resistência a estes antibióticos tem sido reportada (Leavis, Bonten, Willems, 2006; Tsigrelis et al., 2007).

Entre os antimicrobianos que possuem alguma atividade contra VRE encontram-se linezolida, tigeciclina, daptomicina (Leavis, Bonten, Willems, 2006). Daptomicina, um ácido lipopeptiídico tem dados resultados promissores in vitro (Shonekan, Midvan, Handwerger, 1992). Da mesma 
forma dalbavancina, orivotacina são antimicrobianos que têm sido desenvolvidos e são potentes contra infecções por VRE (Patel, 2003; Lin et al, 2006). Platensimicina, um antimicrobiano totalmente novo originado de Streptomyces platensis, tem sido reportado recentemente e tem se mostrado ativo contra VRE e MRSA (Wang et al., 2006).

A natureza transmissível destes genes tem causado preocupação na comunidade cientifica devido à possível emergência de resistência a vancomicina em bactérias altamente patogênicas como Staphylococcus aureus (S. aureus), o que já foi relatado nos Estados Unidos (CDC, 2002a, CDC, 2002b, CDC, 2004; Severin et al., 2004; Tiwari, Sen, 2006).

Numerosos surtos de VRE atribuídos à transferência horizontal de determinantes de resistência ou à disseminação clonal de espécies epidêmicas, têm sido reportados em várias regiões do mundo. Um trabalho de revisão realizado por Bontem, Willems, Weinstein, et al. (2001), nos Estados Unidos onde estes microrganismos são endêmicos, mostrou que surtos são bastante freqüentes e que a maioria é causada por um clone de E. faecium que é resistente a ampicilina.

$\mathrm{Na}$ Europa, porém, VRE não tem emergido como um patógeno importante em infecções hospitalares da mesma forma que na América, contudo surtos por VRE ocorrem esporadicamente, geralmente com poucas infecções graves, e são monoclonais. Surtos foram relatados na Polônia (Kawalec et al, 2001), Itália (Peta et al, 2005), Grécia (Kalocheretis et al, 2001), Noruega (Mascini et al., 2006), entre outros paises. 
Em outras regiões do mundo como Brasil, Argentina, Austrália, Turquia, Singapura surtos de infecção hospitalar também têm sido descritos (D`Azevedo, 2000; Colak et al., 2002; Cereda et al. 2002; Zàrate et al., 2006; Pearman, 2006; Koh, Chiu, Lin, 2006 ).

Colonização ou infecção tem sido associada a uma variedade de fatores de risco bem definidos como antibioticoterapia prévia, hospitalização prolongada especialmente em UTI ou em instituição com elevada proporção de VRE, proximidade com paciente colonizado ou infectado, doença de base grave, instrumentação, nutrição enteral e parenteral e ainda, colonização intestinal prévia por VRE (Centikawa, Falk, Mayhall, 2000).

A possibilidade de disseminação de Enterococcus spp., através do contato tem se tornado uma preocupação constante dentro dos hospitais no que se refere à prevenção e controle das infecções hospitalares por este microrganismo.

Em 1995, como resposta ao aumento das taxas de colonização e infecção por VRE ocorridos nos Estados Unidos, o Hospital Infection Control Practices Advisory Commitee (HICPAC) do Center for Disease Control and Prevention (CDC) publicou, recomendações para prevenir a disseminação da resistência a vancomicina que incluem controle do uso de vancomicina, detecção precoce de VRE em amostras clínicas e em culturas de swab retal para vigilância, isolamento do paciente infectado ou colonizado, educação da equipe, higiene das mãos com clorohexidina, uso de luvas, desinfecção ambiental (CDC, 1995). 
Em 1997, a Society for Healthcare Epidemiology of America (SHEA) publicou um guideline para prevenir a resistência a antimicobianos em hospitais e em 2003 publicou um guideline específico para prevenir a transmissão de S. aureus e Enterococcus spp (Muto et al., 2003).

O Managment multidrug-resistant organisms in Healthcare Settings, publicado pelo "Centers for Dsieases Control and Prevention" (CDC) em 2007, ampliou as recomendações para outros microrganismos além de S.aureus e Enterococcus spp. Este documento enfatiza que a prevenção da emergência e transmissão de microrganismos multiresistentes requer uma compreensão que inclui não apenas intervenções relativas a medidas de controle, mas também a envolvimento administrativo (Siegel et al., 2007).

Entre estas intervenções pode-se destacar a educação da equipe médica e de outros profissionais da área da saúde, compreensão de métodos de vigilância para microrganismos multiresistentes, aplicação de precauções padrão no cuidado aos pacientes, medidas de cuidados do ambiente como limpeza e desinfecção do ambiente do paciente colonizado ou infectado, materiais não críticos de uso exclusivo, aparelhos individuais, entre outros sistemas de comunicação, um processo que assegure a adesão às recomendações do controle de infecção, uso racional de antimicrobianos (Siegel et al., 2007). .

O papel da contaminação ambiental na disseminação de VRE permaneceu controverso por décadas. Embora alguns pesquisadores tenham relatado que taxas de infecções hospitalares não se relacionam com o grau de contaminação ambiental, especialmente ar, superfícies e fômites 
(Maki et al, 1982; Rutala et al, 1983; Boyce et al, 1995), em uma revisão recente Boyce (2007) relata que atualmente existem evidências de que superfícies ambientais contaminadas contribuem para as infecções associados aos serviços de saúde.

Tem sido bem documentado que o ambiente de pacientes colonizados ou infectados com bactérias Gram positivas se torna freqüentemente contaminado e, portanto, superfícies e objetos podem servir como reservatório secundário para transmissão cruzada (Lemmen et al. 2004). A contaminação de superfícies ambientais e de equipamentos médicos nos quartos de pacientes colonizados por VRE como camas, mesas de cabeceira, maçanetas, termômetros retais, esfigmanômetros, estetoscópios, bombas de infusão, monitores de eletrocardiograma, comadres e papagaios, roupas de cama e dos pacientes tem sido bem documentados e considerados fatores de risco para aquisição deste microrganismo (Livornese et al, 1993; Boyce et al, 1995; Slaughter et al, 1996; Weber; Rutala, 1997; Centikawa, Falk, Mayhall, 2000).

Além disto, VRE é capaz de sobreviver em superfícies contaminadas de uma semana a dois meses em, por mais que 7 dias a 4 meses em superfícies secas e por poucos dias a mais de três meses em roupas ou superfícies plásticas (Noskin et al, 1995; Bonilla, Zervos, Kauffman, 1996; Weber; Rutala, 1997; Wendt et al., 1998; Vernon et al., 2006). Aliado a este fato tem sido descrito resistência de Enterococos a hipoclorito e calor (Kearns, Freeman, Lightfoot, 1995). 
Entretanto, estudos têm mostrado que a limpeza ou desinfecção do meio ambiente pode reduzir a incidência de colonização ou infecção por VRE (Schultz et al.2003, Hayden et al., 2006).

A transmissão de VRE através de equipamento também ocorre e tem sido apontada como fonte de vários surtos (Livornese et al., 1992; Porcwancher et al., 1997). Vários autores têm descrito a transmissão de VRE da superfície para as mãos ou para as luvas dos trabalhadores dos serviços de saúde (Tenorio et al., 2001, Ray et al., 2002; Bhalla et al., 2004; Duckro et al., 2005; Vernon et al., 2006, Hayden et al., 2008).

Outra medida importante é o uso prudente de vancomicina. Exposição a este glicopeptídeo parece ser um fator de risco para a aquisição de VRE em pacientes individuais, entretanto o efeito do uso de vancomicina na população é ainda desconhecido e a associação entre o uso de vancomicina e colonização ou infecção por VRE ainda não está clara (de Bruin, Hiley, 2007). Alguns estudos baseados em modelos animais (Loukil et al., 2003; Ryan et al., 2006) e estudos em pacientes (Fry et al., 2005; Carter et al., 2005; Whitener et al., 2004) reforçam o papel do uso da vancomicina na contribuição da aquisição a VRE.

Em uma meta-análise realizada por Carmelli et al. (1999) entre 15 estudos de indivíduos usando grupo de controle, a exposição a vancomicina aumentou 2,7 vezes o risco de aquisição de VRE. Além disso, também aumentou a detecção em pacientes já colonizados, pela eliminação de outra bactéria colonizante e permitiu que VRE se desenvolvesse (Harbarth, Cosgrove, Carmeli, 2002). Estes dados são, todavia, conflitantes, pois este 
mesmo autor relata que a exposição à vancomicina por via intravenosa poderia ter papel limitado na contribuição de aquisição de um novo VRE, enquanto cefalosporinas e antianaeróbios poderiam ter um efeito maior (Rice, 2001).

Outros investigadores relataram que o impacto na redução do uso de vancomicina tem sido heterogêneo na colonização ou infecção por VRE (Morris et al., 1995; Lauthenback et al., 2003; Guglielmo et al., 2005).

Diversos estudos relatam que redução significante no uso de vancomicina acarretou mudanças na aquisição de VRE. Uma investigação realizada por Lai et al. (1998) relatam tentativas iniciais de reduzir uso da vancomicina, (de Bruin e Riley, 2007). O estudo de Lautenbach et al. (2003) aponta uma redução inicial no uso de vancomicina, mas no final do estudo os níveis retornam aos da pré-intervenção. Uma pesquisa clínica realizada por Fridkin et al. (2002) descreve redução no uso de vancomicina para uso em intervenções sítio específicas. Guglielmo et al. (2005) inclui uma intervenção para redução de vancomicina e mudanças correspondentes nas taxas de infecção por VRE. A revisão realizada por de Bruin e Riley (2007) conclui que a maioria dos estudos (54\%) demonstra melhora no controle de VRE seguido pela redução no uso de vancomicina, 23\% reportam que não houve mudança significativa e $23 \%$ relatam aumento. Além disso, a percentagem de aquisição de VRE variou de 82.5\% (Rubin et al., 1992) a um aumento de 475\% (Guglielmo et al., 2005).

Prevenção e controle de transmissão de microrganismos têm sido bem documentados nos Estados Unidos pelo uso de uma variedade de intervenções 
combinadas que incluem melhora na higiene das mãos, uso de precauções de contato até que os pacientes apresentem cultura de vigilância negativa, educação, melhora na limpeza do ambiente e melhora na orientação dos profissionais de saúde quanto ao controle de microrganismos multiresistentes.

No Hospital Universitário de Londrina foi identificado um caso isolado de VRE em 1999 e após adoção das medidas de controle recomendadas pelo CDC, não foi identificado nenhum outro caso até maio de 2002. A partir de então VRE passou a ser identificado e a freqüência de isolamento em culturas de vigilância aumentou gradativamente.

Várias intervenções foram realizadas na tentativa de, inicialmente erradicar e posteriormente, controlar este microrganismo nas UTIs do HU. Foram realizadas reuniões do Serviço de Controle de Infecção Hospitalar (SCIH) com as chefias, médica e de enfermagem, e a Diretoria Clínica, e foi orientada a adoção de medidas de controle como: isolamento tipo coorte do paciente colonizado e/ou infectado, de preferência na UTI II, higiene das mãos com água e sabão ou álcool gel antes e após contato, uso de luvas exclusivas, uso de avental, utilização de materiais não críticos individuais após o uso sempre que possível, ou desinfecção dos mesmos, com álcool $70 \%$, desinfecção concorrente de equipamentos e de materiais não críticos individuais com álcool $70 \%$ e de leito, bancada e parede com ácido peracético, limpeza de piso com água e sabão a cada 6 horas, desinfecção terminal quando da alta ou óbito com lavagem do piso, paredes e leitos com água e sabão e posterior desinfecção com ácido peracético. Foram colocados cartazes alertando para o problema, 
encaminhadas cartas com orientações de controle de VRE para chefias médicas, de enfermagem, com a fisioterapia, nutrição, psicologia, laboratório, setor de Raios-X e hemodiálises, departamentos, residentes e setor de treinamento. Foram coletadas culturas ambientais e realizados treinamentos das equipes de limpeza.

Entretanto, assim como em muitos hospitais, a despeito da adoção das medidas recomendadas, este microrganismo se tornou cada vez mais problemático. A colonização persistente, especialmente de pacientes de alto risco, levou a um aumento da disseminação deste microrganismo e o mesmo se tornou endêmico a partir do ano 2005, fato que nos levou a realizar um estudo multidisciplinar para monitorar profissionais da saúde quanto à adesão a medidas de contato e padrão, assim como as densidades de incidência de colonização, de infecção e a freqüência de contaminação por VRE nas UTIs e realizar um trabalho de intervenção educacional. 
2. OBJETIVOS 


\subsection{Objetivo Geral}

Avaliar o impacto da intervenção educacional na adesão às medidas de controle de VRE nas taxas de colonização ou infecção e avaliar o papel da contaminação ambiental e de equipamentos na transmissão de VRE nas UTIs do HU de Londrina.

\subsection{Objetivos Específicos}

a) Determinar prevalência e incidência de pacientes colonizados e infectados por VRE no HU nos períodos pré e pós-intervenção;

b) Verificar a contaminação ambiental nos períodos pré e pósintervenção;

c) Avaliar o tipo de gene de resistência a glicopeptídeos por PCR;

d) Determinar a linhagem clonal e correlacionar cepas ambientais com cepas de colonização e de infecção, nos períodos pré e pósintervenção;

f) Comparar adesão às medidas de precaução dos períodos pré e pós-intervenção. 


\section{MÉTODOS}




\subsection{Local do Estudo}

\section{Descrição do Hospital}

O Hospital Universitário (HU), da Universidade Estadual de Londrina, é centro de referência para o Sistema Único de Saúde (SUS). É um hospital terciário da Rede Sentinela e que atualmente dispõe de 333 leitos, sendo 29 destinados a Unidades de Terapia Intensiva (17 para UTI geral, 7 para UTI neonatal e 5 para UTI pediátrica). A UTI Geral é dividida em duas áreas, uma com 10 leitos onde são internados pacientes gerais (UTI I) e outra com 7 leitos para onde são transferidos os pacientes que estão em precaução de contacto (UTI II). Cada leito fica localizado em um box, separado por divisórias de vidro, sendo que a UTI I tem quatro boxes com porta e a UTI II também são 4 os boxes com porta. Na UTI I há sete pias, uma em cada um dos boxes fechados e mais duas centrais, já na UTI II são cinco, uma central e uma em cada um dos boxes fechados. Nos postos de enfermagem, de cada uma das UTIs tem mais uma pia. O número de dispensadores para o anti-séptico clorexidina com peróxido de hidrogênio é de 10 na UTI I e sete na UTI II. As UTIs I e II são ilustradas nas figuras 1 e 2. 


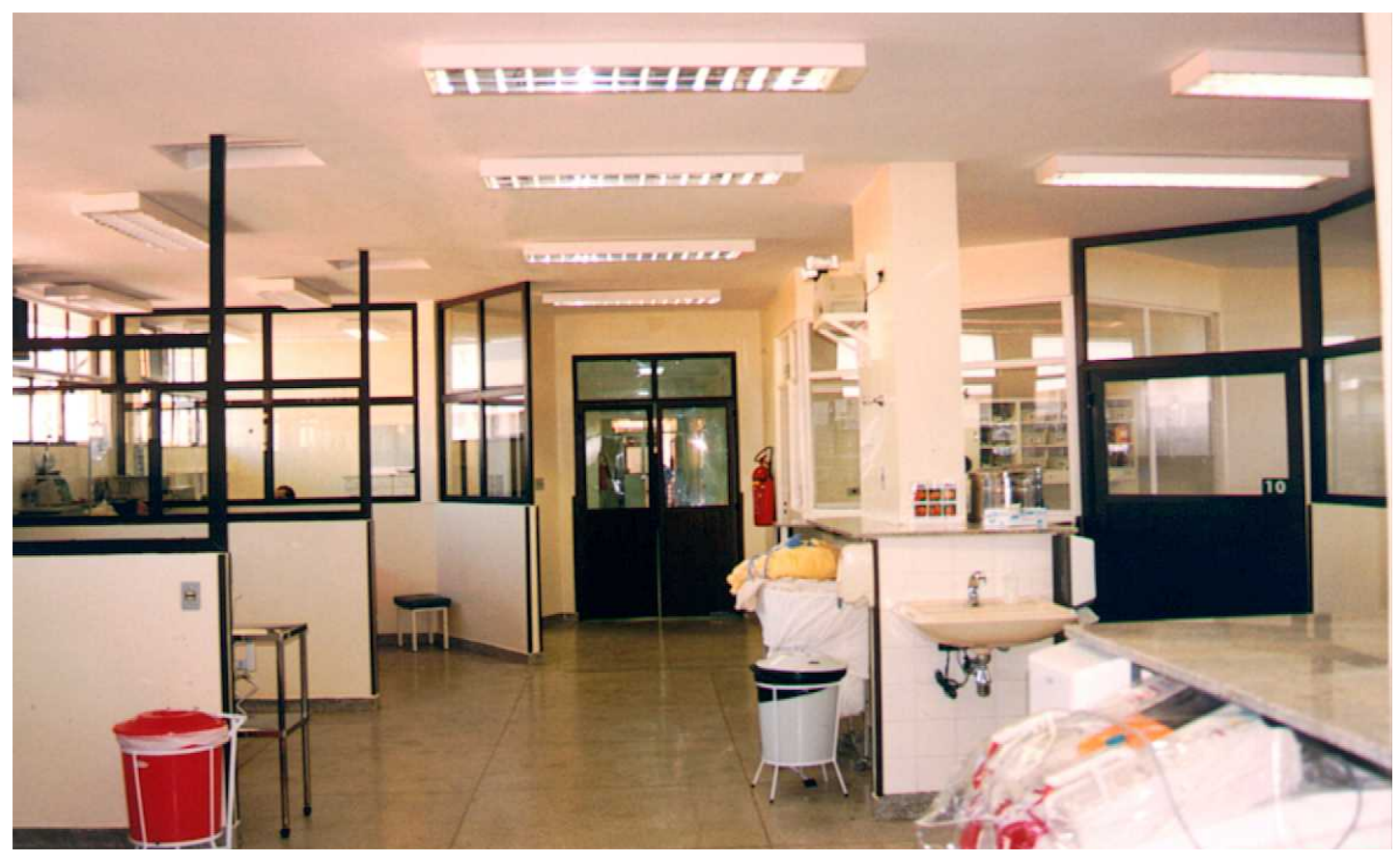

Figura 1 - Unidade de Terapia Intensiva (UTI I) do Hospital Universitário da Universidade Estadual de Londrina

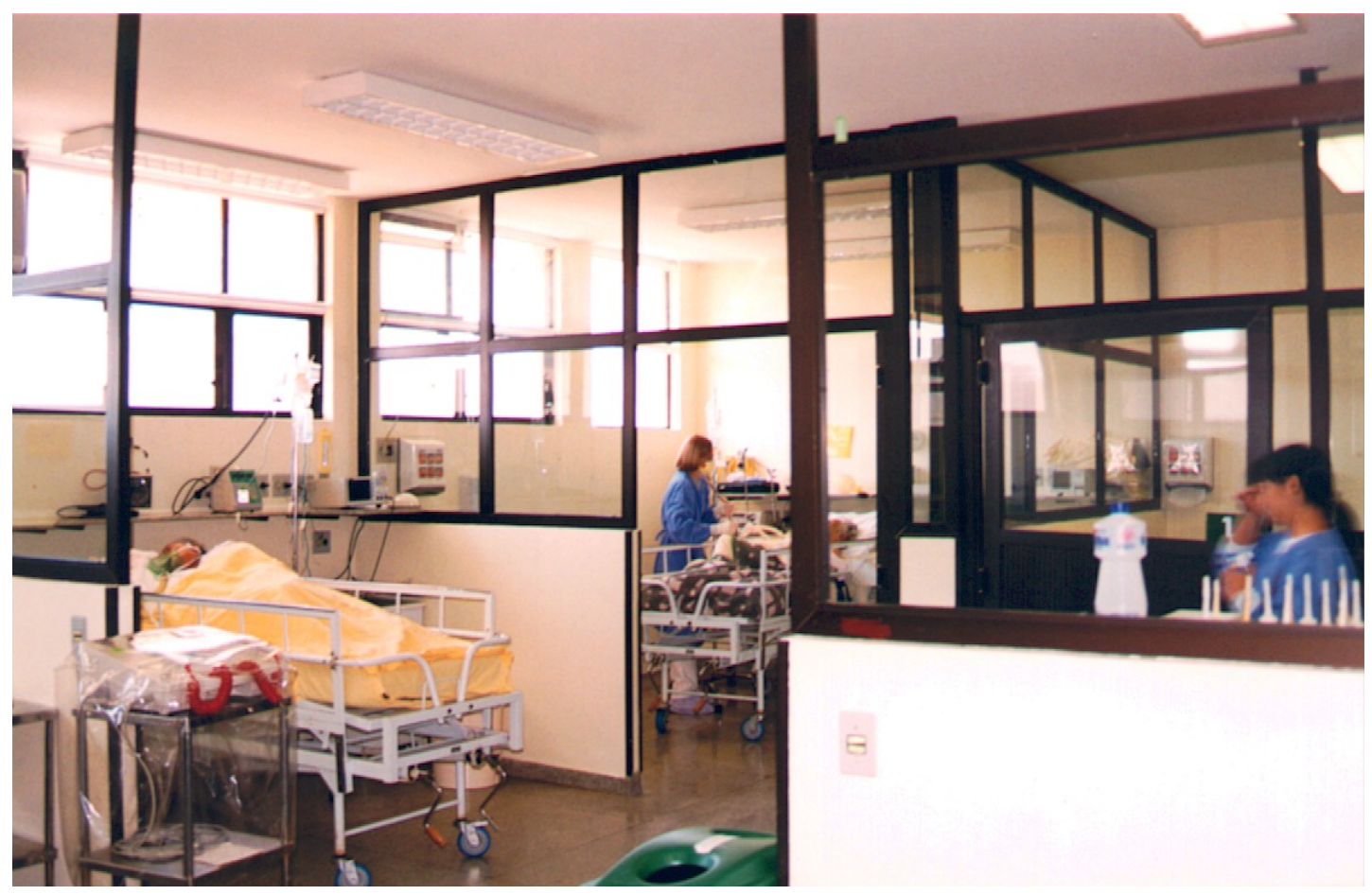

Figura 2 - Unidade de Terapia Intensiva (UTI II) do Hospital Universitário da Universidade Estadual de Londrina 
As atividades nas UTIs são realizadas por uma equipe de 10 médicos plantonistas, 10 enfermeiros, 34 técnicos de enfermagem, 7 fisioterapeutas, 2 residentes, 2 internos das áreas médica, de enfermagem e de fisioterapia, e por 4 zeladores. Outros profissionais como técnicos de Raios-, de laboratório, de hemodiálise, farmacêuticos, nutricionistas, psicólogos também executam atividades nas UTIs.

A média anual de atendimentos no hospital no período de janeiro de 2002 a novembro de 2007 foi de 92.000 pacientes-dia. Neste período estiveram internados nas UTIs I e II 29.914 pacientes-dia, uma média de cerca de 6.000 pacientes-dia por ano.

Este hospital conta com uma Comissão de Controle de Infecção Hospitalar $(\mathrm{CCIH})$ com um Serviço da Comissão de Controle de Infecção Hospitalar (SCIH), atuante desde 1980, composto por duas médicas infectologistas, uma enfermeira exclusiva e duas técnicas de enfermagem, duas microbiologistas (uma biomédica e uma bioquímica) e uma farmacêutica. Esta equipe se reúne quinzenalmente para discussão de assuntos pertinentes ao controle das Infecções Hospitalares. Os trabalhos são desenvolvidos com o apoio de uma equipe de 15 estagiários de farmácia, 10 de enfermagem e três de medicina.

A vigilância epidemiológica é realizada pela equipe de enfermagem através de busca ativa e os dados obtidos são analisados através do Programa SINAES. O Hospital conta com controle de antimicrobianos realizado através de fichas de prescrição de antimicrobianos que são avaliadas por médicas infectologistas. A Farmácia conta com um sistema de 
controle de antimicrobianos, preparo de dieta enteral e quimioterapia, além de possuir uma central de diluição de desinfetantes e antissépticos. O SCIH dispõe de um laboratório de microbiologia exclusivo onde as atividades de coleta, cultivo e testes de sensibilidade a antimicrobianos das culturas para diagnóstico clínico, controles microbiológicos e de vigilância epidemiológica são desenvolvidas por uma equipe de dois técnicos de laboratório e pelos estagiários de farmácia, supervisionados pelas docentes microbiologistas. 0 controle de microrganismos multiresistentes (MR) é desenvolvido com o auxílio do grupo de estagiários de medicina e de enfermagem da $\mathrm{SClH}$, a partir dos resultados das culturas que são encaminhados diariamente do laboratório de microbiologia. Os pacientes portadores de MR são identificados por estes estagiários através da colocação de uma placa de papel colorido no box dos pacientes, com a identificação MR e as recomendações de medidas de precaução de contato.

\subsection{Delineamento do Estudo}

Após a constatação da endemicidade de VRE no HU mesmo após a adoção de várias medidas de controle foi realizado um estudo de intervenção para avaliar a adesão dos profissionais de saúde das UTIs de adultos às medidas de controle de VRE, constituído de 3 etapas: período pré-intervenção, que compreendeu de janeiro de 2006 a março de 2007, período de intervenção, abril de 2007 e período de pós-intervenção, de maio 
a dezembro de 2007. Este estudo foi aprovado pelo Comitê de Ética em Pesquisa envolvendo seres humanos da UEL de acordo com normas do Conselho Nacional de Saúde, sob o número CAAE 0168.0.268.000-06, folha de rosto 101137

\subsection{Períodos Pré-Intervenção}

a) Análise microbiológica de cepas de VRE obtidas de culturas de vigilância do banco de bactérias do setor de microbiologia do Laboratório de Análises Clínicas do HU no Laboratório de Investigação Médica (LIM 54) do Departamento de Doenças Infecciosas e Parasitárias do Hospital das Clínicas da Faculdade de Medicina da Universidade de São Paulo.

b) Determinação da densidade de incidência de colonização e infecção por VRE por 1.000 pacientes-dia nas UTIs de adultos do HU/UEL;

c) Análise Molecular das cepas de VRE;

d) Avaliação da adesão ao isolamento de contato e da limpeza e desinfecção de equipamentos e superfícies adotados pelos profissionais da saúde que atuavam nas UTIs de adultos;

e) Determinação do consumo de glicopeptídeos em Dose Diária Definida (DDD). 


\subsubsection{Análise Microbiológica}

\subsubsection{Amostras bacterianas}

Foram incluídas na análise amostras de VRE obtidas no período de maio de 2002 a dezembro de 2007, entre elas amostras obtidas de swab retal dos pacientes internados nas UTIs, swab de mãos de profissionais que atuavam nas UTIs e culturas do ambiente próximo aos pacientes. As coletas de swab retal foram realizadas, sempre que possível, no dia da internação do paciente nas UTIs e semanalmente, enquanto permanecessem nesta unidade. Os swabs das mãos foram cultivados apenas no ano de 2002 e as culturas ambientais foram obtidas sempre que o SClH verificava um aumento nas densidades de incidência de colonização ou infecção por 1000 pacientes-dia por VRE nestas unidades.

\subsubsection{Coleta de materiais}

Amostras de swab retal foram coletadas de pacientes internados nas UTIs segundo protocolo de vigilância estabelecido pelo $\mathrm{SCIH}$ do $\mathrm{HU}$. Utilizou-se meio de transporte Stuart.

As culturas das mãos foram coletadas friccionando-se um swab estéril por todas as partes das mãos dos profissionais. As amostras de ambiente foram obtidas da mesma forma, passando-se um swab estéril umedecido, em caldo de cultura TSB (caldo de soja tripticaseina) na superfície dos materiais a serem cultivados e colocando-os em seguida dentro de um tubo contendo o meio de cultura. 
As coletas ambientais e de equipamentos para avaliação da efetividade da intervenção foram realizadas em quatro momentos, dois na faz pré-intervenção e dois na fase pós. Na fase pré-intervenção as coletas foram realizadas um ano antes da intervenção (abril de 2006 - momento I), e imediatamente antes da intervenção (março de 2007 - momento II), da mesma forma na fase pós as coletas foram realizadas logo em seguida à intervenção (maio de 2007 - momento III) e oito meses depois (novembro de 2007 - momento IV).

Entre as culturas ambientais e de equipamentos foram analisados swabs das grades de proteção ou colchões dos leitos; de bancadas de granito colocadas nas cabeceiras dos leitos onde ficam os equipamentos, materiais não críticos, entre outros; swabs dos equipamentos médicos como monitores cardíacos, respiradores, bombas de infusão; de válvulas de ar, de materiais não críticos como estetoscópios, esfigmanômetros, termômetros, ambus, oxímetros de pulso, glucosímetros, otoscópios; pranchetas de prontuários médicos e de enfermagem; interruptores de luz, botão do ar condicionado, porta da geladeira, teclados de computador, telefone e maçaneta da porta de acesso do posto de enfermagem.

\subsubsection{Cultivo e identificação dos isolados clínicos}

Os swabs foram inoculados caldo VRE (OXOID®, Inglaterra) contendo $6 \mu \mathrm{g} / \mathrm{mL}$ de vancomicina e repicados após incubação overnight, a $35^{\circ} \mathrm{C}$, em agar VRE (OXOID®, Inglaterra), contendo $6 \mu \mathrm{g} / \mathrm{mL}$ de vancomicina, $6 \mu \mathrm{g} / \mathrm{mL}$ de ciprofloxacino e $8 \mu \mathrm{g} / \mathrm{mL}$ de colistina. 
Após nova incubação, as colônias negras que se desenvolveram foram submetidas à análise microscópica, catalase, hidrólise de esculina, crescimento em caldo $\mathrm{NaCl} 6,5 \%$, sensibilidade a vancomicina, produção de pigmento, motilidade, prova de pirrolidonil-aminopeptidase (PYR). As amostras resistentes a vancomicina foram, então, identificadas através de metodologia automatizada MicroScan WalkAway® (Dade Behring ${ }^{\circledR}$, Sacramento, CA) utilizando-se o painel PosCombo 12. As identificações foram confirmadas pelo método API $20 S$ (bioMérieux®, Hazelwood, Mo.).

\subsubsection{Reativação e identificação das amostras}

As amostras estocadas em caldo de soja tripticaseina (TSB) acrescido de $30 \%$ de glicerina, sob refrigeração $-70{ }^{\circ} \mathrm{C}$ foram reativadas em TSB e inoculadas em ágar sangue e ágar VRE contendo vancomicina (Oxoid®, Inglaterra), e incubadas over-night a $35^{\circ} \mathrm{C}$. As colônias negras que se desenvolveram no Agar VRE e as transparentes em ágar sangue foram submetidas à análise microscópica e à reação de catalase.

\subsubsection{Biotipagem}

Foi realizada a biotipagem das cepas estudadas através de testes bioquímicos de utilização de substratos segundo API 20S (bioMérieux®., Hazelwood, Mo.) e sistema automatizado MicroScan WalkAway® (Dade Behring ${ }^{\circledR}$, Sacramento, CA), utilizando as placas Pos Combo 12 (PC 12). 


\subsubsection{Determinação da sensibilidade a antimicrobianos}

O perfil de sensibilidade a antimicrobianos foi determinado pelo método qualitativo de disco difusão de Kirby e Bauer utilizando-se discos de vancomicina, ampicilina, penicilina, gentamicina, estreptomicina, teicoplanina, tetraciclina, rifampicina, cloranfenicol, ciprofloxacino seguindo as recomendações do Clinical Laboratory Standards International (CLSI, 2007) e microdiluição automatizada em placas PC 12 do sistema MicroScan WalkAway® (Dade Behring, Sacramento, CA) de acordo com orientações do fabricante.

Para confirmação da resistência foram realizadas as técnicas de screening diluição em Agar Brain Heart Infusion (BHI) para vancomicina, teicoplanina, gentamicina e estreptomicina de alto nível de acordo com recomendações do CLSI (2007). Cepas de Enterococus faecalis ATCC 29212 e 51299 foram utilizados como controle de qualidade.

\subsubsection{Determinação de Concentração Mínima Inibitória}

A concentração inibitória mínima (CIM) foi determinada, para cepas selecionadas, pelos métodos de microdiluição manual (anexo 1) para vancomicina, teicoplanina e ampicilina (CLSI, 2007) e Etest ${ }^{\circledR}$ (AB BIODISK, Solna, Suécia) para vancomicina, teicoplanina, ampicilina, gentamicina e estreptomicina, de acordo com as especificações do fabricante. As cepas resistentes a vancomicina pelo método de disco difusão tiveram suas Concentrações Inibitórias Mínimas (CIMs) para vancomicina, teicoplanina, ampicilina e penicilina determinadas pelo método da microdiluição em caldo 
MHCA (Mueller-Hinton Cátion Ajustado), conforme normas padronizadas pelo CLS I (2007) E. faecalis ATCC 29212 e 51299 foram utilizados para controle de qualidade.

As concentrações dos antimicrobianos testados através do método da microdiluição em caldo compreenderam concentrações de $0,25 \mu \mathrm{g} / \mathrm{mL}$ a 128 $\mu \mathrm{g} / \mathrm{mL}$, conforme descrito abaixo.

As concentrações testadas abrangeram os cortes descritos nas tabelas do documento M100-S17 (para uso com M7-A5, CIM) do CLSI, de $256 \mu \mathrm{g} / \mathrm{mL}$ a $0,125 \mu \mathrm{g} / \mathrm{mL}$. A solução inicial de $256 \mu \mathrm{g} / \mathrm{mL}$ foi obtida a partir da solução estoque de concentração igual a $10.000 \mu \mathrm{g} / \mathrm{mL}$. Foram realizadas diluições do antimicrobiano com o diluente adequado para cada antimicrobiano (CLSI, 2007).

\subsubsection{Determinação da densidade de incidência}

Os resultados das culturas de vigilância para VRE foram lançados num banco de dados no programa Excel, que incluiu: número da amostra, nome do paciente, número do Registro Geral, idade, gênero, unidade de internação, data de internação, data da coleta da amostra, espécie identificada, perfil de sensibilidade a antimicrobianos.

A densidade de incidência por 1.000 pacientes-dia foi obtida a partir do número de casos novos de VRE durante o ano e usando como denominador o número de pacientes-dia que estiveram internados nas UTIS no mesmo período. 


\subsection{Avaliação dos Dados Demográficos dos Pacientes}

Para os pacientes que apresentaram culturas positivas para este microrganismo em materiais clínicos foi realizada análise de prontuário e consulta à Comissão de Controle de Infecção Hospitalar (CCIH).

Foram coletados dados demográficos, co-morbidades, unidade de internação provável da aquisição da amostra em questão, espécime clínico com crescimento de VRE, colonização prévia, tempo de internação anterior à colonização e/ou infecção, procedimentos invasivos, classificação do episódio infeccioso, tipo de infecção, terapia realizada e desfecho do paciente (alta ou óbito) de acordo com anexo 2. Os episódios de infecção foram definidos segundo critérios estabelecidos pelo Centers for Diseases Control and Prevention (Gardner, et al., 1988).

Os dados foram coletados a partir dos registros do Laboratório de Bacteriologia e da revisão de prontuários médicos. As variáveis coletadas foram: idade, sexo, doença de base. Foi verificado ainda se os pacientes se encontravam utilizando agentes antimicrobianos, imunossupressores, medicações quimioterápicas ou corticoesteróides, foi calculado o tempo entre internação e colonização, entre internação e infecção, uso prévio de glicopeptídeos e cefalosporinas. 


\subsubsection{Análise Molecular}

\subsubsection{Eletroforese em Campo Pulsado (PFGE)}

O preparo do DNA cromossomal foi realizado como descrito por Pfaller et al. (1992) sub-cultivando-se as amostras em agar sangue por 24 horas a $37{ }^{\circ} \mathrm{C}$ Blocos de gel foram obtidos utilizando-se volumes de suspensão bacteriana contendo $9 \times 10^{8}$ células por $\mathrm{mL}$ e mesmo volume de agarose low-melting (BioRad). O DNA foi digerido com a enzima de restrição Sma-I fast (New England BioLabs) a $37^{\circ} \mathrm{C}$ por 5 minutos no sistema $\mathrm{CHEF}$ DRII (BioRad) sob as seguintes condições:tempo de corrida 23 horas, temperatura, $14{ }^{\circ} \mathrm{C}$; voltagem, $6 \mathrm{~V} / \mathrm{cm}$; pulso initial , 5s;30s. Como padrão de peso molecular foi utilizado Fago Lambda. Os genótipos foram definidos com base no padrão de bandas observadas e foram avaliados de acordo com os critérios de Tenover et al. (1997) (Tabela 1).

Tabela 1 - Critérios interpretativos para análise de tipagem molecular

\begin{tabular}{cccc}
\hline $\begin{array}{c}\text { Interpretação } \\
\text { microbiológica } \\
\text { baseada nos } \\
\text { resultados de } \\
\text { tipagem }\end{array}$ & $\begin{array}{c}\text { Número de } \\
\text { diferenças genéticas } \\
\text { comparadas com } \\
\text { determinado isolado }\end{array}$ & $\begin{array}{c}\text { Número de fragmentos } \\
\text { diferentes comparados } \\
\text { ao padrão de } \\
\text { determinado isolado }\end{array}$ & $\begin{array}{c}\text { Correlação } \\
\text { epidemiológica }\end{array}$ \\
\hline $\begin{array}{c}\text { Indistinguíveis } \\
\text { Estreitamente } \\
\text { relacionados }\end{array}$ & 0 & 0 & $\begin{array}{c}\text { Isolado faz parte do } \\
\text { surto }\end{array}$ \\
$\begin{array}{c}\text { Possivelmente } \\
\text { relacionados }\end{array}$ & 1 & $2-3$ & $\begin{array}{c}\text { Isolado } \\
\text { provavelmente faz } \\
\text { parte do surto }\end{array}$ \\
& 2 & $4-6$ & $\begin{array}{c}\text { Isolado } \\
\text { possivelmente faz } \\
\text { parte do surto }\end{array}$ \\
Diferentes & 3 & 27 & $\begin{array}{c}\text { Isolado não faz parte } \\
\text { do surto }\end{array}$ \\
\hline
\end{tabular}


O detalhamento das etapas de extração e preparo do gel para corrida pode ser visualizado no anexo 3 .

Para o estudo do polimorfismo das bandas geradas pela eletroforese de campo pulsado, a imagem digitalizada foi analisada pelo programa "GelWorks 1D Advanced - UVP", versão 4.01 e "GelWorks 1D Database UVP", versão 1.12. Os perfis foram agrupados de acordo com os coeficientes de similaridade de Jaccard e demonstrados graficamente na forma de dendrograma. Os coeficientes empregados utilizam o número de bandas em comum e o número total de possíveis posições das bandas para calcular a porcentagem de similaridade entre os isolados, foi considerado relacionado quando o clone apresentava até $80 \%$ de similaridade (Kaufmann, 1998).

\subsubsection{PCR}

A caracterização dos genótipos de resistência a vancomicina (vanA e vanB) foi realizada usando PCR como descrito por Petrich et al.(1999). O primer vanA1 (5'CTGCGATATTCAAAGCTCA3') e o primer reverso vanA2 (5"CAGTACAATGCGGCCGTTA3') foram baseados na seqüência vanA descrita por Dutka-Malen et al. (1995) e geraram um produto de amplificação de 545 pares de bases.

Os parâmetros de amplificação foram desnaturação por 10 min a $94{ }^{\circ} \mathrm{C}, 45$ ciclos de $94{ }^{\circ} \mathrm{C}$ por 30 s, $50^{\circ} \mathrm{C}$ por 30 s e $72{ }^{\circ} \mathrm{C}$ por 60 s, seguido por uma extensão final de $10 \mathrm{~min}$ a $72{ }^{\circ} \mathrm{C}$.

Os géis foram corados em solução de syber green e as bandas de DNA foram visualizadas em transluminador com luz ultravioleta.

O detalhamento das etapas da reação é mostrado no anexo 4. 


\subsubsection{Avaliação da Adesão dos Profissionais da Saúde às Medidas de Controle de VRE}

Os profissionais da saúde das UTIs I e II foram observados quanto à adesão às medidas de prevenção e controle de VRE. Esta avaliação se fez necessária em função do aumento acentuado na densidade de incidência de colonização e de infecção por 1.000 pacientes-dia verificada no ano 2005.

As observações foram realizadas por uma equipe composta de uma microbiologista, uma enfermeira e três estagiários do quarto ano do curso de Farmácia da UEL, com duração de 30 minutos por leito, nos turnos matutino, vespertino e noturno, incluindo sábados, domingos e feriados.

Antes de serem iniciadas as observações, a equipe passou por um processo de validação. Inicialmente os estagiários foram treinados para realização das observações pela enfermeira e pela microbiologista. Posteriormente foram realizadas observações simultâneas por um profissional e um estagiário seguidas por uma discussão dos resultados das observações com o objetivo de padronização. A primeira semana de observação foi considerada como período de treinamento e familiarização com o instrumento de coleta de dados coletados. Os resultados encontrados neste período não foram computados.

A mesma equipe realizou as observações dos períodos pré e pósintervenção com exceção da enfermeira que não participou do período pósintervenção. As observações do período pré-intervenção foram realizadas durante todo o mês de fevereiro e de março de 2007 e as do período pós foram realizadas em alguns momentos dos meses de maio, setembro e novembro de 2007. 
As observações se iniciavam quando o profissional entrava no box do paciente e iniciava alguma atividade que envolvia contato com paciente ou objetos.

As variáveis monitoradas incluíam categoria do profissional, tipo de contato com o paciente, utilização de quarto privativo, identificação no leito de pacientes portadores de VRE, higiene das mãos antes e após o contato, uso de luvas, uso de avental, uso de material não crítico individual, desinfecção de material não crítico com álcool $70 \%$ entre outros, de acordo com protocolo do anexo 5.

Vale ressaltar que tais profissionais não foram nomeados e as observações foram realizadas quanto aos procedimentos adotados com os pacientes e estes não foram identificados a não ser pela categoria profissional. Considerando que o conhecimento prévio dos profissionais dos objetivos da pesquisa poderia interferir nos resultados e que, portanto, não seria recomendável, a Comissão de Ética do HU/UEL a realização das observações sem consentimento esclarecido.

\subsubsection{Avaliação dos Profissionais da Limpeza}

A equipe de limpeza das UTIs de adultos é composta por 8 zeladoras e pelos técnicos de enfermagem do próprio quadro de funcionários do hospital. As zeladoras realizam limpeza concorrente de piso e paredes como água e sabão, uma vez a cada 6 horas e são as responsáveis pela desinfecção terminal de pisos, parede, leitos, mobiliário 
em geral, os quais são lavados com água e sabão. Paredes, leito e mobiliário são desinfetados com ácido peracético a 0,5\% após a limpeza. Desinfecções terminais de toda a unidade são realizadas por vários zeladores, mesmo atuantes em outras áreas do hospital.

A desinfecção de equipamentos e materiais não críticos de uso individual é realizada pelos técnicos de enfermagem através de fricção com álcool $70^{\circ}$ a cada 6 horas. Para materiais não críticos de uso coletivo recomenda-se a desinfecção com álcool $70 \%$ antes de cada uso.

Estes profissionais foram observados quanto à limpeza de superfícies como pisos, paredes e desinfecção dos materiais e equipamentos. Foram avaliados os seguintes aspectos: categoria do profissional, tipo de limpeza, higiene das mãos antes e após o procedimento, uso de luvas, uso de avental, produto utilizado para limpeza e desinfecção entre outros de acordo com protocolo do (anexo 6).

As observações foram realizadas pela mesma equipe em todos os dias da semana, incluindo sábados, domingos e feriados, durante um período de no máximo 30 minutos por profissional, nos turnos matutino, vespertino e noturno.

\subsubsection{Determinação do Consumo de Glicopeptídeos}

O consumo de glicopeptídeos em miligramas entre 2002 e 2007 foi convertido em dose diária definida (DDD) por 1.000 pacientes-dia para permitir a interpretação dos resultados. A DDD de glicopeptídeos foi calculada dividindo-se o total de gramas do agente antimicrobiano usado 
pelo número de gramas na média diária da dose do agente dada a pacientes adultos de $2 \mathrm{~g}$ para vancomicina e $400 \mathrm{mg}$ para teicoplanina pelo número de pacientes-dia, multiplicado por 1.000 (Polk et al., 2007).

\subsection{Período de Intervenção}

No mês de abril de 2007, foram realizados nas UTIs treinamentos em serviço das equipes de saúde da unidade com divulgação das taxas verificadas de maio de 2002 a março de 2007 . Esta etapa foi constituída de:

- Divulgação dos resultados das culturas de vigilância de VRE realizadas na Unidade;

- Apresentação dos resultados das análises moleculares;

- Divulgação dos resultados obtidos das observações dos profissionais;

- Aulas enfatizando a importância da adesão às medidas de controle de prevenção deste agente, higienização das mãos bem como de limpeza e desinfecção de equipamentos, mobiliários e superfícies;

- Cartazes reforçando a importância da higiene das mãos e medidas de controle.

O treinamento foi realizado através de aulas teórico-práticas, utilizando-se multimídia, com apresentação dos resultados das densidades de incidência de VRE nas UTIs, no período de 2002 a 2006, 
das observações de procedimentos na assistência, e dos dados das análises moleculares.

Foram realizadas, ainda, culturas das mãos dos profissionais, de tal forma que apenas o próprio conhecia a identificação, com o objetivo de evidenciar a presença dos microrganismos e assim sensibilizá-los sobre a importância da higiene das mãos, antes e após procedimentos assistenciais. Resultados das culturas que revelavam contaminação ambiental e adesão à desinfecção dos equipamentos e materiais de uso coletivo também foram apresentados.

\subsection{Período pós-intervenção}

a) Análise microbiológica de cepas de VRE obtidas de culturas de vigilância do entre maio e dezembro de 2007, no setor de microbiologia do Laboratório de Análises Clínicas do HU no Laboratório de Investigação Médica (LIM 54) do Departamento de Doenças Infecciosas e Parasitárias do Hospital das Clínicas da Faculdade de Medicina da Universidade de São Paulo;

b) Determinação da densidade de incidência de colonização e infecção por VRE por 1.000 pacientes-dia nas UTIs de adultos do HU/UEL;

c) Análise Molecular das cepas de VRE;

d) Avaliação da adesão ao isolamento de contato e da limpeza e desinfecção de equipamentos e superfícies adotados pelos profissionais da saúde que atuavam nas UTIs; do HU/UEL 
e) Determinação do consumo de glicopeptídeos em Dose Diária Definida (DDD);

f) Comparação das análises realizadas nos períodos pré e pósintervenção através de análises estatísticas.

\subsection{Análise Estatística}

Foi criado um banco de dados nos programas Excel e Epilnfo, CDC, version 6, 04 (CDC) com os dados descritivos da população estuda. O teste de $\chi^{2}$ foi utilizado para comparar a incidência de colonização, infecção e contaminação ambiental por VRE, consumo de vancomicina (DDD) e adesão às precauções de contato dos períodos pré e pós-intervenção e o teste $\chi^{2}$ para tendência foi utilizado para avaliar a distribuição de VRE, a proporção de espécies e o uso de glicopeptídeos durante o período de estudo, considerado significante o valor de $\rho<0.05$. 
Desde o surgimento de VRE no HU de Londrina vários surtos foram detectados. Em 2002 iniciou-se o primeiro surto por E. faecium resistente a vancomicina, que foi erradicado em março de 2004. Entre 2002 e 2004 foram realizadas 2.665 culturas de vigilância, sendo 2024 de swab retal, 560 de ambiente e equipamentos e 81 de swab das mãos de profissionais da unidade. Do total de culturas analisadas, $172(6,4 \%)$ foram positivas para VRE. Entre as culturas de swab retal o percentual de isolamento de VRE foi $8,2 \%$ e entre as do ambiente e equipamentos foi $1 \%$. A densidade de incidência por 1.000 pacientes-dia do período 2002 a 2004 é mostrada no anexo7.

De janeiro a março de 2005 iniciou-se um surto por E. faecalis e a partir de março uma nova cepa de E. faecium passou a ser isolada de culturas de vigilância inicialmente de pacientes internados nas UTIs e a partir de junho de culturas clínicas, não só nas UTIs como também nas Enfermarias e Pronto Socorro. A incidência de VRE aumentou gradativamente até se tornar endêmico. A proporção de culturas de vigilância realizadas e o percentual de positividade de VRE nos anos 2002 a 2006, é mostrado na figura 3.

E. faecium foi a espécie mais freqüentemente identificada em praticamente todo o período de estudo, exceto em 2005 quando houve um equilíbrio na proporção das duas espécies. Quando se observa o ano 2005, 
mês a mês pode-se constatar que, nos primeiros meses do ano, a incidência de E. faecalis foi maior, entretanto, a partir de junho de 2005 , E. faecium voltou a ser a espécie mais freqüentemente isolada de pacientes colonizados, conforme pode ser visualizado na figura 4.

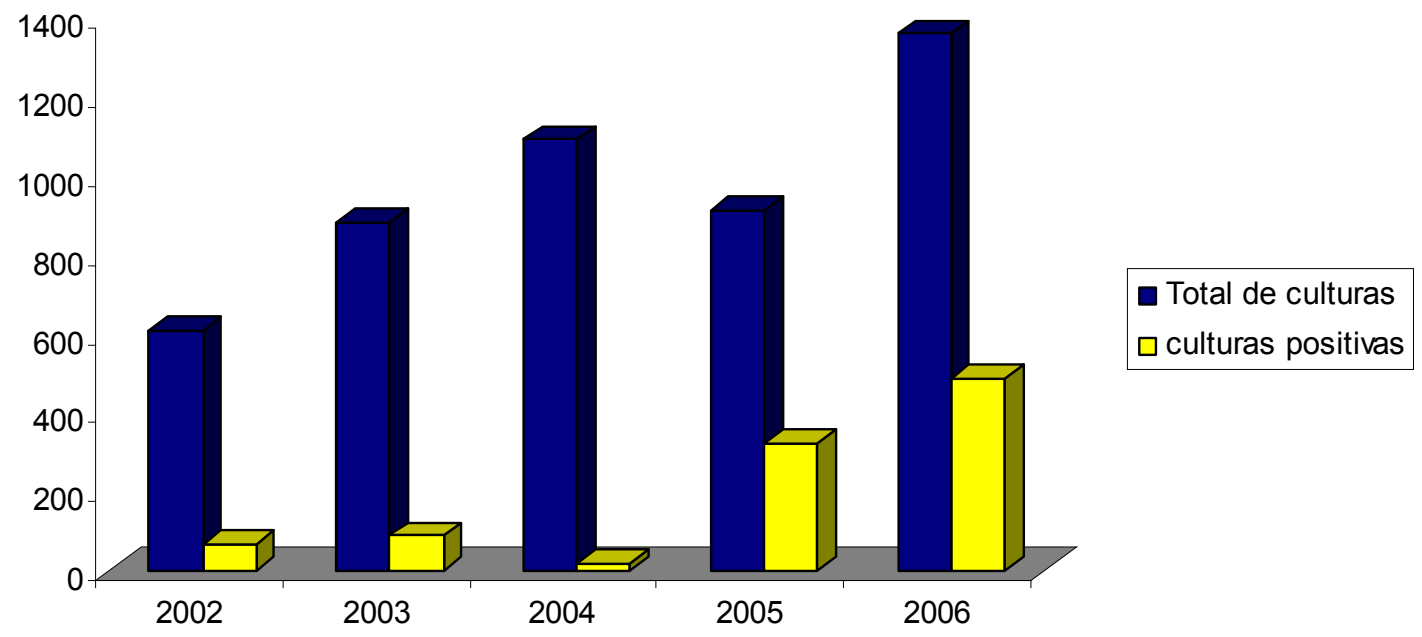

Figura 3 - Freqüência de VRE em identificados de culturas de vigilância realizadas no HU/UEL, de maio de 2002 a dezembro de 2006, por ano.

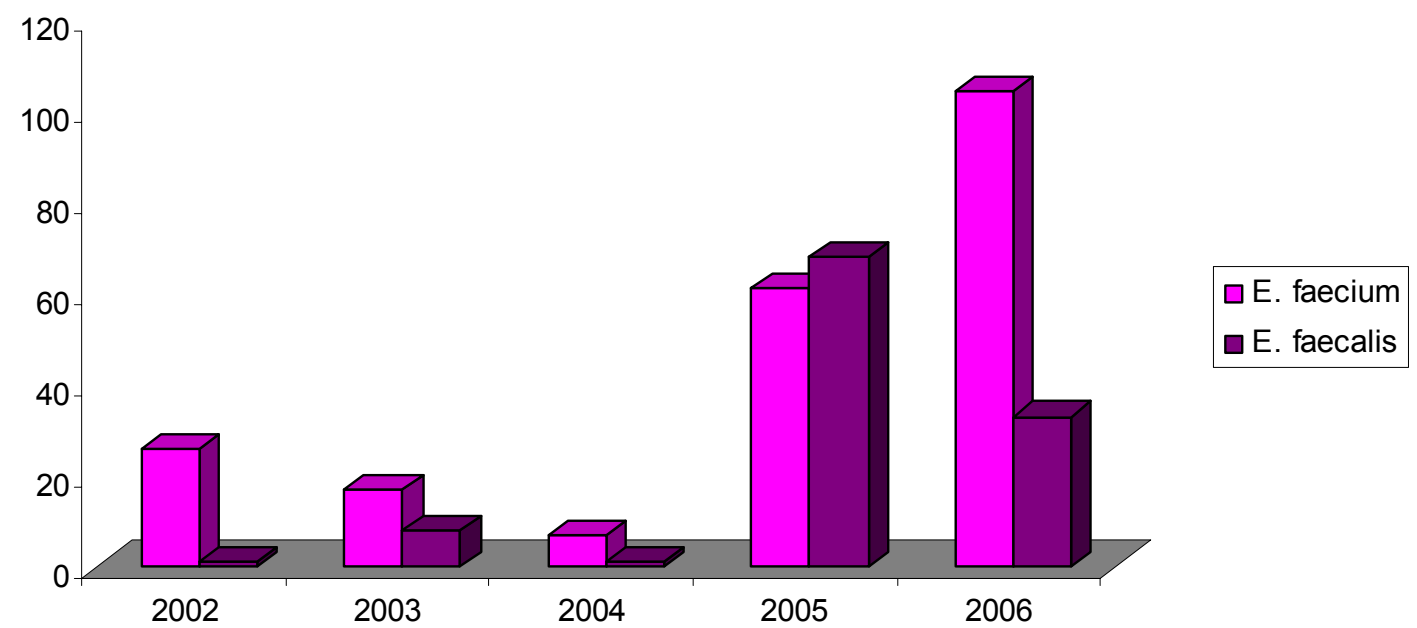

Figura 4 - Freqüência de espécies identificadas entre 516 VRE, obtidos de pacientes colonizados e infectados do $\mathrm{HU}$, por ano, no período de maio de 2002 a dezembro de 2007. 
E. faecium foi a espécie de VRE mais isolada no $\mathrm{HU}$ tanto em pacientes colonizados quanto infectados, correspondendo a $71,7 \%$ de 516 culturas nas quais a espécie foi identificada. E. faecalis foi isolado em $28 \%$, e $E$. durans em $0,3 \%$ das culturas apenas.

Comparando-se a incidência de espécies entre pacientes colonizados e infectados de 2002 a 2007 verifica-se que E. faecium foi a espécie mais freqüente em ambos os grupos, $70 \%$ entre pacientes colonizados e $86 \%$ entre os infectados (Figura 5).

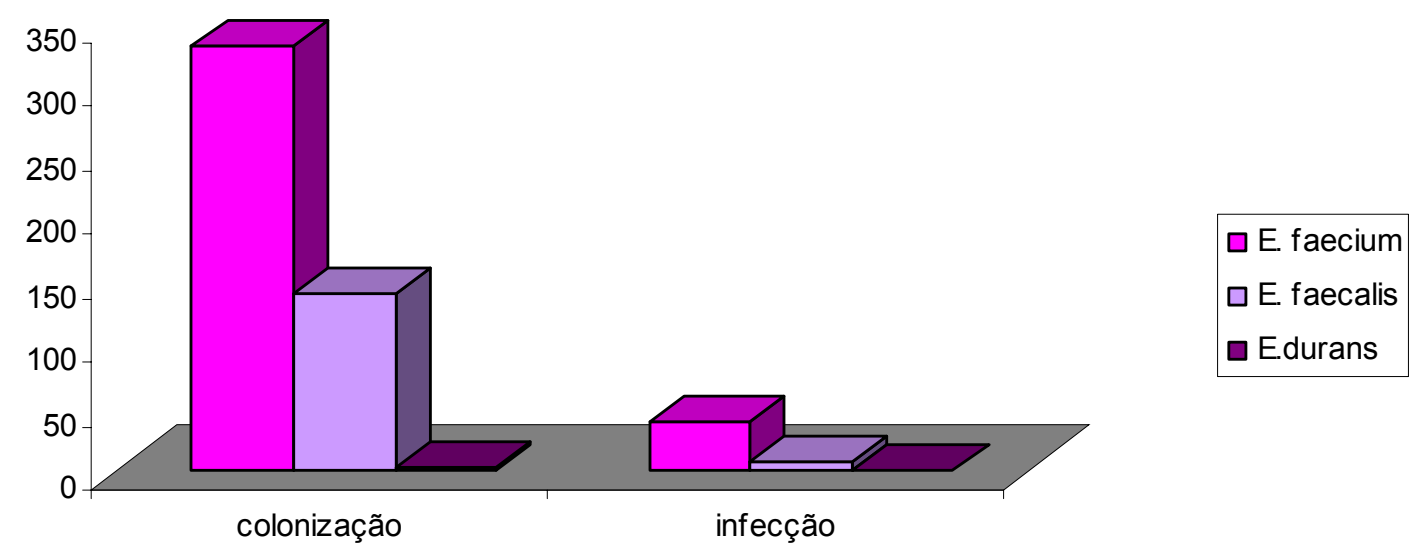

Figura 5 - Freqüência de espécies identificadas entre 516 VRE, obtidos de pacientes colonizados e infectados do $\mathrm{HU}$, por ano, no período de maio de 2002 a dezembro de 2007.

A densidade de incidência de colonização por VRE de 7,5 por 1.000 pacientes-dia em 2002 e 7,02 em 2003 diminuiu para 1,95 em 2004. Entretanto aumentou para 25,54 em 2005 e para 42,95 em 2006 (Figura 6). 


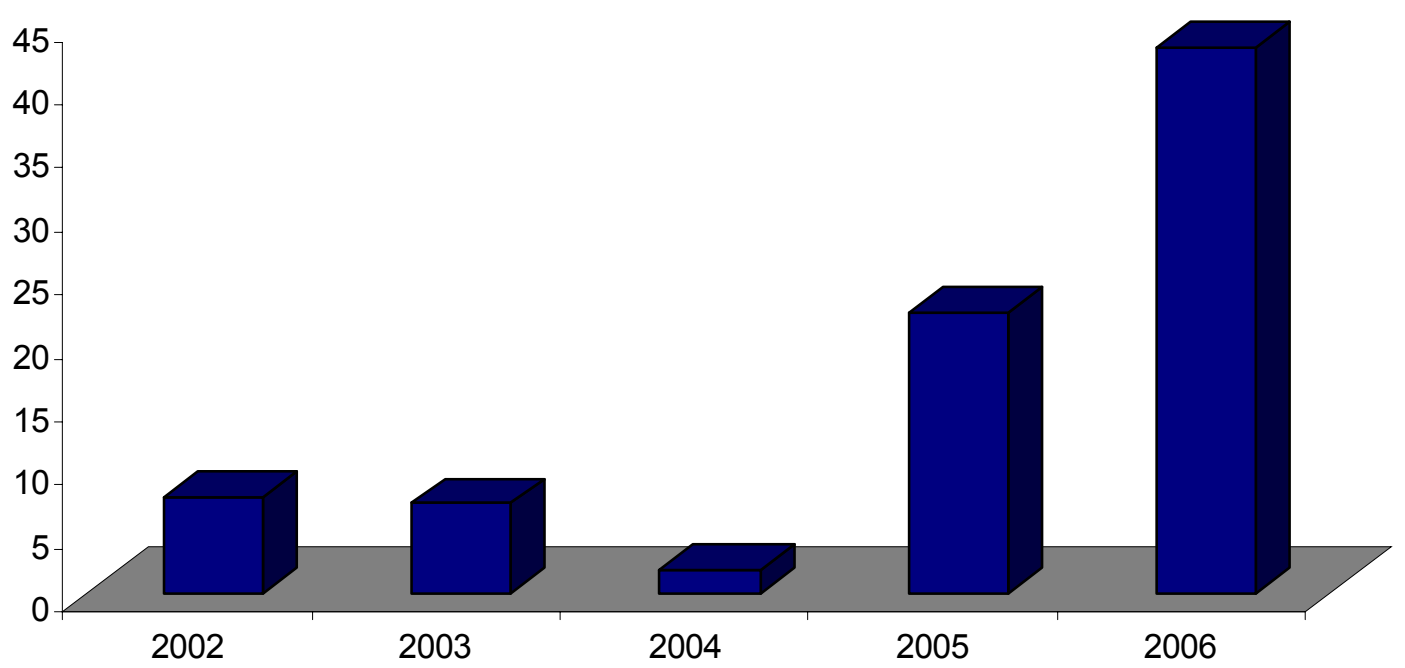

Figura 6 - Densidade de Incidência de colonização por VRE por 1.000 pacientesdia nos anos de 2002 a 2006.

Várias intervenções foram realizadas pelo $\mathrm{SCIH}$ na tentativa de erradicar VRE. No início os resultados foram animadores, entretanto as altas taxas de colonização e infecção por VRE verificadas em 2006 demonstraram a necessidade de realizar uma intervenção educacional mais efetiva.

Em abril de 2007, quando foi realizada a intervenção, foram treinados 136 profissionais que exerciam atividades nas UTIs. Entre eles a grande maioria 75 (55\%) pertencia ao quadro de enfermagem, sendo 19 enfermeiros, 50 técnicos de enfermagem, dois residentes e quatro internos de enfermagem. Foram treinados também, 12 (9\%) profissionais da área médica, quatro médicos plantonistas, seis residentes médicos e dois internos do curso de Medicina, além de sete (5\%) fisioterapeutas, 31 (23\%) técnicos de laboratório, seis $(4,4 \%)$ profissionais de limpeza. Estes profissionais foram informados da taxas de incidência, da contaminação ambiental, da avaliação molecular das amostras isoladas, das observações das precauções de 
contato e padrão. A maioria demonstrou grande interesse e se mostrou preocupada com a situação de endemicidade instalada no hospital.

Após intervenção foram realizadas mais 1.532 culturas de vigilância, das quais 1.205 de swab retal e 327 de ambiente e equipamentos. A densidade de incidência de colonização dos períodos pré, pós e de intervenção foi comparada e é mostrada na figura 7. Comparando a densidade de incidência de colonização de 1,99 VRE por 1.000 pacientes-dia em 2004, com 36,29 do período pré-intervenção em 2007 constata-se que houve um aumento significativo de colonização $(\rho<0,001)$. Considerando-se apenas 0 período pré-intervenção (janeiro de 2006 a março de 2007) observa-se que a densidade 42,02, não foi maior do que durante a intervenção 43,93 e nem que a do período pós-intervenção $34,73(\rho=0,56)$. Analisando-se o $\chi^{2}$ para tendência, verifica-se que da mesma forma não houve diferença $(\rho=0,41)$.

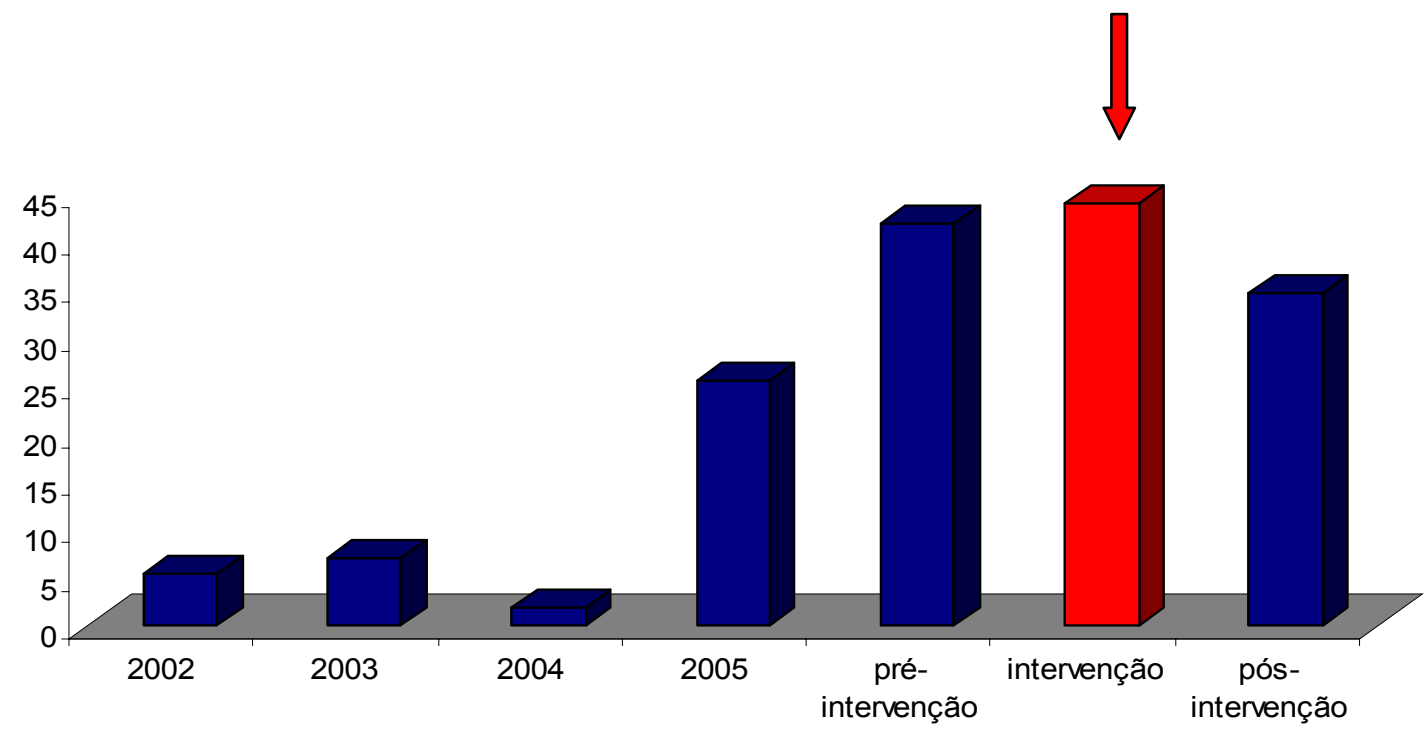

Figura 7 - Densidade de incidência de colonização por VRE por 1.000 pacientesdia, nas UTIs de adultos do HU de maio de 2002 a dezembro de 2007. 
A partir de junho de 2005 foram identificados os primeiros casos de infecção totalizando 9 pacientes com uma densidade de incidência de infecção por 1.000 pacientes-dia de 2,53 no ano 2005, 24 casos e densidade de 3,723 no período pré-intervenção, 1 caso e densidade de 2,09 no período intervenção e 3 casos com densidade de 0,72 no período pós-intervenção, uma diferença estatisticamente significativa $(\rho=0,004)$, como pode ser visualizado na figura 8.

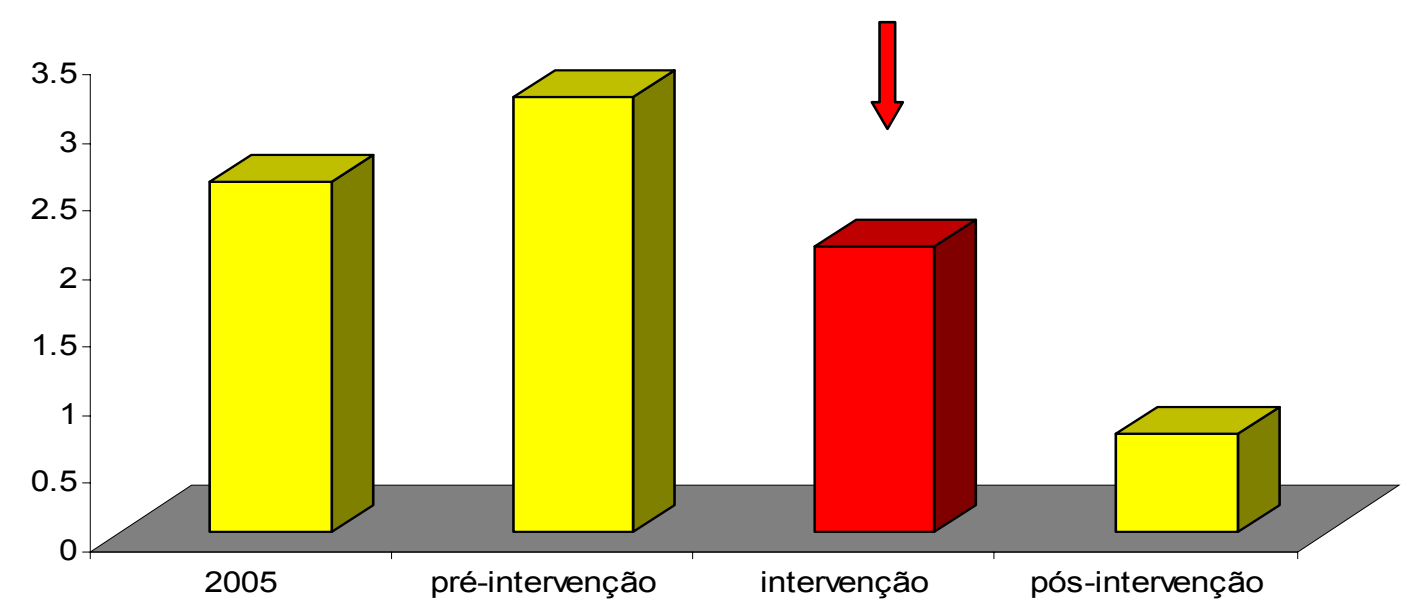

Figura 8 - Densidade de incidência de infecção por VRE por 1.000 pacientes-dia, nas UTIs Gerais do HU dos períodos pré-intervenção, janeiro de 2006 a março de 2007, intervenção, abril de 2007 e pós-intervenção, de maio a dezembro de 2007.

Observando-se a figura 9 verifica-se que a densidade de incidência de colonização mês a mês, de janeiro de 2006 a março de 2007, se manteve acima de 40 colonizações por 1.000 pacientes-dia em quase todo o período, da mesma forma que no período de intervenção, abril de 2007 (43,93). Imediatamente após intervenção, no mês de maio, houve uma redução de colonização para 22,86 , entretanto no mês de julho voltou a subir $(53,89)$, e 
permaneceu em média 36,7 de julho a outubro. Pode-se constatar ainda que, embora não tenha havido diferença entre a densidade de incidência de infecção dos meses de março $(5,8)$ a maio $(3,8)$ de 2007 , de julho a dezembro de 2007 a densidade caiu para zero $(\rho<0.001)$.

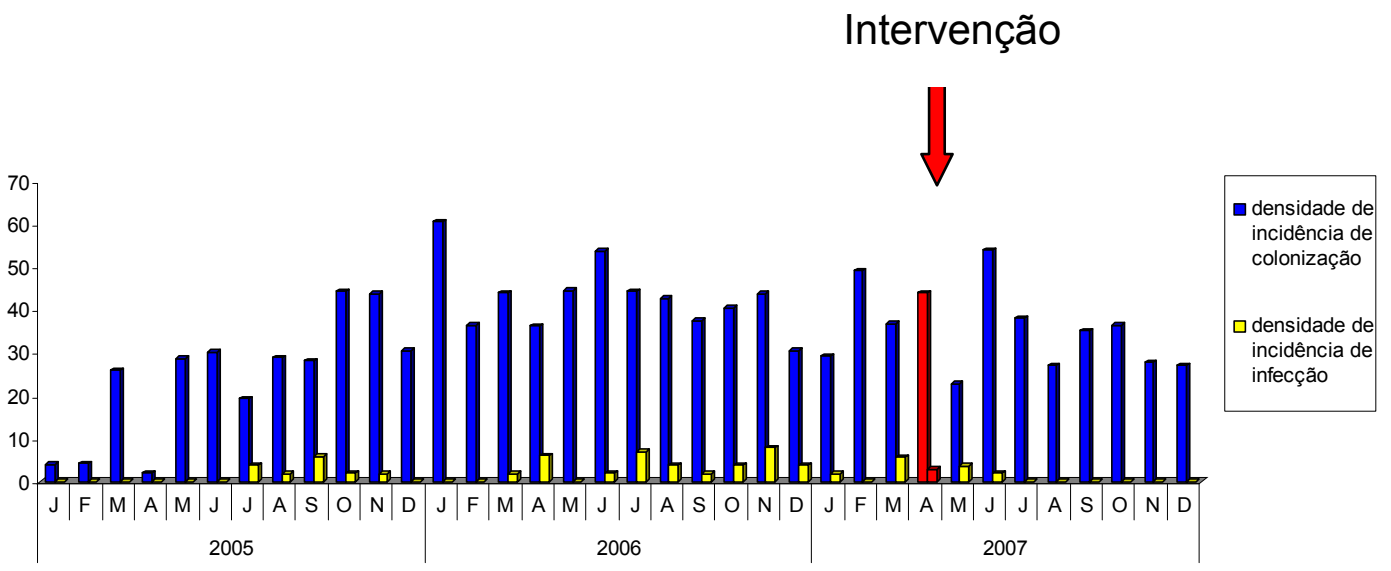

Figura 9 - Densidade de incidência de colonização por VRE por 1.000 pacientesdia, nas UTIs Gerais do HU de janeiro de 2005 a dezembro de 2007, mês a mês, nas fases pré e pós-intervenção..

Durante o período de estudo, de 719 pacientes novos colonizados nas UTIs, 36 apresentaram infecção de maio de 2002 a dezembro de 2007. A proporção média de pacientes colonizados que se infectaram por VRE foi de $6 \%$. A média de idade foi de 58 anos em uma faixa de 15 a 91 anos, dos quais $66 \%$ eram do sexo masculino. A tabela 2 resume as características clínicas e demográficas dos pacientes que apresentaram infecção por VRE.

A grande maioria dos episódios (83\%) foi causada por E. faecium, e, a corrente sangüínea foi o sítio de infecção foi o mais freqüente $(47 \%)$, seguido pelo trato urinário (36\%). Analisando-se a freqüência de amostras 
positivas nos períodos pré e pós-intervenção, pode-se constatar pela figura 10 que houve redução nas infecções de corrente sangüíneas causadas por VRE.

Entre os diagnósticos de internação dos pacientes verifica-se que as doenças respiratórias foram as mais freqüentes $(26 \%)$, seguida por insuficiência renal, hipertensão arterial e neoplasias com 14\% cada, insuficiência cardíaca, doença neurológica, cirrose e trauma com 7\%.

Sessenta e dois pacientes (72\%) apresentaram colonização prévia por VRE, sendo que o tempo médio entre internação e colonização foi de 16 dias, variando de 0 a 50 dias e o tempo entre internação e infecção foi de 38 dias, variando de 7 a 180 dias.

O uso prévio de glicopeptídeos e cefalosporinas ocorreu em $45 \%$ dos pacientes, sendo em média 13 dias para glicopeptídeos e 11 dias para cefalosporinas.

Dos 36 pacientes infectados, $12(44 \%)$ receberam tratamento específico, 5 foram tratados com linezolida e 5 com tigeciclina, sendo que a taxa de mortalidade geral foi de $66 \%$.

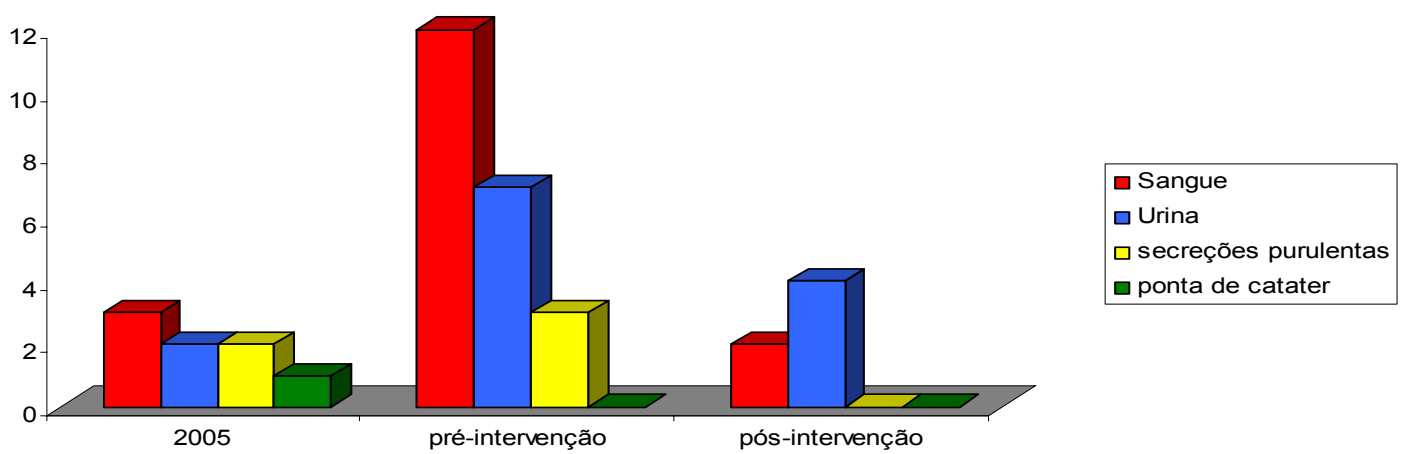

Figura 10 - Distribuição de 36 materiais biológicos obtidos de infecções causadas por VRE, no período de julho de 2005 a dezembro de 2007. 
Tabela 2 - Características clínicas e demográficas de 36 pacientes com infecção por VRE identificadas de junho de 2005 a dezembro de 2007

\begin{tabular}{|c|c|}
\hline Característica & Número com a característica \\
\hline Idade média (anos) & $58(15-91)$ \\
\hline \multicolumn{2}{|l|}{ Gênero } \\
\hline Masculino & $20(66 \%)$ \\
\hline Feminino & $16(44 \%)$ \\
\hline \multicolumn{2}{|l|}{ Espécie (\%) } \\
\hline E. faecium & $30(83 \%)$ \\
\hline E. faecalis & $6(17 \%)$ \\
\hline \multicolumn{2}{|l|}{ Sítio de infecção } \\
\hline Sangue & $47 \%$ \\
\hline Urina & $36 \%$ \\
\hline Secreção & $14 \%$ \\
\hline Cateter venoso central & $3 \%$ \\
\hline \multicolumn{2}{|l|}{ Diagnóstico de internação (\%) } \\
\hline Insuficiência renal & $14 \%$ \\
\hline Insuficiência cardíaca & $7 \%$ \\
\hline Doença respiratória & $26 \%$ \\
\hline Doença neurológica & $7 \%$ \\
\hline Hipertensão arterial & $14 \%$ \\
\hline Neoplasia & $14 \%$ \\
\hline Cirrose & $7 \%$ \\
\hline Trauma & $7 \%$ \\
\hline Cirurgia & $4 \%$ \\
\hline \multicolumn{2}{|l|}{ Uso prévio de antimicrobianos } \\
\hline Sim - glicopeptídeos & 13 dias $(02-30)$ \\
\hline Cefalosporinas & 11 dias $(0-31)$ \\
\hline Não - glicopeptídeos & $55 \%$ \\
\hline Cefalosporinas & $55 \%$ \\
\hline Colonização prévia & $72 \%$ \\
\hline \multicolumn{2}{|l|}{ Tempo médio entre } \\
\hline Internação e Colonização & 16 dias $(0-50)$ \\
\hline Internação e Infecção & 38 dias $(7-180)$ \\
\hline \multicolumn{2}{|l|}{ Tratamento: } \\
\hline Sim & $12(44 \%)$ \\
\hline Linezolida & 5 \\
\hline Tigeciclina & 5 \\
\hline Outro & 2 \\
\hline Óbito & $24(66 \%)$ \\
\hline
\end{tabular}

O anexo 8 demonstra a relação de pacientes que apresentaram infecção e seus dados demográficos. 
A contaminação ambiental e de equipamentos foi analisada a partir de 1.064 culturas realizadas de 2002 a 2007, sendo 210 de swabs de equipamentos médicos, 167 de estetoscópios, 156 de leitos, 154 de bancadas de cabeceira de leitos, 136 de válvulas de ar, 57 de termômetros, 31 de esfigmanômetros, 27 de medidores de cuff, 10 de ambus, e 60 de outras culturas incluindo swabs de oxímetros, otoscópios, pranchetas de prontuários médicos e de enfermagem, maçaneta e porta da geladeira do posto de enfermagem, telefone, teclado de computador, saboneteiras, pias, bacias de alumínio, poltronas, banco, travesseiro, e outros. De todas as culturas de ambiente e equipamentos realizadas, 135 (12,7\%) foram positivas para VRE. A figura 11 mostra alguns pontos de investigação de contaminação ambiental e de equipamentos.

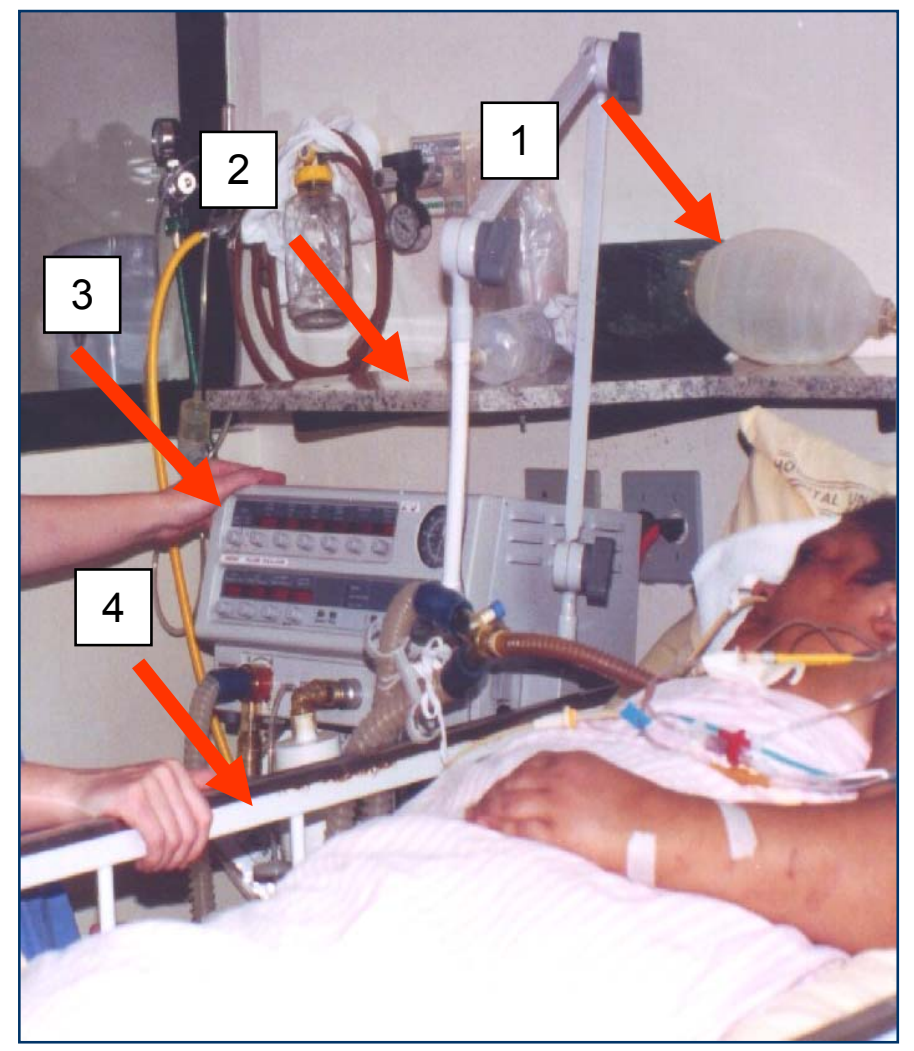

Figura 11 - Alguns pontos de coleta de ambiente e equipamentos por box.

Legenda: 1- ambu, 2- bancada de cabeceira do leito, 3 - equipamento, 4 - grade do leito 
Analisando-se todo período, os locais de onde foram isolados VRE em maior freqüência foram: bancadas de cabeceira $(20,1 \%)$ e leitos $(19,87 \%)$, seguidos pelos equipamentos como monitores cardíacos, respiradores, (11,24\%), válvulas de ar (11\%), estetoscópios $(10,17 \%)$, esfigmanômetros e outros materiais não críticos como otoscópios, oxímetros, glucosímetros, ambus, medidores de cuff, bombas de infusão e máscaras de oxigênio $(9,6 \%)$, termômetros $(5,2 \%)$ e materiais de escritório como pranchetas (2\%). De outros locais como teclado de computadores, telefones, maçanetas de portas, portas de geladeira, poltronas, bancos, não foi solado nenhum VRE. A figura 12 ilustra os percentuais de positividade encontrados entre todas as culturas realizadas de 2002 a 2007.

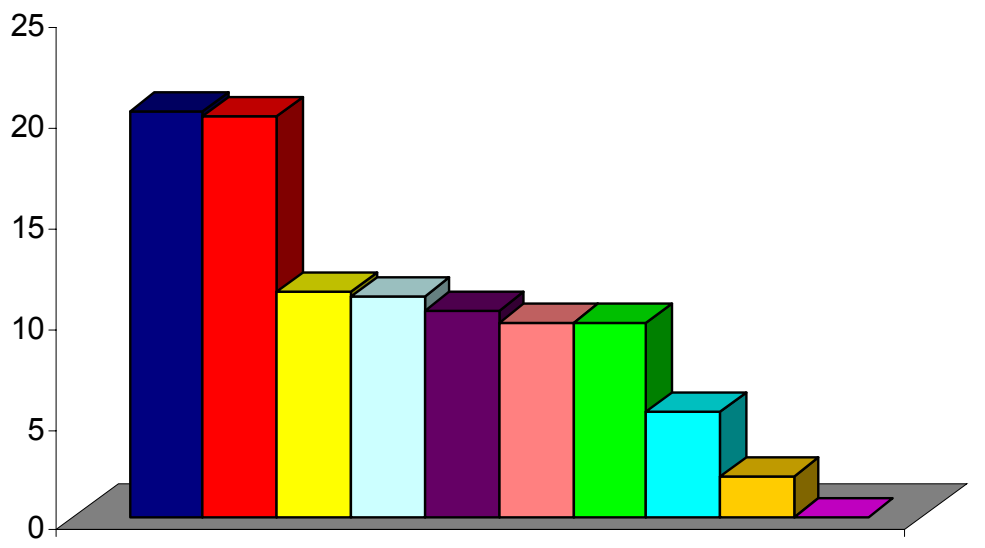

$\square$ bancada de cabeceira
$\square$ leito
$\square$ equipamentos
$\square$ válvula de ar
$\square$ estetoscópio
$\square$ esfigmanômetro
$\square$ materiais não críticos
$\square$ termômetro
$\square$ materiais escritorio
$\square$ outros

Figura 12 - Percentual de VRE de 135 culturas positivas, isolados de 1063 culturas do ambiente e equipamentos próximos a pacientes, realizadas entre maio de 2002 a dezembro de 2007 .

Analisando-se os dados por período verificou-se variação no índice de positividade nas culturas ambientais e de equipamentos. Em 2002, o índice de positividade foi baixo, tendo sido identificados VRE em apenas $2(3,44 \%)$ 
das culturas. Em 2003, da mesma forma, foram apenas duas $(3,38 \%)$ culturas positivas e em 2004 nenhum VRE foi isolado a partir de ambiente ou equipamento.

A partir de 2005, porém, verificou-se uma elevada contaminação ambiental e de equipamentos. Das 160 culturas realizadas no período préintervenção, $37(23,2 \%)$ foi positiva para VRE, enquanto no período pósintervenção de 252 culturas, isolou-se VRE apenas em 22 (8,7\%), uma redução estatisticamente significativa $(\rho<0,001)$. Dos materiais, equipamentos e ambiente próximo aos pacientes, dos quais mais freqüentemente se isolou VRE, na fase pré-intervenção, foram: bancadas de cabeceira dos leitos $(37,9 \%)$, seguido pelos esfigmanômetros $(33,3 \%)$, leitos $(25,9 \%)$, equipamentos $(25 \%)$, estetoscópios $(14,8 \%)$. Já na fase pósintervenção, como pode ser visualisado na figura 21, ocorreu uma redução nas taxas de contaminação das bancadas $(11,1 \%)$, leitos $(15,38 \%)$, equipamentos $(8,57 \%)$, estetoscópio $(5,88 \%)$, esfignômetros $(4,34 \%)$, em comparação à fase pré-intervenção, como pode ser visualizado na figura 13.

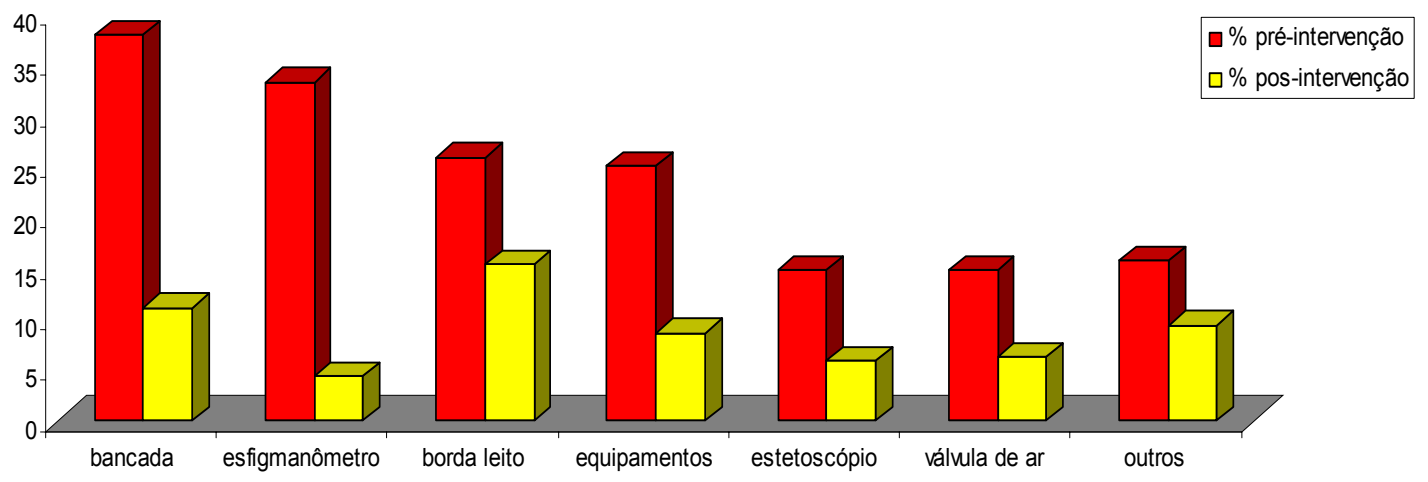

Figura 13 - Percentual de positividade de VRE entre 160 culturas de ambiente próximo a pacientes realizadas de abril de 2006 a março de 2007 (período pré-intervenção) e de 252 realizadas de maio a dezembro de 2007 (período pós-intervenção). 
As coletas realizadas no período pré-intervenção podem ser divididas em 2 momentos: momento I em abril de 2006 e momento II em março de 2007. A fase pós-intervenção compreendeu o momento III em maio de 2007 e momento $V$ em novembro de 2007. O percentual de contaminação das culturas no momento I de $23 \%$ foi semelhante ao momento II de $21,6 \%$ e reduziu significativamente nos momentos III para $11,5 \%$ e no momento IV para $2,47 \%(\rho<0,001)$.

A tabela 3 relaciona o percentual de positividade para VRE das culturas de ambiente e equipamentos, nos períodos pré-intervenção (momentos I e II) e pós-intervenção (momentos III e IV). No período pré-intervenção, os materiais que se destacam pela contaminação foram aqueles que estavam mais próximos aos pacientes como bancadas de cabeceira $(37,9 \%)$, borda de leitos $(33,3 \%)$, e esfigmanômetros $(25,9 \%)$. Esta contaminação reduziu drasticamente após o treinamento dos funcionários, sendo nítida a redução da contaminação de bancada (15 e 0\%) e de esfigmanômetros $(7,6$ e 0\%) nos momentos III e IV, respectivamente $(\rho<0,001)$. Os demais materiais também apresentaram redução significativa na contaminação comparando o período pré com o período pós-intervenção. A contaminação de equipamentos por VRE reduziu de $25 \%$ no período pré para $11 \%$ no momento III e para $5,8 \%$ no momento IV após intervenção $(\rho=0,001)$. Da mesma forma culturas de estetoscópios e válvulas de ar que apresentaram 14,8\% de positividade para VRE antes do treinamento, no momento III apresentaram 5,8 e $13,3 \%$ e no momento IV 0 e $5,8 \%(\rho=0,003$ e $<0,001)$, respectivamente. Outros materiais ambientais cultivados também apresentaram redução significativa na contaminação mesmo após 6 meses do treinamento (anexo 9). 
Tabela 3 - Percentual de culturas de ambiente positivas nos momentos I e II do período pré-intervenção e nos momento III e momento IV do período pósintervenção, por material de isolamento.

\begin{tabular}{lcccc}
\hline Itens & $\begin{array}{c}\text { Pré-intervenção } \\
\text { Momentos I e II }\end{array}$ & $\begin{array}{c}\text { Pós-intervenção } \\
\text { Momento III }\end{array}$ & $\begin{array}{c}\text { Pós-intervenção } \\
\text { Momento IV }\end{array}$ & Valor $\boldsymbol{\rho}$ \\
\hline Bancada & $37.9 \%$ & $15 \%$ & 0 & $<0.001$ \\
Esfigmanômetro & $33.3 \%$ & $7.6 \%$ & 0 & $<0.001$ \\
Borda do leito & $25.9 \%$ & $23.5 \%$ & 0 & $<0.001$ \\
Equipamentos & $25 \%$ & $11 \%$ & $5.8 \%$ & 0.001 \\
Estetoscópio & $14.8 \%$ & $5.8 \%$ & $5.8 \%$ & 0.003 \\
Válvula de ar & $14.8 \%$ & $13.3 \%$ & 0 & 0.001 \\
Outros & $15.7 \%$ & $11.5 \%$ & $2.9 \%$ & 0.01 \\
\hline
\end{tabular}

A distribuição dos pontos de contaminação de materiais, equipamentos e mobiliário em cada um dos boxes, dos períodos pré e pósintervenção, foi analisada. A figura 14 refere-se à contaminação verificada na UTI I, no período pré-intervenção (momento I) e a 16 no período pós (momento IV). Da mesma forma, a figura 17 se refere à UTI II no período pré-intervenção e a 18 ao pós. Os locais de contaminação dos boxes verificados nos demais momentos são mostrados nos anexos 10 a 12 .

No período pré-intervenção, dos 17 boxes, verificou-se que 13 (76\%) apresentavam contaminação e que em 100\% destes estavam internados pacientes colonizados por VRE. No momento I foram cinco boxes contaminados na UTI I e quatro na UTI II, em todos estes os pacientes estavam colonizados. Nos outros oito boxes, onde não havia sido detectado este microrganismo, nenhum paciente estava colonizado. $O$ número de pontos contaminados por boxe variou de um a 5 (Figuras 14 e 15). 


\begin{tabular}{|l|c|c|c|c|c|c|c|c|c|c|}
\hline & box & box & box & box & box & box & box & box & box & box \\
\hline Swab retal & 1 & 2 & 3 & 4 & 5 & 6 & 7 & 8 & 9 & 10 \\
\hline Bancada & & & & & & & & & & \\
\hline Borda leito & & & & & & & & & & \\
\hline Equipamentos & & & & & & & & & & \\
\hline Estetoscópio & & & & & & & & & & \\
\hline Esfigmanômetro & & & & & & & & & & \\
\hline Válvula de ar & & & & & & & & & & \\
\hline Otoscópio & & & & & & & & & & \\
\hline Oxímetro & & & & & & & & & & \\
\hline
\end{tabular}

Figura 14 - Distribuição de materiais ambientais e equipamentos positivos para VRE de acordo com o Box da UTI I, no momento I de coleta (abril de 2006) do período pré-intervenção.

\begin{tabular}{|l|c|c|c|c|c|c|c|}
\hline & box & box & box & box & box & box & box \\
\hline Swab retal & 1 & 2 & 3 & 4 & 5 & 6 & 7 \\
\hline Bancada & & & & & & & \\
\hline Borda leito & & & & & & & \\
\hline Equipamentos & & & & & & & \\
\hline Estetoscópio & & & & & & & \\
\hline Válvula de ar & & & & & & & \\
\hline Termômetro & & & & & & & \\
\hline
\end{tabular}

Figura 15 - Distribuição de materiais ambientais e equipamentos positivos para VRE de acordo com o Box da UTI III, no momento I de coleta (abril de 2006), período pré-intervenção.

\section{LEGENDA}


No momento II verificou-se que dos 6 boxes contaminados, em 4 havia paciente colonizado. Verificou-se, ainda, contaminação dos equipamentos num box, sem que o paciente estivesse colonizado e num outro em que não havia paciente, constatou-se contaminação da bancada, mesmo após desinfecção terminal (anexo 10). Foram cultivados 6 outros pontos do posto de enfermagem dos quais detectou-se VRE na bancada central e na prancheta utilizada para prescrição de enfermagem.

Não foram realizadas coletas de ambiente e equipamentos na UTI II, no momento II, pois a mesma havia sido transferida temporariamente para outra área do hospital. Neste momento foi realizada a desinfecção terminal da UTI II.

Após intervenção, no momento III, tanto na UTI I quanto na UTI II encontraram-se 5 boxes contaminados cada, e o número de pontos diminuiu para um por box na UTI I e dois por box na UTI II. Foi observada contaminação ainda de um termômetro, prancheta de prescrição e botão do ar condicionado do posto de enfermagem (anexo 11 e 12).

No momento IV a redução de pontos contaminados foi bastante significativa. Na UTI I apenas dois boxes apresentaram um ponto positivo cada enquanto e os pacientes não apresentavam colonização, entretanto haviam dois pacientes colonizados sem que se observasse qualquer cultura ambiental ou de equipamento positivo. Na UTI II, dos sete boxes nenhum ponto de investigação foi positivo apesar de, em seis deles, estarem internados pacientes colonizados (Figuras 16 e 17). 


\begin{tabular}{|l|c|c|c|c|c|c|c|c|c|c|}
\hline & box & box & box & box & box & box & box & box & box & box \\
\hline Swab retal & & & & & & & & & & 10 \\
\hline Bancada & & & & & & & & & & \\
\hline Borda leito & & & & & & & & & & \\
\hline Equipamentos & & & & & & & & & & \\
\hline Estetoscópio & & & & & & & & & & \\
\hline Válvula de ar & & & & & & & & & & \\
\hline Esfigmanômetro & & & & & & & & & & \\
\hline Termômetro & & & & & & & & & & \\
\hline Botão ar & & & & & & & & & \\
\hline Prancheta & & & & & & & & & & \\
\hline Telefone & & & & & & & & \\
\hline Geladeira & & & & & & & & & \\
\hline
\end{tabular}

Figura 16 - Distribuição de materiais positivos para VRE de acordo com a localização na UTI I, e Posto de Enfermagem, momento IV (novembro de 2007) do período pós-intervenção.

\begin{tabular}{|l|c|c|c|c|c|c|c|}
\hline & \multicolumn{1}{|c|}{ box } & box & box & box & box & box & box \\
\hline Swab retal & Sem paciente & & & & & 7 \\
\hline Bancada & & & & & & & \\
\hline Borda leito & & & & & & \\
\hline Equipamentos & & & & & & \\
\hline Estetoscópio & & & & & & & \\
\hline Válvula de ar & & & & & & & \\
\hline Esfigmanômetro & & & & & & & \\
\hline Termômetro & & & & & & & \\
\hline Prancheta & & & & & & & \\
\hline Maçaneta & & & & & & \\
\hline
\end{tabular}

Figura 17 - Distribuição de materiais positivos para VRE de acordo com a localização na UTI II, momento IV (novembro de 2007) do período pós-intervenção. 
Em resumo, no período pré-intervenção observou-se que 13 (100\%) dos pacientes colonizados estavam em quartos contaminados enquanto no período pós-intervenção houve uma redução para quatro (28,6\%). Verificouse ainda que em $13(86,6 \%)$ dos quartos contaminados estavam internados pacientes colonizados por VRE no período pré-intervenção contra quatro $(30,8 \%)$ no período pós.

Uma comparação das densidades de incidência de colonização e infecção por 1.000 pacientes-dia com os percentuais de contaminação ambiental e de equipamentos através da figura 18 permite observar que quando os percentuais de contaminação aumentaram as densidades de incidência de colonização e de infecção também aumentaram, e que a redução da contaminação de materiais, equipamentos e do ambiente próximo aos pacientes, no período pós-intervenção, foi acompanhada da redução das taxas de infecção, embora a de colonização tenha se mantido no mesmo nível.

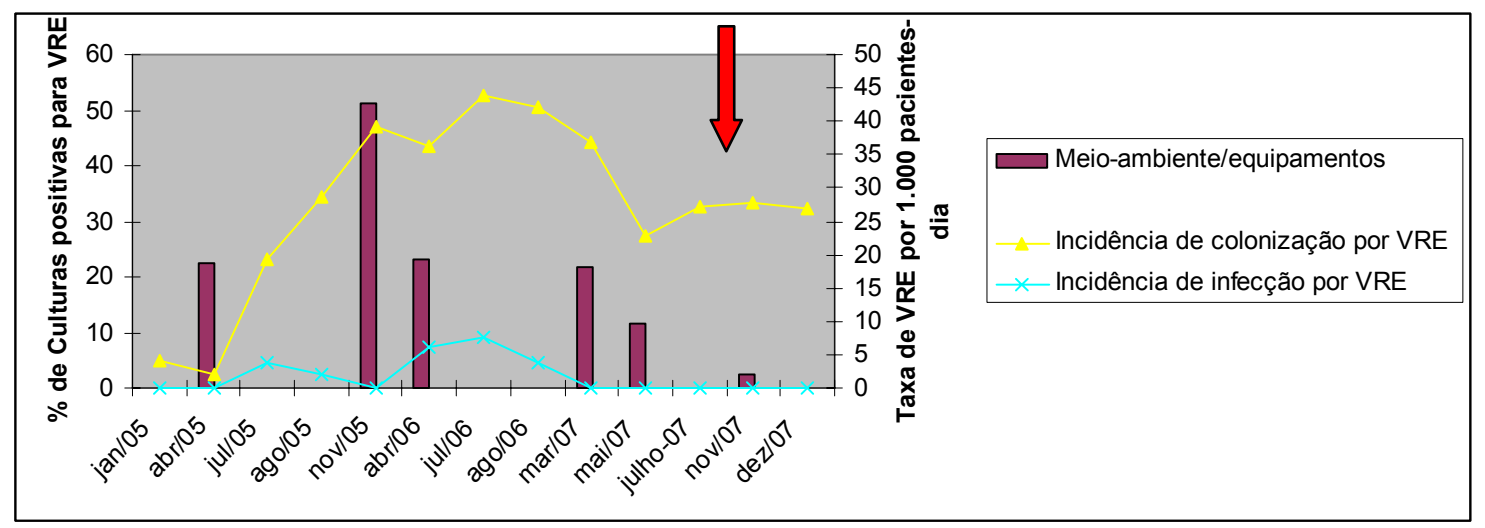

Figura 18 - Comparação da freqüência de culturas positivas de ambiente, densidade de colonização e densidade de infecção por 1000 pacientes-dia, dos períodos em que foram realizadas culturas ambientais e de equipamentos. 
Foram analisados os perfis de sensibilidade a antimicrobianos, pela técnica de disco difusão, de 1.335 VRE obtidos de maio de 2002 a dezembro de 2007, sendo 915 de E. faecium e 349 de E. faecalis. Entre amostras de E. faecium $70 \%$ apresentavam o perfil A (sensível a linezolida, gentamicina, estreptomicina e tetraciclina e resistente a vancomicina, teicoplanina, ampicilina, gentamicina, ciprofloxacino, eritromicina, cloranfenicol e rifampicina) $28 \%$ perfil $B$, que diferia do $A$ apenas pela resistência a gentamicina e $6 \%$ de outros perfis estreitamente relacionados, ou seja, diferiam em uma ou duas drogas apenas.

Para E.faecalis verifica-se que houve predomínio do perfil E em $60 \%$ dos VRE isolados, que demonstrava sensibilidade a ampicilina, linezolida, tetraciclina e rifampicina e resistência a vancomicina, teicoplanina, ciprofloxacino, eritromicina, cloranfenicol, gentamicina e estreptomicina. O antibiotipo $\mathrm{G}$ foi encontrado em $15 \%$ das vezes tendo demonstrado sensibilidade a ampicilina, linezolida e rifampicina apenas. Outros fenótipos de resistência foram verificados em $25 \%$ das amostras analisadas.

Comparando-se o período pré-intervenção com o pós, pode-se observar o predomínio do perfil $\mathrm{B}$, tanto no período pré quanto no período pós-intervenção em $55 \%$ e $72 \%$ dos E. faecium, respectivamente. O perfil A também foi encontrado freqüentemente em ambos os períodos, com 39 e $20 \%$ respectivamente, como pode ser observado na tabela 4 .

Da mesma maneira, houve predomínio de um clone que apresentava o perfil $E$ entre $E$. faecalis no período pré-intervenção $(74 \%)$ e pós-intervenção (54\%), seguido pelo perfil G em 6 e 10\% respectivamente (Tabela 5). 
Tabela 4 - Percentual de perfis de sensibilidade a antimicrobianos de E. faecium de 189 amostras obtidas no período pré-intervenção e de 143 do período pósintervenção

\begin{tabular}{ccccccc}
\hline & \multicolumn{3}{c}{ E. faecium } & \multicolumn{3}{c}{ E. faecalis } \\
\cline { 2 - 6 } & A & B & O & E & G & O \\
\hline pré-intervenção & $74(39 \%)$ & $103(55 \%)$ & $12(6 \%)$ & $50(74 \%)$ & $4(6 \%)$ & $14(20 \%)$ \\
pós-intervenção & $28(20 \%)$ & $103(72 \%)$ & $12(8 \%)$ & $21(54 \%)$ & $4(10 \%)$ & $14(36 \%)$ \\
\hline
\end{tabular}

Tabela 5 - Concentração inibitória mínima de antimicrobianos de 77 isolados de E.faecuim e 34 de E. faecalis

\begin{tabular}{|c|c|c|c|c|}
\hline \multirow{2}{*}{$\begin{array}{c}\text { Agente } \\
\text { antimicrobiano }\end{array}$} & \multicolumn{2}{|c|}{ E. faecium } & \multicolumn{2}{|c|}{ E. faecalis } \\
\hline & $\mathrm{CIM}_{50}$ & $\mathrm{CIM}_{90}$ & $\mathrm{CIM}_{50}$ & $\mathrm{CIM}_{90}$ \\
\hline Vancomicina & $>128 \mu \mathrm{g} / \mathrm{mL}$ & $>128 \mu \mathrm{g} / \mathrm{mL}$ & $>128 \mu \mathrm{g} / \mathrm{mL}$ & $>128 \mu \mathrm{g} / \mathrm{mL}$ \\
\hline Teicoplanina & $32 \mu \mathrm{g} / \mathrm{mL}$ & $64 \mu \mathrm{g} / \mathrm{mL}$ & $32 \mu \mathrm{g} / \mathrm{mL}$ & $64 \mu \mathrm{g} / \mathrm{mL}$ \\
\hline Ampicilina & $2 \mu \mathrm{g} / \mathrm{mL}$ & $>128 \mu \mathrm{g} / \mathrm{mL}$ & $>18 \mu \mathrm{g} / \mathrm{mL}$ & $>18 \mu \mathrm{g} / \mathrm{mL}$ \\
\hline
\end{tabular}

Destas amostras, 111 amostras de VRE, 77 E. faecium e 34 E.faecalis obtidas de colonização e infecção, foram selecionadas para determinação da Concentração Inibitória Mínima (CIM) pela técnica de microdiluição para vancomicina, teicoplanina e ampicilina. $\mathrm{A} \mathrm{CIM}_{50}$ e a $\mathrm{CIM}_{90}$ para vancomicina foi $>128 \mu \mathrm{g} / \mathrm{mL}$, tanto entre $E$. faecium quanto entre E. faecalis. Para teicoplanina a $\mathrm{CIM}_{50}$ foi de $32 \mu \mathrm{g} / \mathrm{mL}$ e a $\mathrm{CIM}_{90}$ foi de $64 \mu \mathrm{g} / \mathrm{mL}$, também em ambas espécies. Para Ampicilina, entretanto a $\mathrm{CIM}_{50}$ para 9 cepas de $E$. faecalis foi $2 \mu \mathrm{g} / \mathrm{mL}$ e a $\mathrm{CIM}_{90}$ foi 128 , já para 44 cepas de E. faecium, tanto a $\mathrm{CIM}_{50}$ quanto a $\mathrm{CIM}_{90}$, foi $>18 \mu \mathrm{g} / \mathrm{mL}$ (Tabela 4). 
A tabela 6 mostra os perfis moleculares de $E$. faecium e de $E$. faecalis predominantes nos anos de 2002 a 2004 e 2005 a 2007. A análise do DNA pela técnica de PFGE por período permitiu a identificação de 12 perfis moleculares diferentes entre 30 E. faecium tipados nos anos 2002 a 2004, com predomínio do Clone A em $37 \%$ dos isolados e de outros nove clones estreitamente relacionados em $57 \%$ das amostras.

Tabela 6 - Distribuição dos 12 perfis moleculares de 30 amostras de E. faecium anos 2002 a 2004, de 14 perfis de 144 amostras dos anos 2005 a 2007, e de 4 perfis de E. faecalis identificados nos e 2005 a 2007, de acordo com os critérios de Tenover et al. (1997)

\begin{tabular}{lcccc}
\hline & \multicolumn{2}{c}{ E. faecium } & \multicolumn{2}{c}{ E. faecalis } \\
\cline { 2 - 5 } & $2002-2004$ & $2005-2007$ & $2002-2004$ & $2005-2007$ \\
\hline Clone predominante & $11(37 \%)$ & $\mathbf{7 8 ( 5 5 \% )}$ & 0 & $36(74 \%)$ \\
$\begin{array}{l}\text { Estreitamente } \\
\text { relacionado }\end{array}$ & $17(57 \%)$ & $62(43 \%)$ & 0 & $2(4 \%)$ \\
Não relacionado & $\mathbf{2 ( 6 \% )}$ & $\mathbf{4 ( 2 \% )}$ & $\mathbf{5 ( 1 0 0 \% )}$ & $\mathbf{1 1 ( 2 2 \% )}$ \\
\hline Total & 30 & 144 & 5 & 49 \\
\hline
\end{tabular}


$\mathrm{Na}$ figura 19 , pode-se visualizar os perfis moleculares das amostras isoladas nos anos 2002 e 2003.

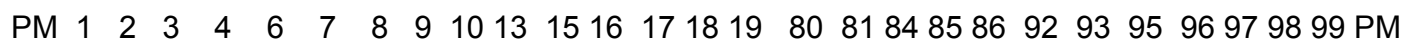

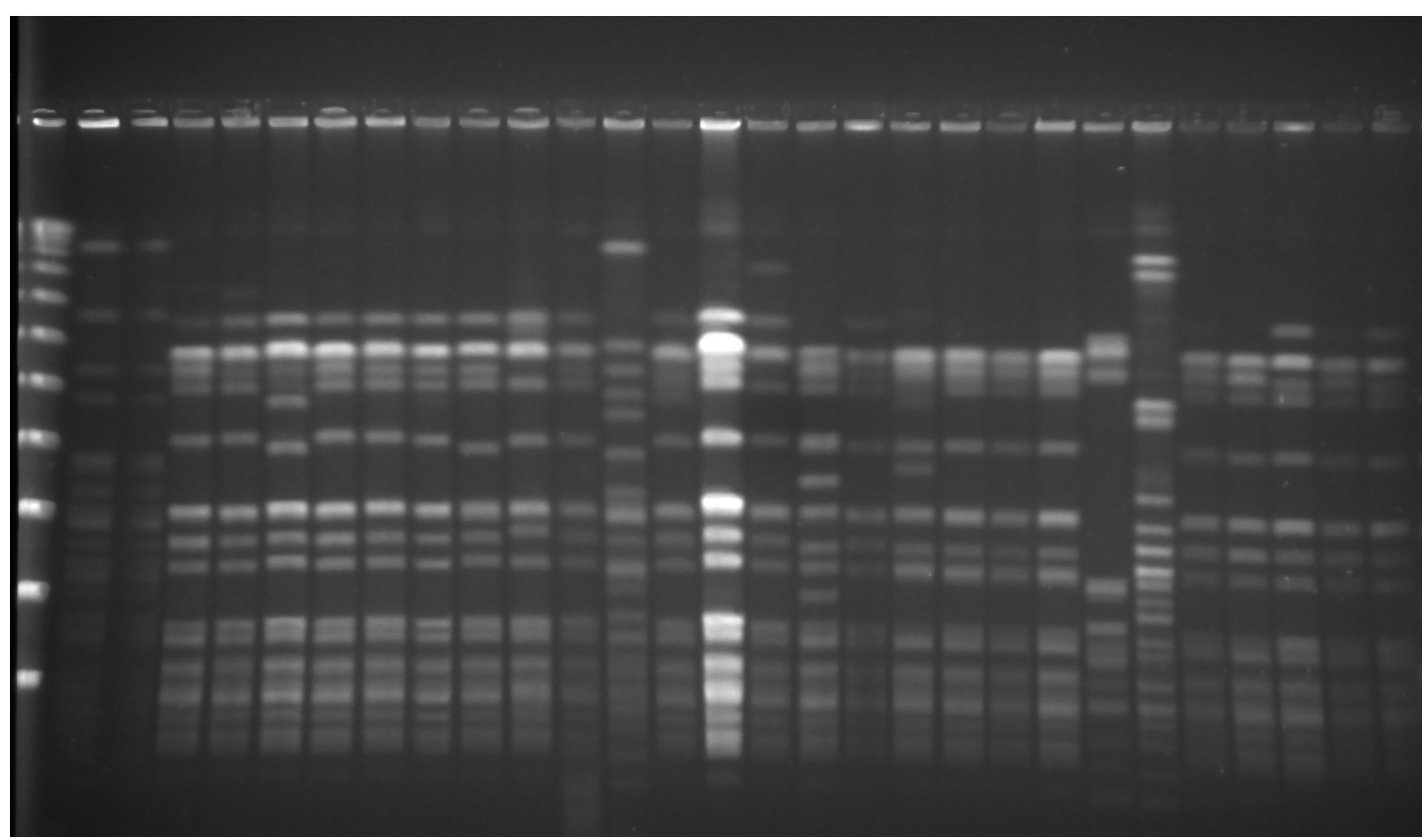

Figura 19 - Padrão de Restrição de 15 cepas de E. faecium e 2 de E.faecalis obtidas de materiais biológicos, de colonização e de contaminação ambiental dos anos 2002 e 2003.

Entre as 144 amostras de E. faecium obtidas de 2005 a 2007, foram encontrados 14 perfis moleculares diferentes, tendo o clone B predominado em $55 \%$ das amostras. Outros nove clones estreitamente relacionados foram identificados em $43 \%$ das amostras. Apenas quatro perfis não relacionados, que corresponderam a $2 \%$ foram identificados. 
Neste mesmo período entre 48 E. faecalis, obtidas foram encontrados quatro perfis moleculares com predomínio do clone $\mathrm{W}$ em $74 \%$ e de um estreitamente relacionado em $4 \%$. Dois outros clones não relacionados foram identificados, o clone $Z$ com 10 amostras e o clone $Y$ em 1 amostra. A figura 20 apresenta o perfil molecular do clone B, e dos estreitamente relacionados, de E. faecium e do clone W de E. faecalis, isolados nos anos 2005 e 2006.

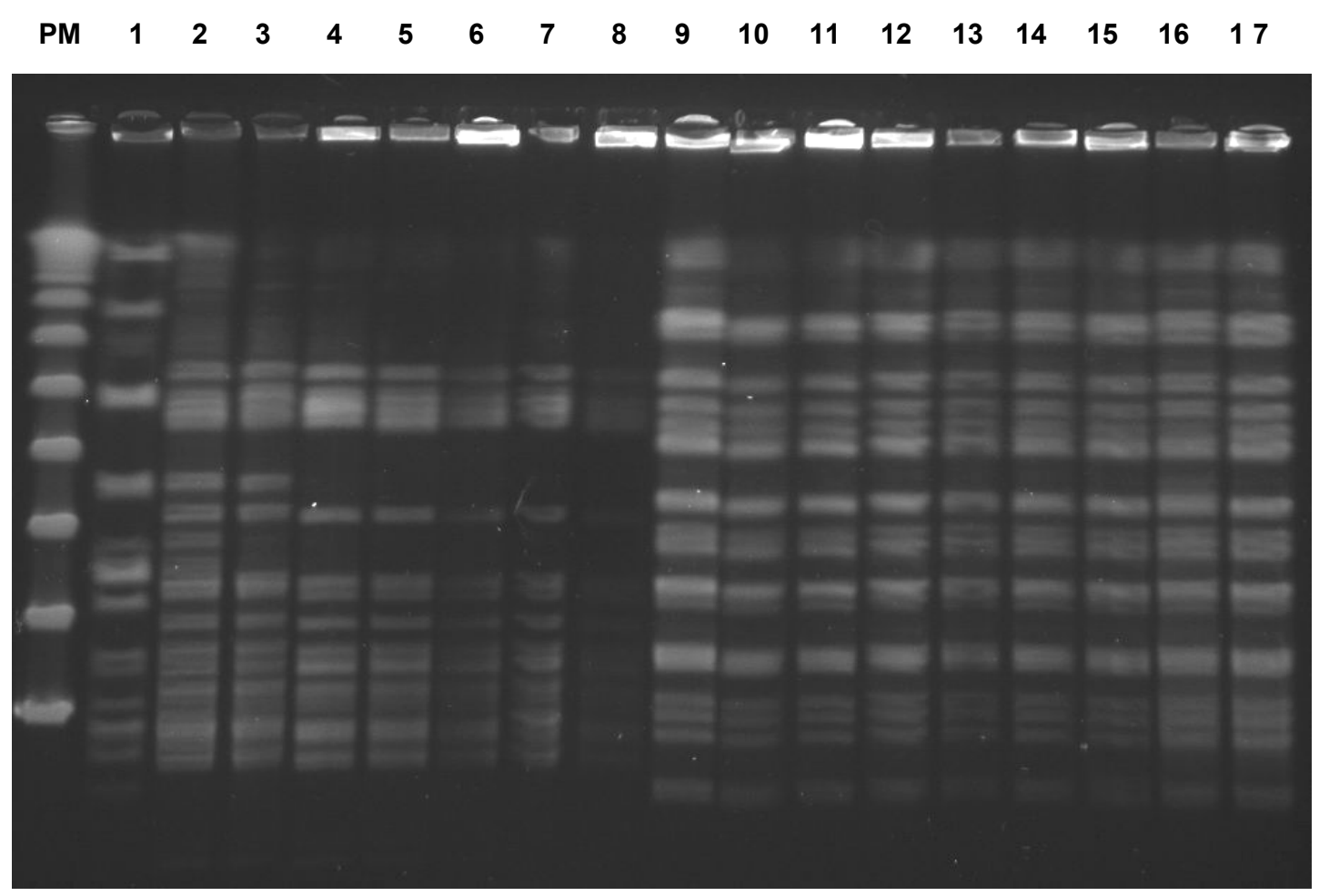

Figura 20 - Padrões de restrição de isolados de E. faecium e E.faecalis. PM: peso molecular 50 a $1000 \mathrm{~kb}$ (New England, BioLabs); Coluna 1: cepa controle $E$. faecalis, Colunas 2 e 3: E. faecium isolados de amostras clínicas em 2005; Colunas 4, 5: E. faecium de colonização de 2006; Colunas 6, 7 e 8: E. faecium de ambiente de 2006; Colunas 9 e 10: E. faecalis de colonização em 2006; Colunas 11 a 15: $E$. faecalis de amostras ambientais 2006; Colunas 16 e 17 E. faecalis de amostras clínicas em 2006. 
Comparando-se a fase pré-intervenção do ano 2007 foram encontrados seis clones ou genótipos diferentes de E. faecium sendo o clone B presente em $35(52,2 \%)$ das cepas tipadas, o clone B7 em 16 $(23,8 \%)$ e o clone B2 em $13(19,4 \%)$. Já na fase pós-intervenção foram oito clones ou genotipos, sendo, da mesma forma, os clones B e B7 os mais freqüentes com $14(40 \%)$ cada um. O padrão molecular das cepas obtidas de ambiente e equipamentos dos períodos pré e pós-intervenção podem ser observados na figura 21.

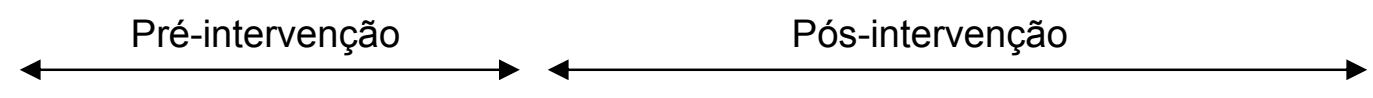

$\begin{array}{llllllllllllllllllllllllllllll}\mathrm{PM} & 1 & 2 & 3 & 4 & 5 & 6 & 7 & 8 & 9 & 10 & 11 & 12 & 13 & 14 & 15 & 16 & 17 & 18 & 19 & 20 & 21 & 22 & 23 & 24 & 25 & 26 & 27 & 28 & 29\end{array}$

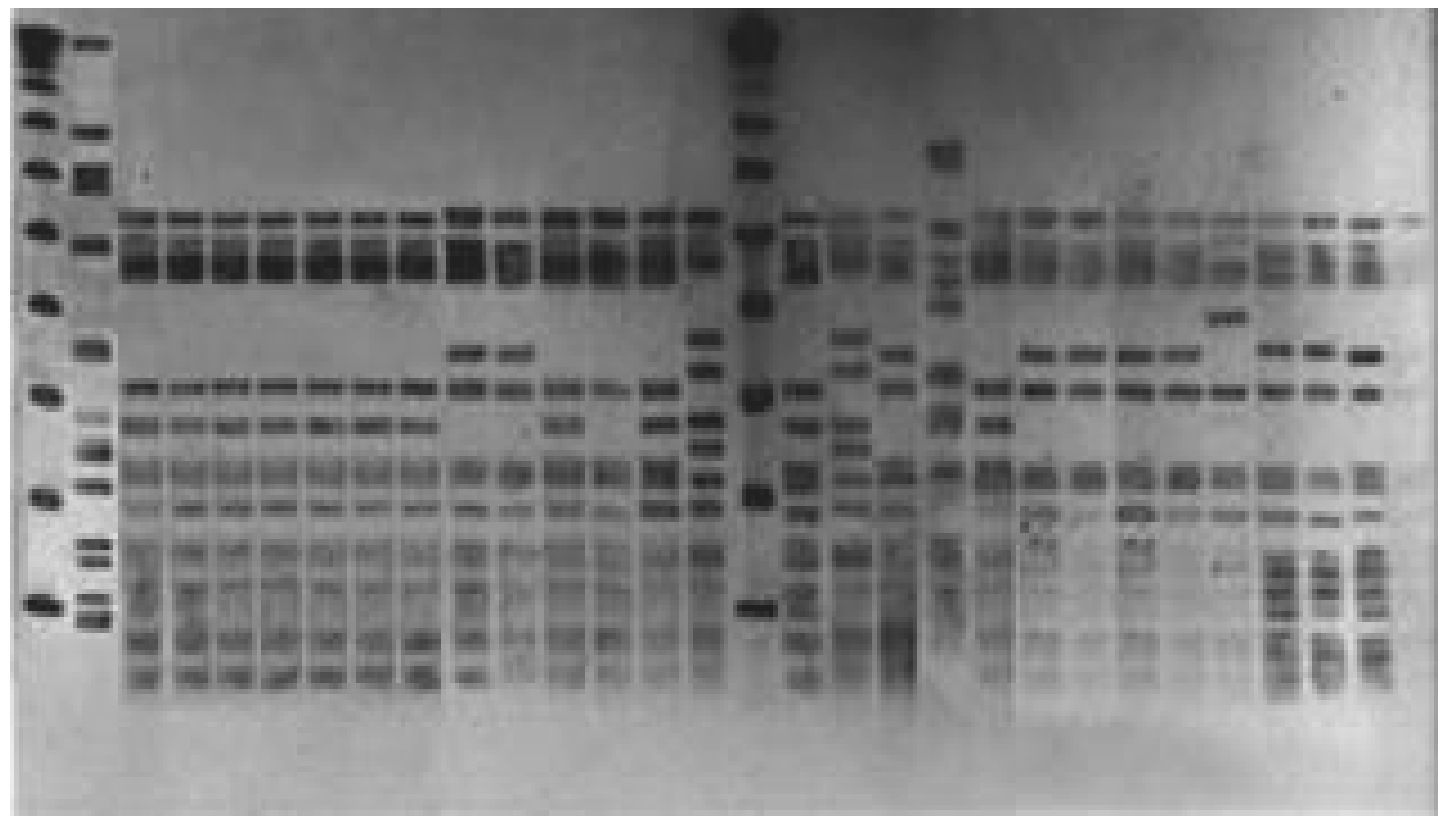

Figura 21 - Padrões de restrição de isolados de E. faecium de 2007. PM: peso molecular 50 a 1000kb (New England, BioLabs); Colunas 1: ATCC, Colunas: 2 a 11: E. faecium isolados de amostras ambientais do período pré-intervenção; Coluna 15: peso molecular; Colunas 12, 13, 14 e 16 a 29 : E. faecium de ambiente do período pós-intervenção. 
Todas as amostras de materiais clínicos, analisadas no período préintervenção, (100\%) pertenciam ao clone B ou a seus clones estreitamente relacionados, enquanto no período pós, este percentual foi de $87 \%$, enquanto $13 \%$ pertenciam a clones não relacionados. O perfil molecular de cepas isoladas de materiais biológicos é mostrado na figura 22 .

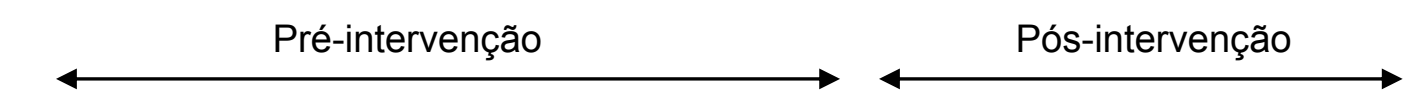

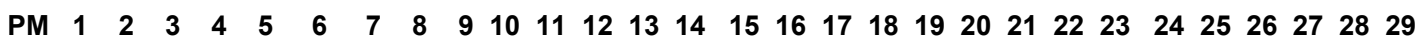

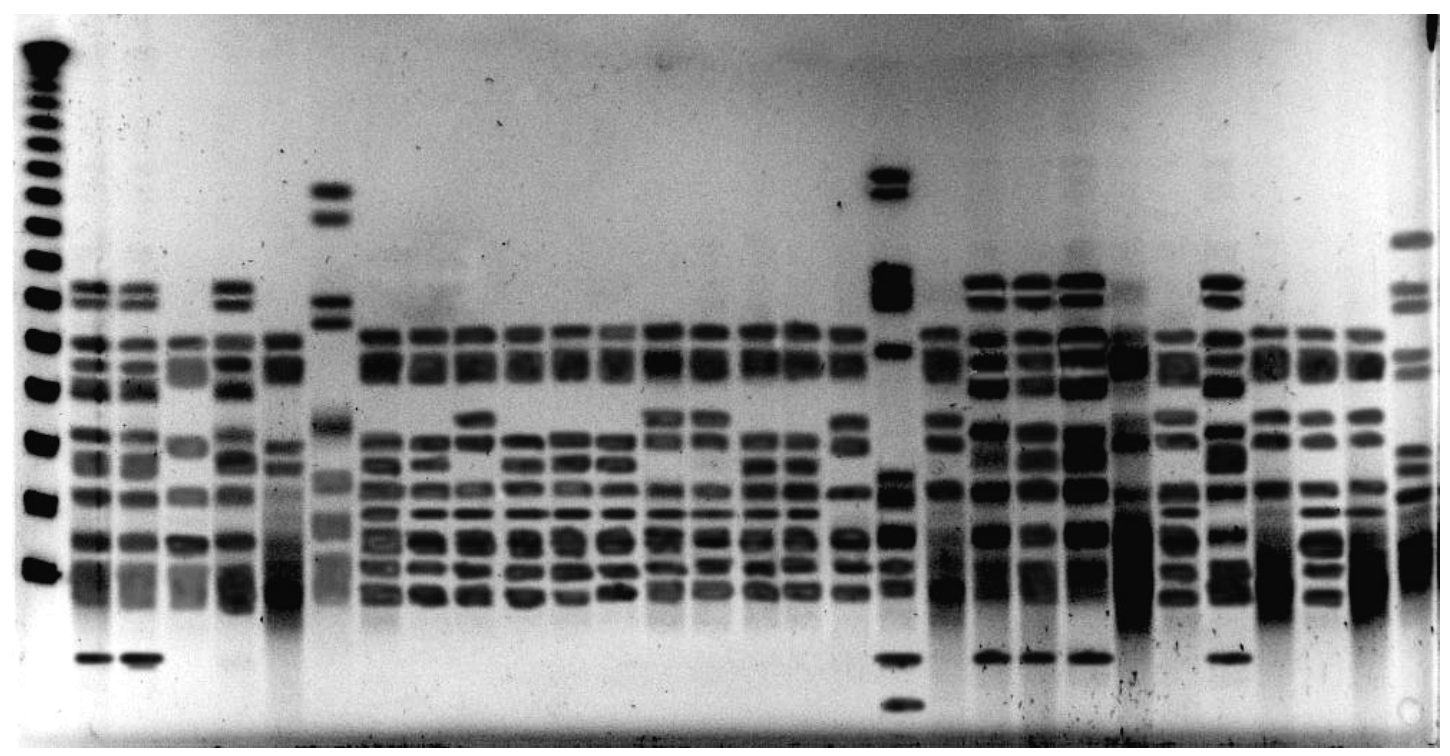

Figura 22 - Padrões de restrição de isolados de E. faecium e E. faecalis obtidos de materiais biológicos em 2007 de pacientes internados nas UTIs, Pronto Socorro e Enfermarias. PM: peso molecular 50 a 1000kb (New England, BioLabs); Colunas 1, 2, 4, 20, 21, 22, 23 e 25: E. faecalis; Colunas 5, 7, 8, 9, 10, 11, 12,13, 14, 16, 17, 19, 24, 26, 27, 28 e 29: E. faecium. 
A figura 23 mostra os diferenetes padrões moleculares verificados entre as análises de PFGE. O dendrograma de 27 amostras de VRE foi analisado ainda de acordo com coeficiente de similaridade de Jaccard. Foi possível verificar que 14 clones tinham mais que $80 \%$ de similaridade: A e A3 apresentavam 93\%, assim como A2 e A4 e estes dois grupos entre si apresentavam $80 \%$. Entre B e B7, os dois clones de maior prevalência, a similaridade verificada foi de $88 \%$, para $\mathrm{K}, \mathrm{P}, \mathrm{E}$ foi de $83 \%$, para F1 e F, da mesma forma que $\mathrm{E}, \mathrm{P}$ e $\mathrm{K}$ foi de $80 \%$.Verificou-se que as amostras pertencentes aos clones $\mathrm{G}, \mathrm{H}, \mathrm{I}$ e J apresentavam similaridade de 40 a $60 \%$, com as demais amostras de E. faecium (Figura 24).

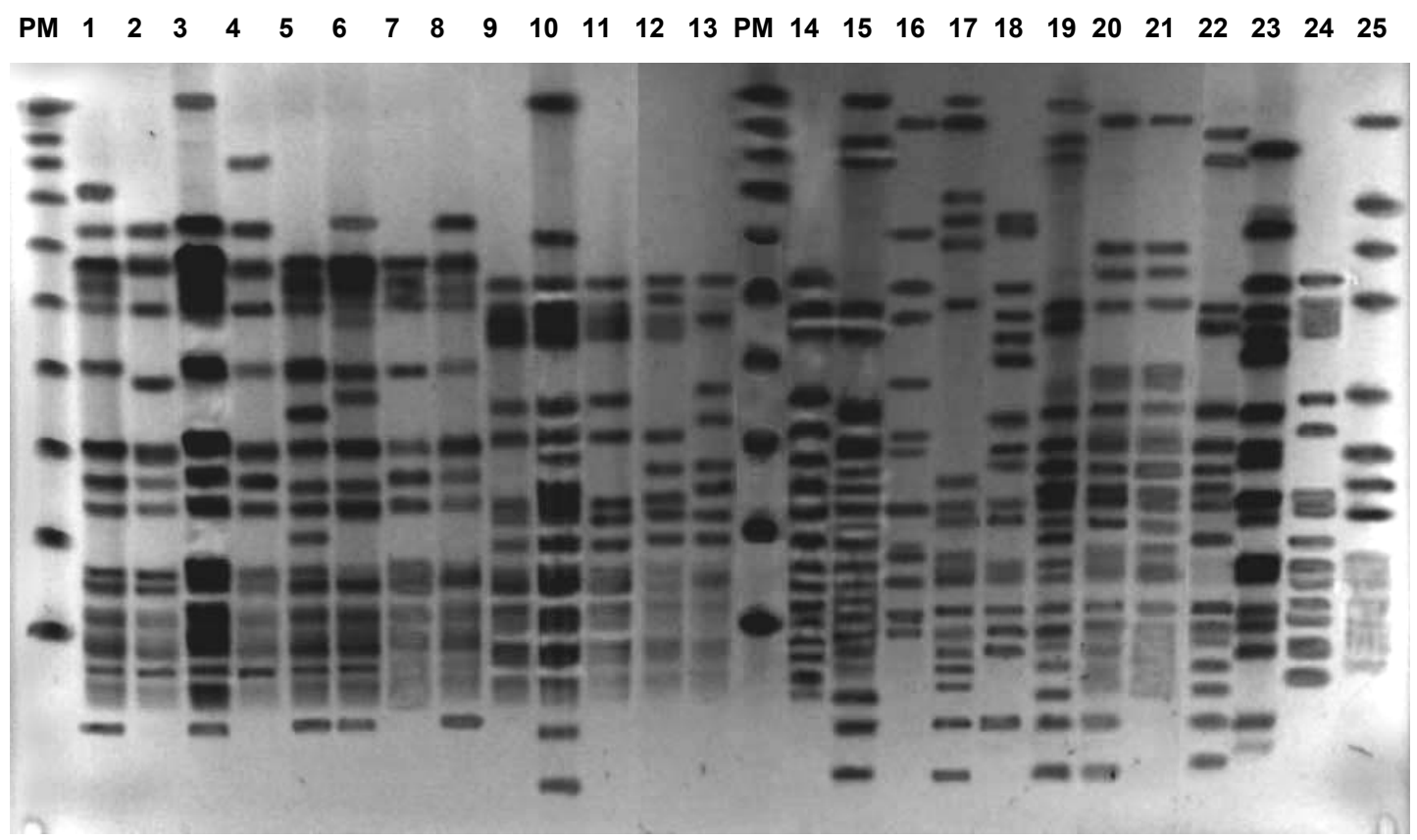

Figura 23 - Padrões de restrição de isolados de E. faecium de 2004 a 2007. PM: peso molecular 50 a 1000kb (New England, BioLabs); Colunas 1: ATCC, Colunas: 2 cepa controle; Colunas 3 a 6 E. faecium isolados em 2004; Colunas 7 a 11 E. faecium isolados em 2005; Colunas 12 a 17 E. faecium isolados em 2006; Coluna s 18 a 24 E. faecium isolados em 2007; Coluna 25 Cepa ATCC. 


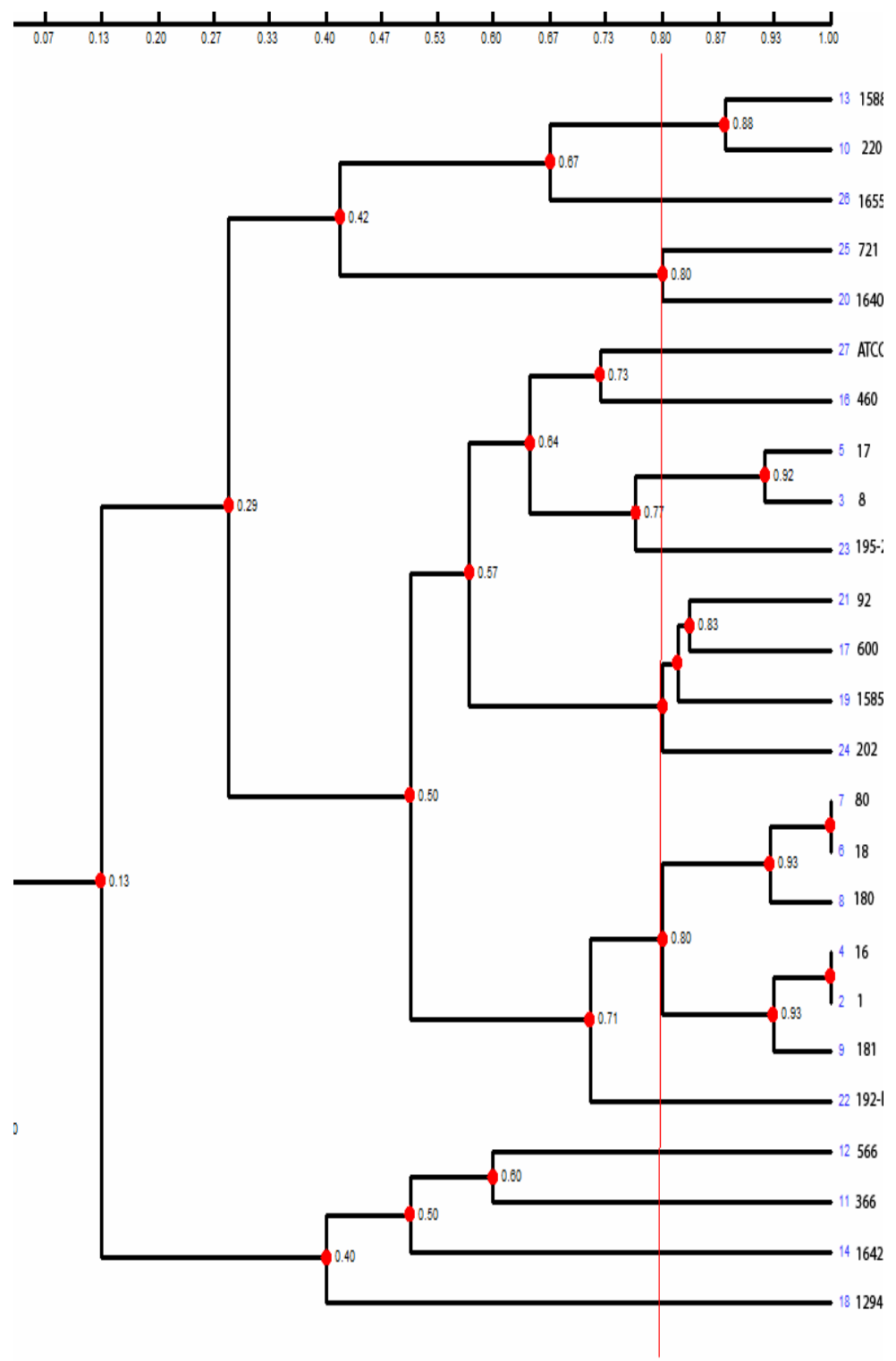

E. faecium - B7

E. faecium - B

E. faecalis - W

E. faecalis - F1

E. faecalis - $F$

E. faecalis - ATCC 29212

E. faecalis $-\mathrm{Q}$

E. faecium - A4

E. faecium - A2

E. faecalis - A6

E. faecium - K

E. faecium - $\mathrm{P}$

E. faecium - E

E. faecalis - Z

E. faecium -A5

E. faecium - A5

E. faecium - A7

E. faecium - A

E. faecium - A

E. faecium - A3

E. faecalis $-\mathrm{Y}$

E. faecium - J

E. faecium - I

E. faecium - H

E. faecium - G

Figura 24 - Dendrograma contendo padrões moleculares de PFGE de 27 amostras de VRE entre $E$. faecium e de $E$. faecalis que paresentaram perfis moleculares diferentes. A diversidade genética foi determinada usando o coeficiente de Jaccard, considerado diferenca quando o indice de similaridade for menor que $80 \%$. 
A reação em Cadeia da Polimerase (PCR) mostrou que $100 \%$ de 66 cepas de VRE, 51 E. faecium e 13 E. faecalis, analisadas possuíam o gen vanA. Destas 25 foram obtidas de infecção, 23 de colonização e 18 de ambiente ou equipamentos. No período pré-intervenção, foram amplificadas 41 amostras enquanto que no pós foram 15. A figura 25 mostra amplificação dos genes vanA de 12 amostras de infecção e do ambiente isoladas no ano 2005.A relação de amostras isoladas que foram submetidas a análise por PFGE e PCR pode ser visualizada no anexo 13.

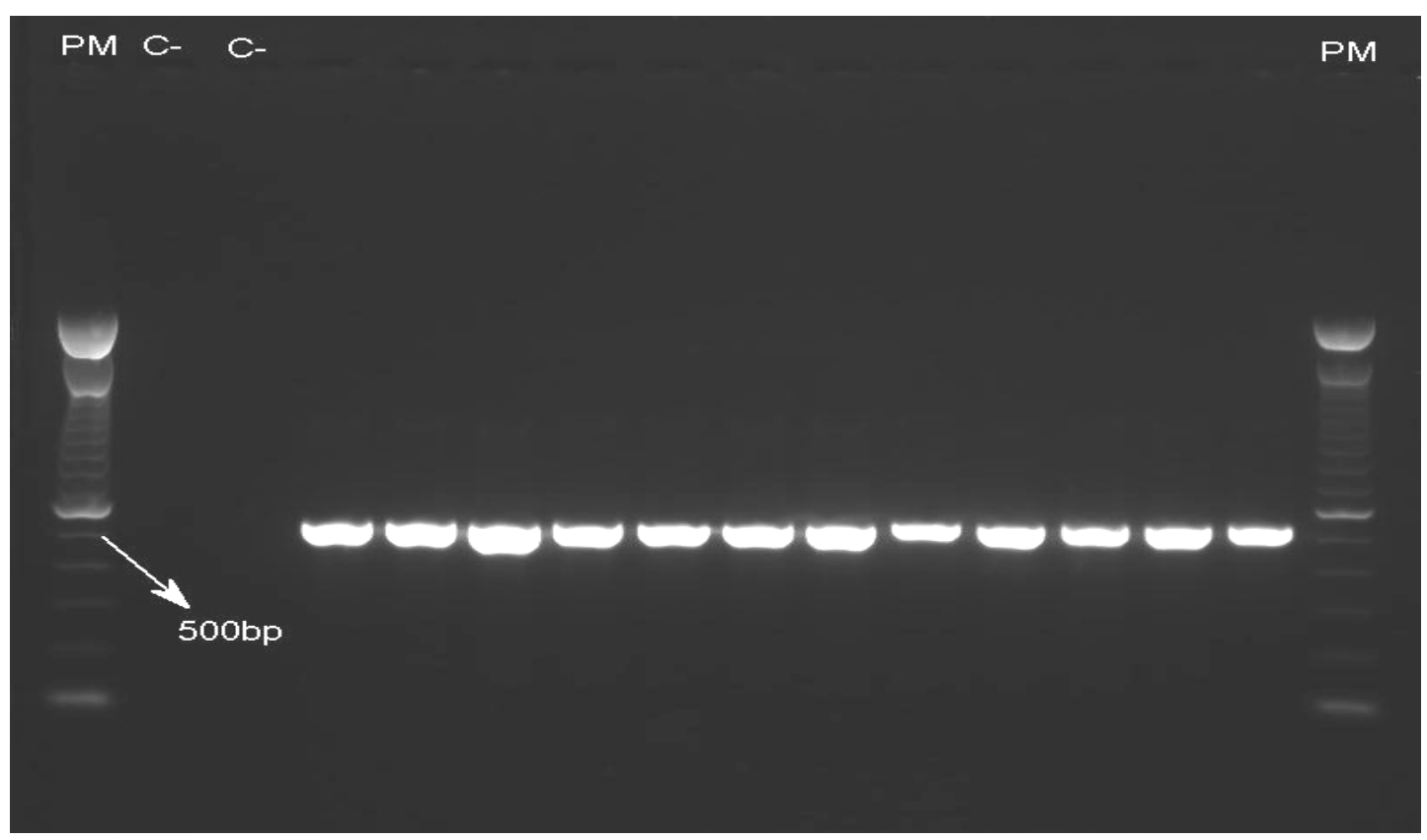

Figura 25 - Reação de Cadeia em polimerase (PCR) de 12 amostras E.faecium e E. faecalis isoladas de infecção e de ambiente.

Foram realizadas observações de profissionais da saúde enquanto realizavam procedimentos, diretos ou indiretos, com pacientes portadores de VRE nas UTIs de fevereiro a março de 2007 do período pré-intervenção, e 
de maio a dezembro de 2007 do período pós-intervenção. No primeiro momento foram observadas 605 oportunidades de higiene das mãos antes do contato, 566 de uso de luvas individuais, 594 de uso de avental para MR, e 523 de higiene das mãos após contato direto ou indireto com pacientes portador de VRE. Após treinamento dos profissionais foram observadas 247 oportunidades de higiene das mãos antes dos procedimentos, 253 de uso de luvas novas, 249 de avental exclusivo para microrganismos multiresistentes e de 240 de higiene das mãos após contato.

Entre os procedimentos observados $70 \%$ foram realizados pela equipe de enfermagem ( $57 \%$ técnicos de enfermagem e 13 de enfermeiros), $14 \%$ pela equipe de fisioterapia, $9 \%$ pela equipe médica e $7 \%$ por profissionais não pertencentes ao quadro da UTI, como técnicos do laboratório, técnicos de hemodiálise e técnicos de Raios-X.

De fevereiro a março de 2007, verificou-se que os boxes estavam identificados com placas alertando para o fato de o paciente ser portador de VRE em $70 \%$ das ocasiões observadas e que, a partir de maio até dezembro, as placas de identificação foram observadas em $49 \%$ destes boxes.

A higienização das mãos, com água e sabão ou solução de clorexidina, antes e após realização de procedimentos assistenciais a pacientes portadores de microrganismos multiresistentes foi verificada em apenas $39 \%$ e $32 \%$ dos profissionais observados, nos períodos pré e pósintervenção, respectivamente $(\rho=0.06)$.

O uso de luvas foi observado em $61 \%$ das vezes durante a realização de qualquer procedimento com estes pacientes ou no contato com o 
ambiente ou equipamentos no período pré-intervenção, reduziu significativamente para $41 \%$ no período pós $(\rho=0,02)$. Considerou-se apenas o uso de luvas novas exclusivas para cada paciente.

Avental próprio para microrganismos multiresistentes de tecido de cor laranja forte está padronizado no hospital desde 2005. A utilização destes aventais ou do tipo descartável ocorreu em $43,6 \%$ das vezes na fase préintervenção, não sendo diferente da fase pós quando foi verificado em $41,3 \%(\rho=0,54)$.

Materiais não críticos, sempre que possível eram de uso individual, porém em determinadas situações era necessário usá-los coletivamente. Verificou-se, ainda, que o uso de materiais não críticos de uso coletivo como oxímetros, glucosímetros, placas de Raios-X, lanternas, bandejas de medicação, máquinas de hemodiálise e ocasionalmente otoscópios, estetoscópios, esfigmanômetros, termômetros, entre outros, ocorreu em 150 procedimentos com estes pacientes, no período pré-intervenção, entretanto a desinfecção, com álcool $70 \%$ foi realizada em apenas $3,3 \%$ das vezes. No período pós-intervenção, foi verificado que o uso destes materiais ocorreu em 17 procedimentos e a desinfecção foi feita em 5,8\% das vezes, uma diferença não significativa $(\rho=0,48)$.

Para os 145 e 37 procedimentos em que se utilizaram materiais de uso individual (estetoscópios, esfigmanômetros, termômetros, máscaras de oxigênio, ambus, bombas de infusão, medidores de cuff) observados no período pré e pós-intervenção, respectivamente, a desinfecção, com álcool $70 \%$, ocorreu em $2,8 \%$ das vezes. As proporções da adesão às precauções 
padrão e de contato recomendadas para controle de VRE, nos período pré e pós-intervenção, para os profissionais, de maneira geral, é mostrada na tabela 7 .

Tabela 7 - Proporção de adesão a precauções de contato e padrão por profissionais da saúde durante os períodos pré e pós-intervenção, nas UTIs do HU

\begin{tabular}{|c|c|c|c|c|c|c|}
\hline \multirow[b]{3}{*}{ Procedimentos } & & \multirow{2}{*}{\multicolumn{2}{|c|}{$\begin{array}{c}\text { Período pré-intervenção } \\
\text { Oportunidades }\end{array}$}} & \multirow{2}{*}{\multicolumn{2}{|c|}{$\begin{array}{c}\text { Período pós-intervenção } \\
\text { Oportunidades }\end{array}$}} & \multirow{3}{*}{$\begin{array}{c}\text { Valor de } \\
\rho\end{array}$} \\
\hline & & & & & & \\
\hline & & Número & $\%$ & Número & $\%$ & \\
\hline \multirow{2}{*}{$\begin{array}{l}\text { Higiene das mãos } \\
\text { antes do contato }\end{array}$} & Sim & 240 & 39 & 80 & 32 & \multirow{2}{*}{0.06} \\
\hline & Não & 365 & & 167 & & \\
\hline \multirow{2}{*}{ Uso de luvas } & Sim & 347 & 61 & 133 & 41 & \multirow{2}{*}{0.02} \\
\hline & Não & 219 & & 120 & & \\
\hline \multirow{2}{*}{ Uso de avental } & Sim & 259 & 43 & 103 & 53 & \multirow{2}{*}{0.54} \\
\hline & Não & 335 & & 146 & & \\
\hline \multirow{2}{*}{$\begin{array}{l}\text { Higiene das mãos } \\
\text { após contato }\end{array}$} & Sim & 310 & 59 & 128 & 6,25 & \multirow{2}{*}{0.12} \\
\hline & Não & 213 & & 112 & & \\
\hline \multirow{2}{*}{$\begin{array}{l}\text { Desinfecção de } \\
\text { materiais não críticos } \\
\text { de uso coletivo }\end{array}$} & Sim & 5 & 3,3 & 1 & 5,8 & \multirow{2}{*}{0.48} \\
\hline & Não & 145 & & 16 & & \\
\hline \multirow{2}{*}{$\begin{array}{l}\text { Desinfecção de } \\
\text { materiais não críticos } \\
\text { de uso individual }\end{array}$} & Sim & 4 & 3 & 1 & 3 & \multirow{2}{*}{0.58} \\
\hline & Não & 141 & & 36 & & \\
\hline
\end{tabular}

Entre os procedimentos avaliados, observou-se que a higiene dos pacientes foi o tipo de contato de maior adesão às medidas de controle, tanto na fase pré quanto na pós-intervenção. O uso de luvas ocorreu em 
$100 \%$ em ambos os momentos, o uso de avental em 80 e $100 \%$ e a higiene das mãos após contato em 80 e 90\% nos períodos pré e pós-intervenção, respectivamente. Já para manipulação de equipos e cateteres, medicação, contato direto com paciente e contato com aparelhos verificou-se a menor adesão a todas as medidas, em ambas as fases.

A higiene das mãos antes do contato foi a medida de menor adesão pela maioria dos profissionais, na maioria dos tipos de contatos, seja na fase pré seja na fase pós-intervenção, exceto para os técnicos de radiologia que passaram de 40 para $75 \%$.

Os fisioterapeutas foram os profissionais que mais adotaram as precauções de contato e padrão, tanto no período pré quanto pósintervenção.

O impacto do treinamento na adesão às medidas de controle foi maior entre os médicos, técnicos de Raios $X$ e técnicos de hemodiálise. $O$ uso de luvas pela equipe médica aumentou de 48 no período pré para $90 \%$ no período pós-intervenção, da mesma forma observou-se entre os técnicos de hemodiálise um aumento de 36 para $88 \%$ e para os técnicos de Raios-X de 67 para 100\%. Avental exclusivo para manipulação do paciente portador de microrganismo multiresistente também foi mais utilizado entre os médicos que aumentaram a adesão de 20 no período pré para $60 \%$ no período pós-intervenção, assim como, para os técnicos de hemodiálise que passaram de 18 para $44 \%$ e para os técnicos de Raios-X para os quais o aumento passou de 0 para $100 \%$. 
Quanto à desinfecção de materiais não críticos de uso coletivo como estetoscópios, aparelhos de hemodiálise e termômetros, pode-se ressaltar que, esta foi realizada em duas ocasiões por técnicos de enfermagem e técnicos de hemodiálise, uma por residente de Medicina e outra por residente de Enfermagem. Materiais de uso individual foram desinfetados por fisioterapeutas e técnicos de enfermagem. As placas de Raios-X não foram desinfetadas, entretanto foram revestidas com saco plástico descartável entre um paciente e outro.

Procedimentos de desinfecção concorrente e terminal foram observados em poucas ocasiões, 15 e 30 vezes, respectivamente. A desinfecção concorrente foi realizada em piso, parede, leito, latas de lixo e aparelhos por profissionais da equipe de limpeza. A utilização de luvas ocorreu em $86 \%$ e o uso de avental próprio em $66 \%$. A limpeza foi realizada do piso foi realizada com água e sabão e a de leitos, bancadas, paredes e vidros dos boxes com ácido peracético a 0,5\%. A desinfecção de equipamentos foi realizada por técnicos de enfermagem com álcool a $70 \%$ e foram observadas em apenas 3 momentos de desinfecção concorrente.

Desinfecção terminal de todos os boxes da UTI II foi observada no mês de abril de 2007, imediatamente após a intervenção. Os pacientes haviam sido transferidos para outro setor, assim a unidade toda foi lavada por 10 funcionários da equipe de limpeza, do piso ao teto com água e sabão e posteriormente foi aplicado ácido peracético. Para este procedimento 
verificou-se a utilização de luvas em $86 \%$ e de avental exclusivo em apenas $2 \%$ das vezes. Importante destacar que a maioria dos funcionários, nesta ocasião não pertencia ao quadro da UTI.

A análise da Dose Diária Definida (DDD) dos glicopeptídeos nas UTIs é mostrada na figura 26. O consumo de vancomicina não apresentou aumento significativo entre 2002 e $2007(\rho=0,97)$. Entretanto, teicoplanina que começou a ser utilizada no hospital em 2004, apresentou aumento significativo durante os últimos meses de $2007(\rho<0,001)$.

O consumo de glicopeptídeos, vancomicina e teicoplanina, dos períodos pré e pós-intervenção, mês a mês, está ilustrado na figura 27 . A DDD de vancomicina foi similar em quase todos os meses do período préintervenção, variando de 191 em fevereiro a 390 em agosto de 2006. No período pós-intervenção a DDD de vancomicina apresentou a mesma variação de 172 em novembro a 368 em julho de 2007. Para teicoplanina verificou-se aumento no consumo quer era de 58 para cerca de 110 nos dois últimos meses de 2007. 


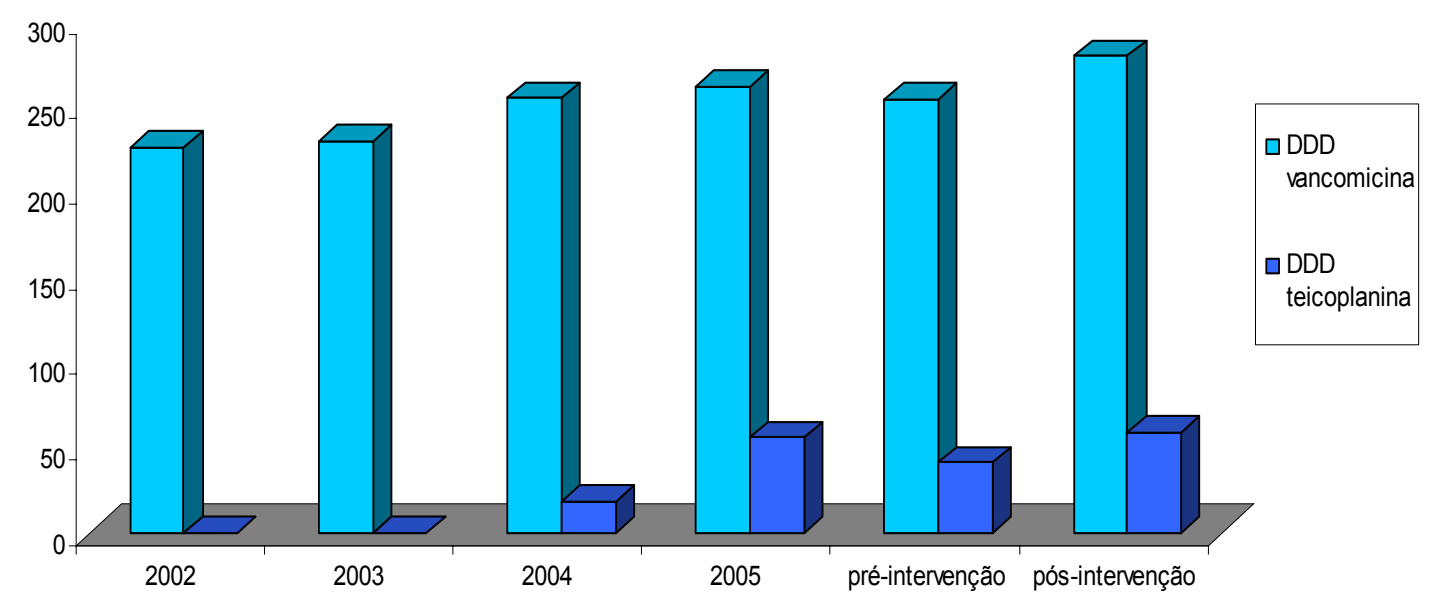

Figura 26 - Média da Dose Diária Definida de Vancomicina (DDD) nos anos de 2002 a 2007.

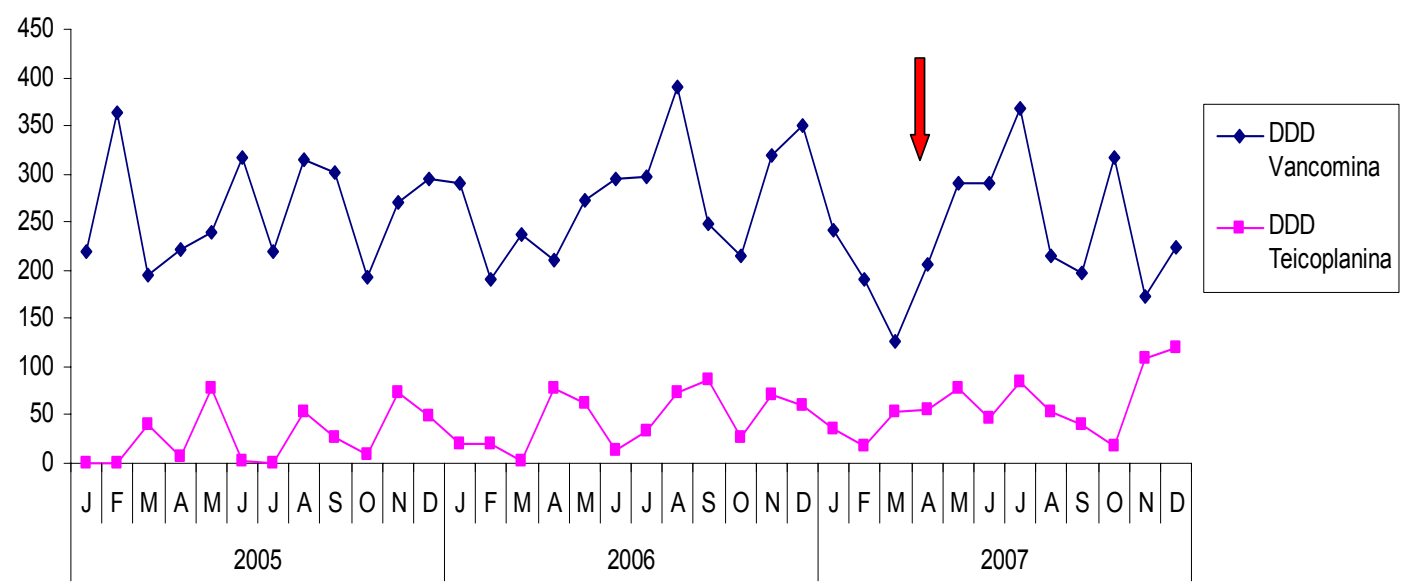

Figura 27 - DDD de vancomicina e teicoplanina dos períodos pré e pós-intervenção por mês. 
Nos últimos quinze anos VRE emergiu com um importante agente de infecção relacionada à assistência a saúde em diversas partes do mundo. Embora não tivesse sido detectado antes de 1985, por volta de 1997 mais de $15 \%$ das infecções enterocóccicas nos Estados Unidos eram devido a este microrganismo (Gardner, Jarvis, Emori, 1988).

Inicialmente os surtos hospitalares acometiam poucos pacientes e podiam ser controlados com medidas de controle de infecção (Boyce et al., 1994; Handwerge et al., 1993). Entretanto, mais e mais pacientes se tornaram colonizados e por volta de 1995 foram descritas situações de endemicidade.

Em um número crescente de hospitais, este microrganismo é endêmico sendo encontrado colonizando $o$ trato gastrintestinal em freqüências que variam de 20 a 53\% nos Estados Unidos (Morris et al., 1995; Slaughter et al., 1996; Tucci, Haran, Isenberg, 1997).

No Brasil, estes índices são bastante heterogêneos, desde que o primeiro caso de VRE foi isolado em 1996. Titze-Almeida et al., 2004, num estudo realizado na cidade de Brasília não encontrou nenhum VRE. Índices baixos como 1,3\% foram relatados por Oliveira Jardim et al. (2006), 2,7\% por Souza et al (2007), 3,6\% por Tresoldi et al. (2006), 13,6\% por Freitas et al., (2006) têm sido detectados em alguns hospitais brasileiros. Furtado et al. 
(2005b) relataram índices crescentes de VRE 9,5\% em 2000, 14,7\% em 2001 e 15,8\% em 2002, num hospital de grande porte da cidade de São Paulo. Em Londrina no Hospital Universitário, verificou-se a ocorrência de um surto com índices semelhantes aos de Furtado nos anos de 2002 a 2003, porém VRE foi erradicado no ano de 2004 neste hospital.

A partir de 2005, VRE voltou a ser isolado no hospital e a incidência de colonização aumentou assustadoramente. A densidade de incidência de 1,9 em 2004 passou para 22 em 2005 e 42,95 VRE por 1.000 pacientes-dia em 2006. O aumento gradativo de VRE verificado neste estudo é compatível com os apresentados por Siefeld et al. (2006), deste mesmo hospital de São Paulo. As taxas de colonização encontradas por estes pesquisadores em 2002 de 7,3 alcançaram 131,11 VRE por 1.000 pacientes-dia em 2005.

E. faecium tem sido a principal espécie de VRE identificada na América do Norte e Europa (Low; Barth; Jones, 2001; Oprea et al, 2004; Deshpande, et al., 2007). Embora estudos similares realizados no Brasil relatem uma predominância de E. faecalis (D' Azevedo et al, 2000; Stern et al, 1994; Caiaffa et al., 2003; Almeida et al, 2004, Vilela et al., 2006), no HU de Londrina a espécie prevalente foi E. faecium, fato preocupante uma vez que esta espécie apresenta resistência a ampicilina e tem a possibilidade de apresentar um gene esp que codifica uma proteína de superfície enterocócica que promove adesão ao trato urinário humano (Tenover, McDonald, 2005). A emergência de E. faecium atualmente tem sido verificada em outros hospitais brasileiros (Siefeld et al., 2006; Santos et al., 2006; Rodrigues et al., 2006). 
Infecção, assim como colonização, por VRE são causas de grande preocupação, tanto devido ao pequeno número de tratamentos alternativos disponíveis, quanto pela natureza das infecções enterocócicas que acometem preferencialmente pacientes debilitados. Estas infecções freqüentemente são relacionadas à assistência em saúde seja em hospitais, seja em casas de repouso e geralmente tem origem clonal (Deshpande et al., 2007).

Apesar de Enterococcus ter sido considerado relativamente não patogênico até recentemente, infecções causadas por VRE com considerável morbidade e mortalidade têm sido descritas entre pacientes imunocomprometidos, e pacientes de terapia intensiva, aqueles que recebem diálise, ou aqueles que foram submetidos a transplantes de órgãos sólidos ou de medula óssea (Freitas et al., 2006). As taxas de colonização e infecção por VRE parecem ser substancialmente menores em pacientes imunocompetentes (Patel, 2003).

$\mathrm{Na}$ América do Norte Enterococcus encontra-se entre os quatro patógenos mais freqüentes $(10,2 \%)$ em infecções da corrente sanguínea, enquanto na Europa está entre as 5 primeiras (7,2\%). Diferentemente na América Latina dados publicados por Biendenbach et al., (2004) apontam índices baixos $(3,3 \%)$ de infecções sangüíneas por VRE entre 11.743 amostras bacterianas isoladas.

As infecções causadas por VRE mais freqüentemente identificadas são aquelas do trato urinário, intra-abdominal, feridas e de cateteres intravasculares. Entretanto, o simples isolamento de VRE na urina não significa infecção (Wong et al., 2000), outros critérios como os propostos 
pelo CDC devem ser adotados (Gardner, Jarvis, Emori, 1988). Da mesma forma a pele pode estar colonizada por VRE o que aumenta o risco de contaminação de culturas de sangue (Tenover, McDonald, 2005).

Infecções urinárias causadas por este agente freqüentemente estão associadas à instrumentação, assim como sepse relacionada a cateter intravascular em pacientes que têm alta prevalência de colonização da pele. Em pacientes submetidos a transplante de fígado a fonte mais comum de bacteremia é o abdômen. Em pacientes neutropênicos a translocação intestinal, a presença de cateter venoso central, o trato urinário pode ser fonte de bacteremia por VRE. Infecções como meningite, endocardite, e outras infecções intravasculares têm sido reportadas raramente (Koc et al., 1998).

Entre os VRE avaliados pelo Programa SENTRY (2007), provenientes dos Estados Unidos e Europa, 36,7\% foram dos VRE foram isolados a partir do trato urinário, $28 \%$ da corrente sanguínea seguida pelas de pele e partes moles com 9,2\% (Deshpande et al., 2007). Os dados obtidos nesta pesquisa foram similares a estes achados, uma vez que a maioria das infecções causadas por VRE foram as urinárias e da corrente sangüínea.

As altas taxas de colonização verificadas neste hospital levaram ao desenvolvimento de um estudo de intervenção por uma equipe multiprofissional para monitorar a adesão a medidas de controle e avaliar se houve melhora após intervenção.

Vários tipos de intervenções têm sido utilizados na tentativa de controlar ou erradicar microrganismos multiresistentes como culturas de vigilância e isolamento de pacientes portadores de VRE, adoção de 
precauções padrão e de contato, melhora na desinfecção e limpeza do ambiente, além de campanhas educacionais, têm sido recomendadas como medidas de controle, porém, a despeito do volume de publicações, medidas baseadas em evidências ainda não estão bem estabelecidas (CDC, 1995; Muto et al., 2003; Siegel et al., 2006; Siegel et al., 2007, Huskins, 2007).

Faltam estudos randomizados, ensaios clínicos controlados comparando uma medida de controle com outra individualmente além de estudos com metodologias similares avaliando medidas de controle da disseminação do VRE.

Em diversos estudos, como os realizados por Christianses et al., (2004), Hachem et al., (2004), Perencevich et al., (2004) observa-se que as medidas de controle são implementadas simultaneamente, o que não permite avaliar a verdadeira efetividade de cada uma isoladamente (Tenover, McDonald, 2005). A ampla variedade de manuais com recomendações (CDC, 1995; CDC, 1997; Muto et al., 2003; Garner et al., 1996; Siegel et al., 2006; Cookson et al., 2006; Brown et al., 2006) reflete a falta de consenso no controle de VRE.

Recentemente o CDC publicou o manual Management of MultidrugResistant Organisms In Healthcare Settings, com foco nos programas de educação, culturas de vigilância, enfatizando a importância das medidas de prevenção e controle de agentes multi-resistentes, dentre eles o VRE, que incluem uso prudente de vancomicina, precauções de contato e precauções padrão (Siegel et al., 2006). 
Embora as recomendações destes manuais não tenham conseguido reverter o aumento da prevalência de VRE, talvez devido à baixa adesão dos profissionais de saúde às medidas de controle, seu uso assíduo obteve sucesso no controle de disseminação de VRE em uma região com 32 serviços de saúde, nos quais as taxas de prevalência diminuíram de 2,2 para 0,5\% (Ostrowsky et al., 2001).

Além disto, num único hospital com endemicidade de VRE, implementação das medidas de controle baseadas nestes manuais, reduziu significativamente infecções sanguíneas (de 2,1 para 0,45 por 1.000 pacientes-dia) assim como reduziu colonização de 20,7 para 10,3 por 1.000 pacientes-dia (Montecalvo et al., 1999).

Entre as medidas recomendadas pelo CDC para controle de microrganismos multiresistentes, as culturas de vigilância são componentes críticos de qualquer programa, permitindo a detecção precoce de patógenos emergentes, monitorando tendências e medindo a efetividade das intervenções. Culturas de vigilância são essenciais para identificar reservatórios que facilitam a disseminação de VRE e auxiliam na prevenção e controle de surtos. (Siegel et al., 2006). De acordo com Ofner-Agostini (2007) a maioria $(89,3 \%)$ das instituições canadenses que respondeu a uma pesquisa conduzida em 2003, afirmavam que realizavam culturas de vigilância na admissão dos pacientes. Os autores enfatizam que esta vigilância precoce seria uma das causas das taxas de VRE permanecerem baixas no Canadá. 
No presente estudo, culturas de vigilância foram realizadas rotineiramente desde 1999. A partir de 2002 quando foi detectado o primeiro surto por VRE no HU de Londrina, as culturas de vigilância permitiram o monitoramento da densidade de incidência de colonização e infecção deste patógeno e nortearam as ações de controle de infecção para prevenção e controle de infecções por VRE.

Intervenções educacionais têm sido utilizadas como ferramenta em vários estudos (Larson, 2000; Rice et al., 1996; Smith et al., 2004). O foco desta intervenção deve ser encorajar mudança de comportamento através do entendimento do microrganismo problema que está se tentando controlar. Mudanças que envolvam higiene das mãos, prescrição de antimicrobianos, interpretação de exames de cultura que promovam progressivamente a mudança do comportamento são vistos como essenciais para o sucesso da intervenção.

Campanhas educacionais que aumentem a adesão às práticas de higiene das mãos em conjunto com outras medidas têm sido associadas temporariamente a controle de agentes multiresistentes em vários serviços de saúde (Muto, 2000, CDC, 2002c, Hayden et al, 2006, Eckstein et al, 2007).

O presente estudo mostrou que após intervenção educacional, a adesão dos profissionais às precauções de contato e padrão foi menor do que esperado, entretanto a proporção de culturas de ambiente e equipamentos reduziu e está associada com uma diminuição significativa das taxas de infecção devido a VRE. Por outro lado, as taxas de colonização 
não diminuíram significativamente, o consumo de vancomicina permaneceu estável e o de teicoplanina aumentou nos últimos meses do estudo.

Os mecanismos de transmissão do VRE incluem pacientes colonizados, contaminação ambiental e as mãos do pessoal da saúde (DeLisle, 2003). De acordo com a literatura, pode-se encontrar VRE nas mãos em 10 a $43 \%$ dos profissionais da saúde (Bonilla, et al., 1997) onde podem permanecer viáveis por mais de 60 horas (Wade, Desai, Casewell, 1991).

Em estudo realizado na Argentina, Zárate et al., (2007) investigaram a contaminação das mãos de 23 profissionais da saúde durante um surto ocorrido em 2003. Não foi encontrado nenhum VRE entre as amostras colhidas das mãos dos profissionais da saúde da mesma forma como ocorreu no presente estudo. Este fato, entretanto, não descarta o possível papel das mãos na disseminação destes microrganismos durante o surto, bem como a possibilidade de transmissão intra-hospitalar e pode ser explicado pelo fato de que o swab das mãos destes profissionais não foi coletado durante ou após procedimento com pacientes colonizados e sim após higiene das mãos, uma vez que a presença da equipe do $\mathrm{SCIH}$ os induzia a realizar higiene das mãos.

O papel da contaminação ambiental, como superfícies e equipamentos, na transmissão de VRE tem sido objeto de vários estudos (Boyce et al., 1997, Noskin et al., 2000, Muto et al., 2003; Bhalla et al., 2004; Hota, 2004, Boyce et al., 2007, Hayden et al., 2008). Embora culturas de ambiente rotineiras não sejam recomendadas, estas podem ser úteis em estudos de surtos para documentar contaminações e planejar intervenções (Simor, 2001; CDC, 2003), 
assim como o uso de materiais não críticos individuais (Rupp et al, 2001; CDC, 2003), designação de pessoal de limpeza específico para ambiente de pacientes portadores de VRE (Falk et al., 2000), melhora na limpeza e desinfecção de superfícies tocadas freqüentemente, como mesas de cabeceira, prontuários, maçanetas, grades dos leitos (Carling et al., 2008).

Segundo Bonten, Willems e Weinstein (2001), considerando a freqüência de contato ambiental e as taxas de higiene das mãos após contato provavelmente menores, a contaminação ambiental pode ter um papel importante na disseminação de VRE.

Estudos prévios mostraram que a desinfecção do ambiente e equipamentos esta associada com diminuição da incidência de colonização e infecção devido a VRE. Uma simples intervenção educacional voltada diretamente à equipe de limpeza reduziu contaminação de superfícies ambientais. Tais intervenções incluíram esforços em monitorar práticas de desinfecção e limpeza e fornecer um “feedback” à equipe (Carling, et al., 2008).

Em um estudo de observação educacional com um grupo definido de pessoal de limpeza houve diminuição persistente na aquisição de VRE em uma UTI (Hayden et al., 2006). Estes autores utilizaram VRE como marcador e investigaram os efeitos da diminuição da contaminação ambiental, com ou sem promoção de adesão à higiene das mãos na disseminação de VRE numa UTI.

O estudo compreendeu uma primeira etapa basal, uma segunda de intervenção educacional para melhorar a limpeza e desinfecção ambiental, uma terceira onde nenhuma atividade específica foi realizada, e uma quarta de ênfase na higiene das mãos. Após o período I de educação os autores 
verificaram redução na densidade de incidência de colonização de 33,4 VRE por 1000 pacientes-dia, para 16,84, e após o período IV, quando foi focada a higiene das mãos, a densidade de colonização reduziu para 10,4. A taxa de VRE em materiais clínicos também diminuiu de 12,7 para 7 por 1.000 pacientes-dia, do período I para o IV. De maneira semelhante foi verificado no presente estudo redução significativa nas taxas de colonização e infecção da fase pré para a pós-intervenção.

No estudo de Eckstein et al., (2007) no qual foram encontrados 17 quartos de pacientes contaminados ou infectados com VRE, 16 (94\%) tiveram uma ou mais culturas ambientais positivas antes da limpeza versus 12 (71\%) após limpeza e desinfecção $(\rho=0,125)$, enquanto nenhum teve cultura positiva após rigorosa desinfecção $(p<0,001)$. Após uma intervenção educacional dos profissionais responsáveis pela desinfecção e limpeza da unidade, as taxas de contaminação ambiental após limpeza reduziram significativamente.

Martinez et al. (2003) constaram que entre todos os fatores associados com a transmissão de VRE, a aquisição deste microrganismo pode depender da contaminação do quarto, mesmo após rigorosa limpeza. Por sua vez, Drees et al. (2008) verificaram que a contaminação prévia do ambiente é um fator altamente preditivo de aquisição de VRE.

Da mesma forma, no presente estudo, após intervenção educacional verificou-se que a redução na contaminação ambiental foi associada com redução das densidades de incidência de infecção e de colonização, mesmo não tendo ocorrido aumento na higiene das mãos, uso de avental e uso de luvas após intervenção educacional. 
Relatos recentes têm documentado um risco aumentado de aquisição de VRE, MRSA e Acinetobacter, após admissão em quarto que tenha sido ocupado previamente por paciente colonizado ou infectado com estes patógenos (Hardy et al., 2006; Huang et al., 2006; Martinez et al., 2006; Denton et al., 2005). Estas observações sugerem que limitações na limpeza e desinfecção do ambiente próximo aos pacientes podem ter papel importante na disseminação destes patógenos.

Assim Carling et al., 2008 realizaram um estudo em seis hospitais com o objetivo de avaliar a efetividade da limpeza ambiental através da utilização de uma solução de limpeza estável, fluorescente na presença de luz Ultra Violeta (UV). A solução era usada como marcadora de um grupo de objetos freqüentemente tocados nos quartos de pacientes das UTIs após limpeza. Os autores sugerem que a utilização desta solução poderia ser útil para enfoques administrativos e intervenções educacionais com o objetivo de melhorar a limpeza e desinfecção do ambiente próximo aos pacientes. Da mesma forma tal procedimento poderia ser utilizado para monitorar a efetividade de tais intervenções.

Zárate et al., (2007) investigaram a contaminação ambiental durante um surto ocorrido em 2003 na Argentina, que se iniciou com o isolamento de uma amostra de VRE em líquido pleural. Foram isoladas no total, 23 amostras de VRE obtidas de materiais clínicos e de swabs retais, num total de 113 pacientes estudados. Com o objetivo de avaliar uma possível contaminação ambiental foi realizado um estudo composto de três etapas nas quais foram coletadas amostras ambientais das UTIs. Foram obtidas 
sete culturas positivas, todas da $\mathrm{UCl} 1$ e somente do primeiro momento. Após implementar as medidas de controle como isolamento dos pacientes, portadores e infectados, limpeza e desinfecção das áreas implicadas, pessoal exclusivo para cada paciente e uso de instrumental descartável, todas as culturas foram negativas.

Num estudo realizado por Wilks et al., 2006, a ênfase na no controle de reservatórios ambientais foi capaz de controlar um surto por Acinetobacter baumannii sem que os pacientes fossem colocados em isolamento.

No presente estudo, foi verificada a contaminação dos materiais mais próximos aos pacientes como bancadas de cabeceira, grades de leitos, equipamentos médicos. Uma das razões para achados ambientais de VRE é a perda de adesão aos procedimentos de limpeza e desinfecção. A intervenção educacional realizada neste estudo, mostrando a contaminação ambiental e a elevada incidência de VRE colonizando e infectando pacientes, e parece ter conscientizado a equipe responsável pela limpeza e desinfecção de ambiente e equipamentos, a ponto de ter atingido um percentual de contaminação significativamente menor no período pósintervenção, especialmente no segundo momento.

Geralmente o mesmo clone de VRE presente no ambiente tem sido encontrado no trato gastrintestinal de pacientes internados ao mesmo tempo na unidade (Bonten et al., 1996) o qual torna quase impossível que seja descartada a transmissão pelas mãos do pessoal.

A disseminação de VRE, freqüentemente clonal caracteriza uma fonte comum com posterior disseminação horizontal da bactéria. Uma vez 
estabelecido em uma unidade, estes clones adaptados ao hospital são extremamente difíceis de erradicar. Diversos investigadores têm usado a tipagem molecular para confirmar a transmissão clonal e assim compreender os mecanismos de transmissão e o efeito das intervenções na transmissão do VRE (Hartstein et al.,1997; Foca et al., 2000;).

De acordo com os estudos de Martinez et al. (2003) a localização de um paciente passou a ser um fator de risco para aquisição de VRE. A ligação epidemiológica entre pacientes colocados em um quarto em particular e a aquisição de VRE verificados por Martinez et al., 2003, da mesma forma que nesta pesquisa, reforçam o papel da contaminação ambiental na transmissão deste microrganismo.

Estudos que combinam vigilância epidemiológica com genotipagem têm elucidado a história natural da epidemiologia nos hospitais, as quais procedem de casos esporádicos de pacientes colonizados com VRE, a pequenos surtos causados por um único clone de VRE, até o estágio final de endemicidade policlonal (Bonten, Willems, Weinstein, 2001).

Pesquisadores brasileiros verificaram em São Paulo, que após o primeiro relato de VRE, mais de 100 casos foram reportados num período de 3 a 4 anos,e a maioria era clonal (Cereda et al., 2002). Dado semelhante foi encontrado no Rio Grande do Sul onde $93,5 \%$ das amostras pertenciam ao mesmo clone (D’ Azevedo et al., 2000).

Na Itália foi relatado recentemente por Stampone et al. (2005) um único clone prevalente em todas as partes do país. Na última década esta tendência também foi verificada nos Estados Unidos, em New York (Storso et al., 1999). 
Kuriyama et al. (2003), entretanto, num estudo de caracterização de VRE isolados de amostras clínicas e ambientais, num hospital-escola em Wales, demonstraram uma população policlonal entre os isolados ambientais e uma associação com certas amostras clínicas. Verificaram ainda o predomínio de um clone entre os isolados clínicos que não foram encontrados no ambiente, sugerindo que não houve transmissão ambiental entre os pacientes.

A admissão de VRE em quarto ocupado previamente por paciente portador de VRE aumentou significativamente a probabilidade de aquisição deste microrganismo, em pesquisa conduzida por Huang et al. (2006).

Alguns pesquisadores mencionam o uso de precauções padrão ou precauções de contato como parte de medidas de controle de microrganismos multiresistentes. Entretanto existem poucos estudos avaliando o impacto das precauções de contato nos pacientes colonizados e ou infectados com VRE. Num estudo de revisão realizado pelo CDC (2002c) são citados estudos que demonstram uma relação temporal entre melhor adesão ás recomendações e práticas de higiene e controle de microrganismos. É interessante que um trabalho reporta que a freqüência de higiene das mãos não melhora com o uso das precauções de contato e também não melhora quando luvas são usadas no contato com pacientes (Kim et al., 2003).

Cada fase da disseminação do VRE necessitaria de um método diferente de controle de infecção. O uso de precauções de barreira, vigilância prospectiva e isolamento de pacientes em quartos privativos tem 
sido eficaz na contenção de pequenos surtos monoclonais (Boyce et al., 1994; Handwerger et al., 1993). O controle em instituições onde a colonização por VRE é endêmica é mais problemático, e embora a erradicação seja impossível, medidas agressivas poderiam conter a disseminação. Em adição, às medidas convencionais, a análise da epidemiologia molecular pode ajudar a identificar clusters de VRE que acarretam endemicidade (Bodnar et al.,1996).

Numa revisão realizada por Bonten, Willems, Weinstein (2001), os autores questionam se todas as medidas de controle devem ser implementadas em todas as circunstâncias, principalmente por que a eficácia de medidas individuais é desconhecida. O uso de luvas e avental, por exemplo, no estudo de Slaugther, Hayden, Nathan (1996) não foi mais efetivo no controle de VRE do que o uso de luvas apenas. Relatam ainda um estudo de Austin et al. (1999) no qual foi verificado que a coorte de pacientes era mais efetivo do que redução no uso de antimicrobianos ou o aumento na adesão à higiene das mãos no controle de infecção.

Em vários relatos a coorte de pacientes, coorte do staff e mesmo da unidade são necessários pra controlar a transmissão durante surtos (Jochimsen et al., 1999; Nicolle, et al., 1999). Já Wilks et al. (2006) descrevem o controle de um surto por Acinetobacter baumannii e sugerem que medidas de controle do ambiente seriam mais efetivas do que isolamento tipo coorte dos pacientes.

A Higiene das mãos é um componente fundamental das precauções padrão e, apesar da indiscutível importância da transmissão cruzada de VRE 
e outros microrganismos pelas mãos, uma melhor adesão às precauções padrão ainda é um desafio.

O uso de luvas e avental também é recomendado para todos os contatos que envolvam o paciente ou áreas potencialmente contaminadas do ambiente do paciente colonizado com microrganismos multiresistentes (CDC, 1995). A elevada adesão dos profissionais, ao uso de luvas no período pré-intervenção, nos surpreendeu. Por outro lado a higiene das mãos e o uso de luvas foram menores e não aumentou após intervenção educacional. Estas observações foram realizadas em diversos momentos após intervenção, não apenas imediatamente após, mas também depois de 2, 3, 5 e 7 meses. De acordo com Muto et al. (2000) embora campanhas de higiene das mãos aumentem após a intervenção em poucos meses voltam aos níveis anteriores.

Alguns estudos avaliaram uso de luvas com ou sem avental, para todos os contatos com pacientes colonizados ou infectados por VRE. Slaughter, Hayden, Nathan, (1996) e Puzniak et al. (2002) relatam que o uso de luvas e avental reduziu a transmissão de VRE, já Srinivasan et al. (2002) não encontrou diferença na transmissão entre os grupos que usaram barreiras de contato e os que não usaram.

Transmissão e disseminação de VRE através das mãos dos profissionais da saúde têm sido demonstradas na literatura por diversos pesquisadores (Bischoff et al., 2000; Gordin et al., 2005; Duckro et al., 2005; Trick et al., 2007; Hayden te al., 200;). Em um estudo, foi cultivada a pele de 22 pacientes colonizados por VRE, assim como os sítios ambientais do 
quarto destes pacientes e as mãos e/ou luvas de 98 profissionais da saúde antes e depois dos cuidados dos pacientes. Foram realizadas 256 culturas de sítios dos pacientes e 1.572 de pontos ambientais, destas encontraram em média $55 \%$ dos sítios corporais e $17 \%$ dos ambientais positivos para VRE. Através da análise das amostras por PFGE verificou-se que VRE foi transferido do ambiente ou da pele dos pacientes pelas mãos ou luvas dos profissionais em $10,6 \%$ das oportunidades.

Trick et al. (2005), em outro estudo, monitoraram a adesão às recomendações de higiene das mãos e uso de luvas e a incidência de microrganismos multiresistentes entre isolados clínicos. Foi introduzida ou aumentada a disponibilidade de álcool-gel em quatro hospitais, e iniciada intervenção e programa educacional interativo com campanha utilizando posters em três deles, no quarto hospital, que foi usado como controle, foi disponibilizado apenas o álcool-gel. Durante três anos foram observadas, 6.948 oportunidades de higiene das mãos, a adesão à higiene das mãos ou uso de luvas aumentou significativamente nos três hospitais onde foi realizada a intervenção (74, 80 e $77 \%)$, mas não no hospital controle (59\%). Uma significante redução na freqüência de VRE (41\%) foi observada apenas no hospital que apresentou o maior percentual de adesão à higiene das mãos $(p<0,001)$.

Um estudo publicado recentemente comparou a contaminação das mãos ou luvas após tocar o ambiente de um quarto ocupado por paciente colonizado por VRE com a contaminação após tocar paciente colonizado e o ambiente. Os autores concluíram que as luvas eram altamente protetoras 
com respeito à contaminação das mãos. As mãos e luvas de profissionais que manusearam estes pacientes ou ambientes foram cultivadas. De 103 profissionais que apresentaram cultura negativa quando entraram no quarto, $52 \%$ contaminaram as mãos ou luvas após tocar o ambiente, e $70 \%$ contaminaram suas mãos ou luvas após tocar o paciente e o ambiente $(p=0.10)$. Em uma análise multivariada, o efeito do número de contatos não pode ser distinguido do efeito do tipo de contato. Além do mais, $37 \%$ daqueles que não usaram luvas contaminaram suas mãos contra apenas $5 \%$ dos que não utilisaram, uma diferença de 86\% (Hayden et al., 2008).

Tem sido relatado que campanhas educacionais de adesão à higiene das mãos, em conjunto com outras medidas, se associam temporariamente com diminuição na transmissão de microrganismos multiresistentes em várias instituições de saúde (Larson, et al., 2000; CDC, 2002c; ArmstrongEvans et al., 1999; Trick et al., 2007). Além do mais, a despeito da introdução de um novo produto de fácil acesso como dispensadores de álcool gel ao lado do leito, verifica-se que a adesão à higiene das mãos aumenta, mas ainda está longe do esperado.

A elevada adesão ao uso de luvas pelos profissionais da saúde observada neste estudo no período inicial nos surpreendeu, entretanto a adesão à higiene das mãos e do uso de avental foi menor que o esperado e não aumentaram após a intervenção educacional, provavelmente por que as observações do período pós-intervenção foram realizadas após 1, 3, 5 e 7 meses após a intervenção. Por que é tão difícil mudar o comportamento do 
profissional de saúde e qual estratégia poderia melhorar a higiene das mãos é um objetivo que ainda precisa ser alcançado.

O tempo que deve durar a precaução de contato dos pacientes infectados e colonizados com VRE ainda não está definido. Pacientes podem permanecer colonizados por muito tempo o que leva estes microrganismos a serem intermitentes, e as culturas de vigilância podem falhar em detectar sua presença (Nouwen et al. 2004). O Guideline HICPAC $(C D C, 1995)$ para prevenção de VRE sugere-se que três culturas de swab retal ou fezes negativas com intervalo de uma semana seria um critério para descontinuar as precauções de contato. Entretanto a recorrência de portadores intermitentes de VRE por mais que um ano tem sido reportado, após terem recebido terapia antimicrobiana (Byers, et al., 2002; Baden et al., 2001; Donskey et al., 2000)

A utilização de antibióticos tem sido apontada como fator predisponente para a seleção do VRE. Os agentes que mais parecem induzir ou facilitar a colonização ou infecção por essa bactéria são a vancomicina, as cefalosporinas e os antianaeróbicos. A duração do tratamento e o número de antibióticos nele envolvidos também parecem ser importantes como fatores de risco (Harbarth, Cosgrove, Carmeli, 2002).

A hospitalização prolongada especialmente em UTI, o tipo de doença de base e condições imunológicas do paciente, intensidade e duração da terapia antimicrobiana, a exposição a instrumentos médicos contaminados, a utilização de procedimentos invasivos e de nutrição enteral parecem ser os principais fatores que predispõem os indivíduos a adquirirem VRE (Delisle, 2003). 
Um estudo caso-controle avaliou a importância da aquisição de VRE em uma UTI e através de uma análise multivariada verificou que permanência no hospital antes e após admissão na UTI maior que uma semana antes da admissão na UTI $(p=0.04)$, o uso de vancomicina antes ou depois da admissão na UTI $(p=0.03)$, o uso de quinolonas antes $(p=0.03)$, e a internação do paciente em um quarto contaminado $(p=0.02)$ estavam associados com aquisição de VRE (Martinez et al., 2003).

Por fim uma das medidas recomendadas para o controle de VRE mais controversas é o uso racional de antimicrobianos. Em 2002, o CDC lançou uma campanha para prevenir resistência a antimicrobianos com princípios baseados em evidências para o uso racional de antibióticos e ferramentas para implementação (Brinsley et al., 2005).

Associações temporais entre mudanças no uso de antimicrobianos e diminuição de microrganismos multiresistentes, têm sido encontradas em diversos estudos, especialmente naqueles focados em bactérias Gram negativas (Madaras-Kelly et al., 2006; Rice et al., 1996; Rahal et al., 2002; Quale et al., 2002; Rupp et al, 2001). Entretanto a importância relativa de restringir o uso de antimicrobianos na tentativa de controlar VRE e MRSA ainda não está clara (Byers et al., 2001; Harbarth, Cosgrove, Carmelli, 2002).

Uma revisão sistemática publicada recentemente, de Bruin et al. (2007) avaliaram o impacto do uso de antimicrobianos na redução de vancomicina na prevalência e incidência de VRE em hospitais americanos. A maioria dos estudos demonstra melhora no controle deste microrganismo 
seguido da redução do uso de vancomicina, embora alguns estudos individuais relatem uma ampla variedade de resultados. Treze estudos apresentavam os critérios de inclusão. Destes sete (54\%) reportaram redução significativa na redução na aquisição de VRE após intervenções, três $(23 \%)$ estudos não verificaram nenhuma mudança significativa e 3 $(23 \%)$ relataram aumento. Além disto, a percentagem de mudança variou de uma redução de $82,5 \%$ (Rubin et al., 1992) a um aumento de $475 \%$ (Guglielmo et al., 2005). Interessantemente, de seis estudos que restringiram vancomicina com única intervenção, apenas dois mostraram uma redução significativa na aquisição de VRE, enquanto entre sete que implementaram restrição do uso de antimicrobianos e outras medidas de controle de infecção, 5 tiveram uma redução significativa na aquisição de VRE. Os autores sugerem que uma intervenção efetiva para controlar colonização e infecção por VRE possa requerer restrição de mais de uma droga. Concluem afirmando que não foi possível determinar o papel potencial da redução no uso de vancomicina no controle de colonização e infecção por VRE em hospitais nos Estados Unidos (de Bruin et al., 2007).

Um estudo realizado no Canadá em 2003 mostrou que de $75 \%$ das instituições avaliadas possuíam política de restrição de antimicrobianos, e embora o impacto desta estratégia não pudesse ter sido medida. Os autores acreditam, entretanto que as baixas taxas de VRE verificadas possam ter sido influenciadas pelos protocolos de triagem dos pacientes na admissão e pela forte política de controle de microrganismos multiresistentes nas instituições canadenses (Ofner-Agostini et al., 2007). 
Em um estudo realizado num hospital terciário de São Paulo (Junior et al., 2007), os autores realizaram vigilância que foi conduzida entre março a setembro de 2002 no qual avaliaram se o uso de vancomicina era apropriado, de acordo com os critérios do CDC (1995), em dois momentos, um primeiro no início da terapia e outro após 72 horas. Constataram que o uso de vancomicina era inapropriado em $65,7 \%$ das vezes nas primeiras 24 horas e em $67 \%$ no segundo momento. Pacientes com menos de 60 anos, não internados em UTIs, e aqueles que não apresentavam neutropenia eram os principais grupos de uso inapropriado. Estes autores sugerem que cada instituição desenvolva protocolos específicos para o uso de vancomicina baseados nos padrões microbiológicos locais. Deveriam ser feitos mais estudos em hospitais pequenos e de médio porte ou em outras áreas do Brasil. Entretanto é provável que os principais achados sejam dificuldade de controle de disseminação de resistência, elevada incidência de MRSA e uso abusivo de vancomicina.

Nesta pesquisa não foi verificada redução no uso de vancomicina no período pós-intervenção, porém houve aumento no uso de teicoplanina, provavelmente por que a intervenção educacional não abordou o uso racional de antimicrobianos, uma vez que a instituição já realiza controle destas drogas. Assim a pressão seletiva causada pelos glicopeptídeos poderia explicar a razão da densidade de colonização não ter diminuído significativamente após intervenção, embora tenha havido redução significativa das infecções. 
No presente estudo, a tipagem molecular mostrou a predominância de um clone de VRE no ambiente e nos pacientes em todo período de estudo reforçando a importância da transmissão cruzada na disseminação de VRE neste hospital. Estes resultados sugerem fortemente a idéia que nos países em desenvolvimento de que o papel da transmissão cruzada na disseminação de VRE é mais importante que a pressão seletiva causada pelo uso de glicopeptídeos.

Entretanto, a importância da racionalização do uso de antimicrobianos não deve ser esquecida e nem tampouco minimizada. Cada instituição deve avaliar a realidade local e desenvolver medidas de controle e prevenção da disseminação de microrganismos multiresistentes baseadas nos problemas encontrados. 


\section{CONCLUSÂO}


O presente estudo mostrou que mesmo depois de uma intervenção educacional, a adesão a medidas de precauções padrão e de contato foi menor do que esperado.

A proporção de culturas de ambiente e equipamentos reduziu quando comparados os períodos pré e pós-intervenção e foi associada com significante redução nas taxas de infecção devido a VRE. Entretanto as taxas de colonização de VRE não diminuíram significativamente.

E. faecium foi a espécie mais freqüente e todos os isolados clínicos apresentaram o gene vanA.

Noventa porcento dos isolados pertenciam ao mesmo clone. Isolados do meio ambiente e equipamentos próximos ao paciente pertenciam ao mesmo clone do paciente.

Estes resultados reforçam a importância da contaminação cruzada de VRE no hospital e o possível papel do meio ambiente com fonte de disseminação de VRE. 


\section{ANEXOS}




\section{Anexo 1 - Protocolo para determinação da Concentração Mínima Inibitória}

\section{Preparo da solução estoque do antimicrobiano}

Os antimicrobianos testados apresentaram em seu rótulo as seguintes informações: número do lote, prazo de validade e a potência expressa em $\mathrm{Ul} / \mathrm{mg}$ ou $\mu \mathrm{g} / \mathrm{mg}$. Para calcular a quantidade necessária do antimicrobiano utilizou-se a seguinte fórmula:

$$
\text { Peso }(\mathrm{mg})=\frac{\text { Volume }(\mathrm{mL}) \times \text { Concentração }(\mu \mathrm{g} / \mathrm{mL})}{\text { Potência }(\mu \mathrm{g} / \mathrm{mg})}
$$

Para cada antimicrobiano foi empregado o solvente adequado, conforme os procedimentos padronizados pelo NCCLS (2004). A concentração final da solução estoque foi de $10.000 \mu \mathrm{g} / \mathrm{mL}$.

\section{Número de diluições}

As concentrações testadas abrangeram os cortes descritos nas tabelas do documento M100-S14 (para uso com M7-A5, CIM) do NCCLS, de $256 \mu \mathrm{g} / \mathrm{mL}$ a $0,125 \mu \mathrm{g} / \mathrm{mL}$. A solução inicial de $256 \mu \mathrm{g} / \mathrm{mL}$ foi obtida a partir da solução estoque de concentração igual a $10.000 \mu \mathrm{g} / \mathrm{mL}$. Foram realizadas diluições do antimicrobiano com o diluente adequado para cada antimicrobiano (NCCLS, 2004). 


\section{Preparo das diluições na microplaca}

Um volume de $50 \mu \mathrm{L}$ de meio de cultura CMHCA (Caldo Mueller-Hinton Cátion Ajustado) foi aplicado em todos os pocinhos da microplaca, exceto na coluna 1 . Foi acrescentado $100 \mu \mathrm{L}$ da diluição a $256 \mu \mathrm{g} / \mathrm{mL}$ em todos os pocinhos da coluna 1. Com uma pipeta multicanal, realizou-se a diluição seriada do antimicrobiano pipetando $50 \mu \mathrm{L}$ do primeiro pocinho da linha $A(A 1)$ para o segundo pocinho da linha A (A2). A mistura foi bem homogeneizada e em seguida foi pipetado $50 \mu \mathrm{L}$ do pocinho A2 para o A3. Este procedimento foi realizado até o pocinho $\mathrm{A} 11$, tendo este um volume final de $100 \mu \mathrm{L}$, o qual foi designado como controle de esterilidade (não foram acrescentadas células bacterianas neste poço, com a finalidade de verificar a possível ocorrência de contaminação durante a diluição do antimicrobiano). O último pocinho de cada linha $\left(\mathrm{A}_{12}-\mathrm{H}_{12}\right)$ foi utilizado como controle de crescimento bacteriano, ou seja, foram inoculados $50 \mu \mathrm{L}$ de meio de cultura MHCA mais $50 \mu \mathrm{L}$ da suspensão bacteriana (diluída 1:100).

\section{Preparo da suspensão bacteriana}

Foi preparada uma suspensão bacteriana na escala 0,5 de McFarland $\left(\sim 1,5 \times 10^{8} \mathrm{UFC} / \mathrm{mL}\right)$ por espectrofotometria, com densidade óptica de 0,08 a 0,1 em comprimento de onda de $625 \mathrm{~nm}$. Esta suspensão foi diluída 1:100 em solução fisiológica ou caldo MHCA ( 1,5 x 106FC/mL). 


\section{Inoculação da suspensão bacteriana}

Foi adicionado $50 \mu \mathrm{L}$ da suspensão bacteriana diluída nos poços 1 a 10 e no poço 12 de todas as colunas $(\mathrm{A}$ a H). Após o preparo das diluições, a inoculação foi realizada num intervalo máximo de 30 minutos. Após semeadura, as placas foram homogeneizadas por movimento rotatório e colocadas em saco plástico estéril. Foram incubadas a $35^{\circ} \mathrm{C}$ por 16 a 20 horas em atmosfera ambiente (NCCLS, 2004).

\section{Leitura das CIMs}

A leitura das placas foi realizada em local iluminado, com auxílio de um espelho para leitura de microplacas. A CIM foi determinada de acordo com a observação de crescimento bacteriano nos pocinhos e por espectrofotometria utilizando um comprimento de onda de $625 \mathrm{~nm}$. O controle de esterilidade foi empregado como branco do teste. 


\section{Anexo 2 - PROTOCOLO PROJETO VRE}

No. DM

VRE

\section{DADOS DE IDENTIFICAÇÃO}

Nome:

RG:

Data internação

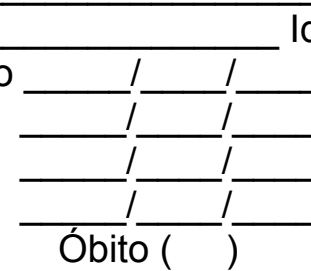

Idade: Local Local Local Local

Alta ( ) Óbito

Data internação anterior

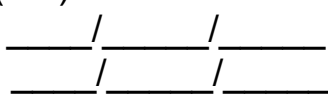

Local:

Local:

\section{DIAGNÓSTICO}

Doença de Base:

Diagnóstico de internação:

APACHE (pacientes UTI):

( ) Infecção hospitalar:
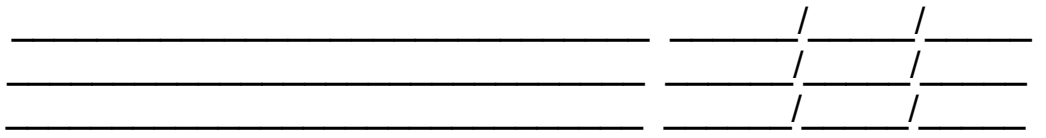

\section{PROCEDIMENTOS INVASIVOS}

Sonda enteral:

Dias:

Cateter Venoso Central: Dias:

Tipo de cateter: ( ) Curta permanência

Ventilação mecânica: Dias:

Cateter Vesical:

Hemodiálise:

Dias:

( ) Nutrição parenteral

( ) Transfusão

Dias:

Cirurgia:
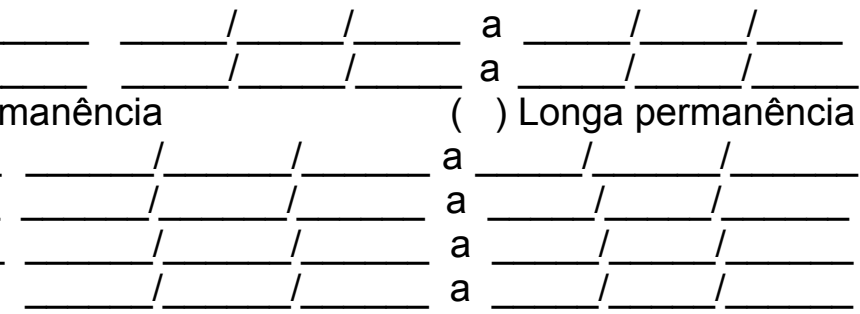

Sexo: F( ) M( )

Leito

Leito

Leito

Leito

Longa permanência

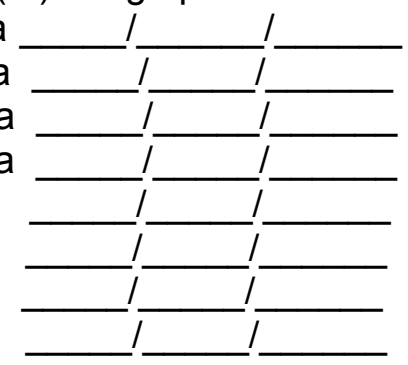

\section{ANTIMICROBIANO}

( ) Não

( ) Vancomicina

( ) Cefotaxima

( ) Maxcef:

( ) Metronidazol

( ) Carbapenem

( )

( )

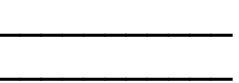

( ) $\mathrm{Sim}$

Dias:

Dias:

Dias:

Dias:

Dias:

Dias:

Dias:
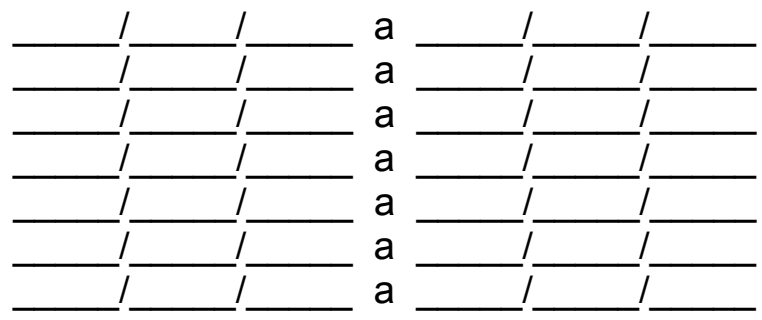


\section{OUTRAS MEDICAÇÕES}
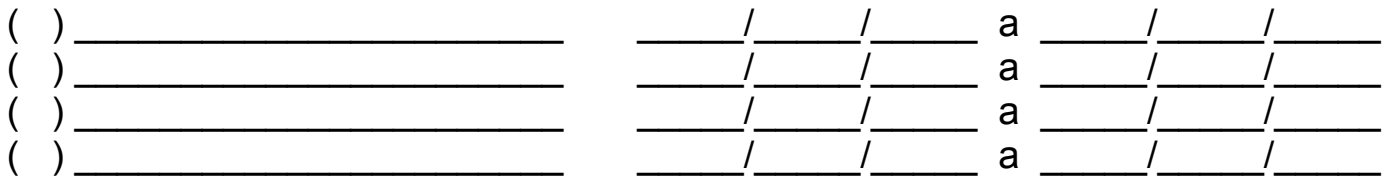

Diarréia: ( ) Sim ( ) Não Incontinência fecal: （） Sim （）Não

\section{RESULTADOS LABORATORIAIS}

CULTURA

Material

1

2

3

4

5

6

NOME
Data de coleta

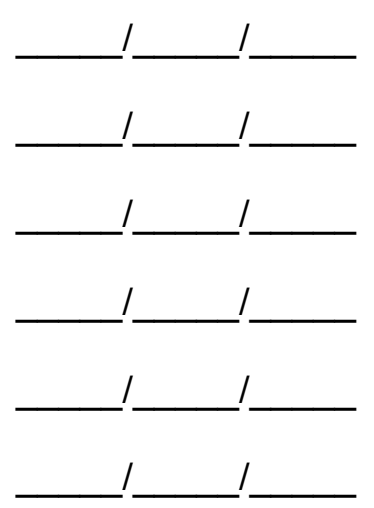

Resultado

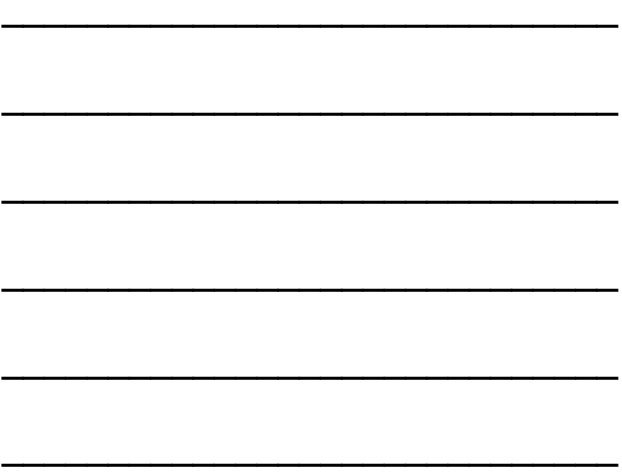

DATA 1 


\section{Anexo 3 - Protocolo Eletroforese em Campo Pulsado (PFGE) - Enterococus}

\section{Preparo da suspensão bacteriana:}

$\checkmark$ Repicar as cepas para meio Agar Sangue de carneiro $5 \%$ ou meio TSA (Tryptic Soy Agar), incubar por $18-24 \mathrm{~h}$ a $37^{\circ} \mathrm{C}$.

$\checkmark$ Repicar 3 a 5 colônias do crescimento em AS para tubos contendo $3 \mathrm{~mL}$ TSB e incubar a $37^{\circ} \mathrm{C}$, overnight;

$\checkmark$ Pesar e identificar os microtubos a serem utilizados;

$\checkmark$ Elaborar um quadro com o numero das amostras e os valores das pesagens do eppendorf, do eppendorf + pellet, peso do pellet e volume de solução fisiológica;

$\checkmark$ Transferir o crescimento do caldo TSB para os respectivos microtubos;

$\checkmark$ Centrifugar os microtubos por 15 minutos a $13.000 \mathrm{rpm} ., 4^{\circ} \mathrm{C}$;

$\checkmark$ Retirar o sobrenadante e adicionar $1 \mathrm{~mL}$ de solução fisiológica estéril ao sedimento;

$\checkmark$ Retirar o sobrenadante e repetir a lavagem com solução fisiológica estéril por mais duas vezes, por 10 minutos nas mesmas condições;

$\checkmark$ Paralelamente Ajustar o Banho-maria para temperatura de $56{ }^{\circ} \mathrm{C}$. Fundir a agarose low melting ( $2 \%$ em TBE $0,5 \mathrm{X})$ e deixar no BM $56{ }^{\circ} \mathrm{C}$

$\checkmark$ Após a última lavagem, retirar totalmente o sobrenadante e pesar 0 microtubo com o sedimento bacteriano;

$\checkmark$ Calcular a massa bacteriana obtida e anotar no quadro;

$\checkmark$ Preparar uma suspensão de bactéria na concentração de $100 \mu \mathrm{g} / \mu \mathrm{L}$ em solução EDTA 50mM pH 8,0 (colocar volume equivalente ao peso do pellet, ver tabela) 
$\checkmark$ Identificar microtubos com os números das amostras.

$\checkmark$ Adicionar $215 \mu \mathrm{L}$ de tampão TEN;.

$\checkmark$ Adicionar $15 \mu \mathrm{L}$ da suspensão bacteriana $100 \mu \mathrm{g} / \mu \mathrm{L}$;

$\checkmark$ Homogeneizar e adicionar $230 \mu \mathrm{L}$ de agarose e homogeneizar.;

$\checkmark$ Distribuir essa mistura nos moldes (evitar a formação de bolhas) e deixar por 30 minutos a $4^{\circ} \mathrm{C}$;

$\checkmark$ Colocar uma placa de cultura de células, aberta, na luz ultra violeta;

$\checkmark$ Distribuir 2mL de tampão EC nos pocinhos que serão usados;

$\checkmark$ Remover os bloquinhos de agarose dos moldes e colocar nos pocinhos contendo tampão EC;

$\checkmark$ Se houver necessidade pode deixar para prosseguir no dia seguinte, mas se for possível continuar;

$\checkmark$ Adicionar $50 \mu \mathrm{L}$ de lisozima e incubar por $3 \mathrm{~h}$ a $37^{\circ} \mathrm{C}$;

$\checkmark$ Retirar o tampão EC e adicionar 2,0mL de tampão CHEF-TE.

$\checkmark$ Retirar o tampão CHEF-TE e novamente adicionar 2,0mL deste tampão. Deixar a temperatura ambiente, por 10 a 30 minutos;

$\checkmark$ Retirar o tampão CHEF-TE;

$\checkmark$ Cobrir os bloquinhos com $2 \mathrm{~mL}$ de tampão ES.

$\checkmark$ Adicionar $100 \mu \mathrm{L}$ de proteinase $\mathrm{K} 20 \mathrm{mg} / \mathrm{mL}$ por pocinho, homogeneizar.e incubar a $50{ }^{\circ} \mathrm{C}$ overnight;

$\checkmark$ Retirar o tampão ES e lavar 5 vezes com 2,0mL de tampão CHEF-TE. A primeira lavagem não tem incubação e as demais devem ser feitas em intervalos de 1 hora;

$\checkmark$ Após a última lavagem, trocar o tampão CHEF-TE e guardar sob refrigeração. 


\section{Preparo para corrida do gel}

$\checkmark$ Adicionar $300 \mu \mathrm{L}$ de tampão DNS nos pocinhos que serão usados, em uma placa de cultura de célula (96 pocinhos);

$\checkmark$ Com auxílio de uma espátula e bisturi, pegar um bloquinho de agarose que está no tampão CHEF-TE e cortá-lo ao meio;

$\checkmark$ Colocar os pedaços no pocinho contendo DNS;

$\checkmark$ Retirar o tampão DNS. E lavar 5 vezes com tampão DNS, com incubações de 1 hora por lavagem.

$\checkmark$ Retirar o tampão DNS e substituí-lo com $200 \mu \mathrm{L}$ de tampão da enzima (1 $\mu \mathrm{L}$ de enzima Smal. fast, $1 \mu \mathrm{L}$ de tampão da enzima e $89 \mu \mathrm{L}$ de água miliQ estéril);

$\checkmark$ Incubar a $37^{\circ} \mathrm{C}$ por 5 minutos no termoblock;

$\checkmark$ Remover o tampão da enzima e adicionar $200 \mu \mathrm{L}$ de TBE 0,5X, retirar em seguida e acrescentar TBE novamente:

$\checkmark$ Preparar o gel de Agarose 1\% em TBE 0,5X (para o pente de 15 amostras preparar $100 \mathrm{~mL}$ ). Aplicar os bloquinhos no pente, retirando o excesso de tampão com papel de filtro e gotejar agarose $1 \%$ para aderir os moldes ao pente;

$\checkmark$ Colocar primeiro um padrão de peso molecular (fago Lambda), uma amostra ATCC e um VRE de outra procedência;

$\checkmark$ Montar a placa para colocar o gel, encaixar a placa perfeitamente com o cuidado de não deixar nenhuma fresta, para não vazar o gel;

$\checkmark$ Colocar o pente na placa na posição vertical, com o cuidado de não deixar tocar no fundo da placa;

$\checkmark$ Adicionar o gel à placa pela extremidade inferior, cuidadosamente, deixando um pequeno volume no frasco; 
$\checkmark$ Colocar o gel que restou no BM;

$\checkmark$ Aguardar a placa solidificar

$\checkmark$ Remover o pente cuidadosamente de maneira que os bloquinhos fiquem inseridos no gel;

$\checkmark$ Preencher os espaços vazios do pente com a agarose que sobrou;

$\checkmark$ Deixar solidificar;

$\checkmark$ Preparar tampão para corrida ( $190 \mathrm{~mL}$ de água destilada e $10 \mathrm{~mL}$ de tampão TBE 0,5X ).

$\checkmark$ Retirar o gel da placa, deixando apenas a placa metálica preta, remover o excesso de agarose nos bordos e fundo da placa;

$\checkmark$ Colocar o gel no aparelho;

$\checkmark$ Ligar o aparelho nas seguintes condições:

\begin{tabular}{lccccc}
\hline $\begin{array}{c}\text { Microrganismo } \\
\text { (Condições da } \\
\text { corrida) }\end{array}$ & $\begin{array}{c}\text { Agarose } \\
(\%)\end{array}$ & $\begin{array}{c}\text { Switch Time } \\
\text { inicial-final }\end{array}$ & Volts/cm & $\begin{array}{c}\text { Tempo de } \\
\text { corrida }\end{array}$ & $\begin{array}{c}\text { Separação dos } \\
\text { fragmentos } \\
\text { em Kb }\end{array}$ \\
\hline Enterococus spp & 1,0 & $5,0-30$ & 6,0 & $22 \mathrm{hs}$ & $100-650$ \\
\hline
\end{tabular}

$\checkmark$ Retirar o gel após a corrida cuidadosamente;

$\checkmark$ Corar o gel em solução de brometo de etídio $1 \mu \mathrm{g} / \mathrm{mL}$, diluída em água destilada;

$\checkmark$ Visualizar as bandas sob transluminação ultra-violeta e fotodocumentar 0 gel. Anotar as condições da corrida no verso da foto. 


\section{Anexo 4 - Protocolo Reação de Cadeia da Polimerase (PCR)}

\section{Extração de DNA}

O DNA será extraído de culturas crescidas em caldo LB à $37^{\circ} \mathrm{C}$ overnight, lavadas em Tris EDTA (50mM Tris, 20mM EDTA pH8,0) e ressuspensas em Tris-EDTA $\left(10^{9}\right.$ células $\left./ \mathrm{ml}\right)$. A $400 \mu$ l de cada amostra será adicionado $50 \mu \mathrm{l}$ de Sodium Duodecyl Sulphate (SDS) $10 \%, 10 \mu \mathrm{l}$ de lisozima (Pharmacia) 5mg/ml, $1 \mu \mathrm{l}$ de RNAse A (Sigma) $10 \mathrm{mg} / \mathrm{ml}$ e $5 \mu \mathrm{l}$ de proteinase $\mathrm{K}(200 \mu \mathrm{g} / \mathrm{ml})$ (Sigma) $20 \mathrm{mg} / \mathrm{ml}$, em tubos eppendorf de $1.5 \mathrm{ml}$. Incubadas por $1 \mathrm{~h}$ à $37^{\circ} \mathrm{C}$ e centrifugadas a $13,000 \times \mathrm{g}$ por $2 \mathrm{~min}$. Ao sobrenadante será adicionado $\mathrm{NaCl}(250 \mathrm{mM})$ e Acetato de sódio (300mM), incubado por $1 \mathrm{~h}$ a $4^{\circ} \mathrm{C}$. Precipitado o DNA com etanol (Merck), será ressuspendido em TE (10mM Tris, 1mM EDTA pH8,0).

\section{Reação de amplificação}

Para a realização da PCR serão utilizados 2,5 L de tampão 10 vezes concentrado, $2 \mathrm{~L}$ de $\operatorname{dNTP}(0,2 \mathrm{mM}), 0,5 \mathrm{pM} / \mathrm{L}$ de primer 1 e primer 2, 1,5 $\mathrm{L}$ de taq polimerase (1U) e 0,5 L de DNA, completando a mistura para $25 \mathrm{~L}$ com água destilada para cada amostra. O material será submetido a um ciclo de $95^{\circ} \mathrm{C}$ por 2 minutos e 30 ciclos específicos a cada primer. Posteriormente, o produto de amplificação será visualizado em gel de agarose 1,0 a $1,5 \%$ contendo brometo de etídio, através do transluminador com luz de ultra-violeta. 


\section{Análise do produto amplificado}

Dez $\mu \mathrm{L}$ de produto amplificado serão analisados por eletroforese em gel de agarose $1,5 \%$ e tampão de corrida TBE (Tris-Borato) a $80 \mathrm{~V} / 4 \mathrm{~h}$. Os géis serão corados em solução de $25 \mu \mathrm{g} / \mathrm{mL}$ de brometo de etídio e as bandas de DNA serão visualizadas em transluminador com luz ultravioleta. 
Anexo 5 - Ficha de Avaliação de Precauções Padrão e de Contato

\begin{tabular}{|c|c|c|c|c|c|c|c|c|c|c|c|c|}
\hline Data & $\mathbf{T}$ & Prof & $\begin{array}{c}\text { Tipo } \\
\text { contato }\end{array}$ & $\begin{array}{l}\text { Box } \\
\text { Priv. }\end{array}$ & $\begin{array}{c}\text { Placa } \\
\text { Mr }\end{array}$ & $\begin{array}{c}\text { Uso } \\
\text { De avent }\end{array}$ & $\begin{array}{l}\text { Higiene } \\
\text { Mãos } \\
\text { Antes }\end{array}$ & $\begin{array}{l}\text { Uso } \\
\text { De } \\
\text { Luva }\end{array}$ & $\begin{array}{c}\text { Desinf } \\
\text { Mat } \\
\text { Individual }\end{array}$ & $\begin{array}{l}\text { Desisnf } \\
\text { Mat } \\
\text { Coletivo }\end{array}$ & $\begin{array}{c}\text { Descarte } \\
\text { Avental? } \\
\text { Onde? }\end{array}$ & $\begin{array}{c}\text { Higiene } \\
\text { Mãos } \\
\text { Após }\end{array}$ \\
\hline & & & & $\begin{array}{l}\text { ( ) Sim } \\
\text { ( ) Não } \\
\text { Box }\end{array}$ & $\begin{array}{l}\text { ( ) Sim } \\
\text { ( ) Não } \\
\text { ( ) VRE }\end{array}$ & $\begin{array}{l}\text { ( ) Sim } \\
\text { ( ) Não }\end{array}$ & $\begin{array}{l}\text { ( ) Sim } \\
\text { ( ) Não }\end{array}$ & $\begin{array}{l}\text { ( ) Sim } \\
\text { ( ) Não } \\
\text { ( ) exclusiva }\end{array}$ & $\begin{array}{l}\text { ( ) S( ) N } \\
\text { ( )Antes } \\
\text { ( )Depois }\end{array}$ & $\begin{array}{l}\text { ( ) S( ) N } \\
\text { ( )Antes } \\
\text { ( )Depois }\end{array}$ & $\begin{array}{l}\text { ( ) Sim } \\
\text { ( ) Não } \\
\text { ( ) Quarto } \\
\text { ( ) Setor }\end{array}$ & $\begin{array}{l}\text { ( ) Sim } \\
\text { ( ) Não } \\
\end{array}$ \\
\hline & & & & $\begin{array}{l}\text { ( ) Sim } \\
\text { ( ) Não } \\
\text { Box }\end{array}$ & $\begin{array}{l}\text { ( ) Sim } \\
\text { ( ) Não } \\
\text { ( ) VRE }\end{array}$ & $\begin{array}{l}\text { ( ) Sim } \\
\text { ( ) Não } \\
\end{array}$ & $\begin{array}{l}\text { ( ) Sim } \\
\text { ( ) Não }\end{array}$ & $\begin{array}{l}\text { ( ) Sim } \\
\text { ( ) Não } \\
\text { ( ) exclusiva }\end{array}$ & $\begin{array}{l}\text { ( ) S( ) N } \\
\text { ( )Antes } \\
\text { ( )Depois }\end{array}$ & $\begin{array}{l}\text { ( ) S( ) N } \\
\text { ( )Antes } \\
\text { ( )Depois }\end{array}$ & $\begin{array}{l}\text { ( ) Sim } \\
\text { ( ) Não } \\
\text { ( ) Quarto } \\
\text { ( ) Setor }\end{array}$ & $\begin{array}{l}\text { ( ) Sim } \\
\text { ( ) Não } \\
\end{array}$ \\
\hline & & & & $\begin{array}{l}\text { ( ) Sim } \\
\text { ( ) Não } \\
\text { Box }\end{array}$ & $\begin{array}{l}\text { ( ) Sim } \\
\text { ( ) Não } \\
\text { ( ) VRE }\end{array}$ & $\begin{array}{l}\text { ( ) Sim } \\
\text { ( ) Não } \\
\end{array}$ & $\begin{array}{l}\text { ( ) Sim } \\
\text { ( ) Não } \\
\end{array}$ & $\begin{array}{l}\text { ( ) Sim } \\
\text { ( ) Não } \\
\text { ( ) exclusiva }\end{array}$ & $\begin{array}{l}\text { ( ) S( ) N } \\
\text { ( )Antes } \\
\text { ( )Depois }\end{array}$ & $\begin{array}{l}\text { ( ) S( ) N } \\
\text { ( )Antes } \\
\text { ( )Depois }\end{array}$ & $\begin{array}{l}\text { ( ) Sim } \\
\text { ( ) Não } \\
\text { ( ) Quarto } \\
\text { ( ) Setor }\end{array}$ & $\begin{array}{l}\text { ( ) Sim } \\
\text { ( ) Não } \\
\end{array}$ \\
\hline & & & & $\begin{array}{l}\text { ( ) Sim } \\
\text { ( ) Não } \\
\text { Box }\end{array}$ & $\begin{array}{l}\text { ( ) Sim } \\
\text { ( ) Não } \\
\text { ( ) VRE }\end{array}$ & $\begin{array}{l}\text { ( ) Sim } \\
\text { ( ) Não } \\
\end{array}$ & $\begin{array}{l}\text { ( ) Sim } \\
\text { ( ) Não }\end{array}$ & $\begin{array}{l}\text { ( ) Sim } \\
\text { ( ) Não } \\
\text { ( ) exclusiva }\end{array}$ & $\begin{array}{l}\text { ( ) S( ) N } \\
\text { ( )Antes } \\
\text { ( )Depois }\end{array}$ & $\begin{array}{l}\text { ( ) S( ) N } \\
\text { ( )Antes } \\
\text { ( )Depois }\end{array}$ & $\begin{array}{l}\text { ( ) Sim } \\
\text { ( ) Não } \\
\text { ( ) Quarto } \\
\text { ( ) Setor }\end{array}$ & $\begin{array}{l}\text { ( ) Sim } \\
\text { ( ) Não } \\
\end{array}$ \\
\hline & & & & $\begin{array}{l}\text { ( ) Sim } \\
\text { ( ) Não } \\
\text { Box }\end{array}$ & $\begin{array}{l}\text { ( ) Sim } \\
\text { ( ) Não } \\
\text { ( ) VRE }\end{array}$ & $\begin{array}{l}\text { ( ) Sim } \\
\text { ( ) Não } \\
\end{array}$ & $\begin{array}{l}\text { ( ) Sim } \\
\text { ( ) Não } \\
\end{array}$ & $\begin{array}{l}\text { ( ) Sim } \\
\text { ( ) Não } \\
\text { ( ) exclusiva }\end{array}$ & $\begin{array}{l}\text { ( ) S( ) N } \\
\text { ( )Antes } \\
\text { ( )Depois }\end{array}$ & $\begin{array}{l}\text { ( ) S( )N } \\
\text { ( )Antes } \\
\text { ( )Depois }\end{array}$ & $\begin{array}{l}\text { ( ) Sim } \\
\text { ( ) Não } \\
\text { ( ) Quarto } \\
\text { ( ) Setor }\end{array}$ & $\begin{array}{l}\text { ( ) Sim } \\
\text { ( ) Não } \\
\end{array}$ \\
\hline & & & & $\begin{array}{l}\text { ( ) Sim } \\
\text { ( ) Não } \\
\text { Box }\end{array}$ & $\begin{array}{l}\text { ( ) Sim } \\
\text { ( ) Não } \\
\text { ( ) VRE }\end{array}$ & $\begin{array}{l}\text { ( ) Sim } \\
\text { ( ) Não }\end{array}$ & $\begin{array}{l}\text { ( ) Sim } \\
\text { ( ) Não } \\
\end{array}$ & $\begin{array}{l}\text { ( ) Sim } \\
\text { ( ) Não } \\
\text { ( ) exclusiva }\end{array}$ & $\begin{array}{l}\text { ( ) S( ) N } \\
\text { ( ) Antes } \\
\text { ( )Depois }\end{array}$ & $\begin{array}{l}\text { ( ) S( )N } \\
\text { ( )Antes } \\
\text { ( )Depois }\end{array}$ & $\begin{array}{l}\text { ( ) Sim } \\
\text { ( ) Não } \\
\text { ( ) Quarto } \\
\text { ( ) Setor }\end{array}$ & $\begin{array}{l}\text { ( ) Sim } \\
\text { ( ) Não } \\
\end{array}$ \\
\hline
\end{tabular}

OBSERVADOR:

LOCAL: 
Anexo 6 - Ficha de Avaliação de Limpeza e Desinfecção

\begin{tabular}{|c|c|c|c|c|c|c|c|c|c|c|}
\hline Data & $\mathbf{T}$ & Profis & $\begin{array}{l}\text { Tipo de } \\
\text { limpeza }\end{array}$ & local & $\begin{array}{l}\text { Produto } \\
\text { utilizado }\end{array}$ & EPI & $\begin{array}{l}\text { Desinf } \\
\text { Equip }\end{array}$ & Produto & $\begin{array}{l}\text { Higiene } \\
\text { mãos } \\
\text { antes }\end{array}$ & $\begin{array}{c}\text { Higiene } \\
\text { mãos após }\end{array}$ \\
\hline & & & $\begin{array}{l}\text { ( ) concorrente } \\
\text { ( ) terminal }\end{array}$ & $\begin{array}{l}\text { ( ) leito } \\
\text { ( ) piso } \\
\text { ( ) parede } \\
\text { BOX } \\
\end{array}$ & $\begin{array}{l}\text { ( ) detergente } \\
\text { ( ) perezal } \\
\text { ( ) álcool }\end{array}$ & $\begin{array}{l}\text { ( ) Luvas } \\
\text { ( ) Avental } \\
\text { ( ) }\end{array}$ & $\overline{\mathrm{BOX}}$ & $\begin{array}{l}\text { ( ) detergente } \\
\text { ( ) perezal } \\
\text { ( ) álcool }\end{array}$ & $\begin{array}{l}\text { ( ) Sim } \\
\text { ( ) Não } \\
\text { ( ) }\end{array}$ & $\begin{array}{l}\text { ( ) Sim } \\
\text { ( ) Não } \\
\text { ( ) }\end{array}$ \\
\hline & & & $\begin{array}{l}\text { ( ) concorrente } \\
\text { ( ) terminal }\end{array}$ & $\begin{array}{l}\text { ( ) leito } \\
\text { ( ) piso } \\
\text { ( ) parede } \\
\text { BOX }\end{array}$ & $\begin{array}{l}\text { ( ) detergente } \\
\text { ( ) perezal } \\
\text { ( ) álcool }\end{array}$ & $\begin{array}{l}\text { ( ) Luvas } \\
\text { ( ) Avental } \\
\text { ( ) }\end{array}$ & $\overline{\mathrm{BOX}}$ & $\begin{array}{l}\text { ( ) detergente } \\
\text { ( ) perezal } \\
\text { ( ) álcool }\end{array}$ & $\begin{array}{l}\text { ( ) Sim } \\
\text { ( ) Não } \\
\text { ( ) }\end{array}$ & $\begin{array}{l}\text { ( ) Sim } \\
\text { ( ) Não } \\
\text { ( ) }\end{array}$ \\
\hline & & & $\begin{array}{l}\text { ( ) concorrente } \\
\text { ( ) terminal }\end{array}$ & $\begin{array}{l}\text { ( ) leito } \\
\text { ( ) piso } \\
\text { ( ) parede } \\
\text { BOX }\end{array}$ & $\begin{array}{l}\text { ( ) detergente } \\
\text { ( ) perezal } \\
\text { ( ) álcool }\end{array}$ & $\begin{array}{l}\text { ( ) Luvas } \\
\text { ( ) Avental } \\
\text { ( ) }\end{array}$ & $\frac{(\mathrm{I})}{\mathrm{BOX}}$ & $\begin{array}{l}\text { ( ) detergente } \\
\text { ( ) perezal } \\
\text { ( ) álcool }\end{array}$ & $\begin{array}{l}\text { ( ) Sim } \\
\text { ( ) Não } \\
\text { ( ) }\end{array}$ & $\begin{array}{l}\text { ( ) Sim } \\
\text { ( ) Não } \\
\text { ( ) }\end{array}$ \\
\hline & & & $\begin{array}{l}\text { ( ) concorrente } \\
\text { ( ) terminal }\end{array}$ & $\begin{array}{l}\text { ( ) leito } \\
\text { ( ) piso } \\
\text { ( ) parede } \\
\text { BOX }\end{array}$ & $\begin{array}{l}\text { ( ) detergente } \\
\text { ( ) perezal } \\
\text { ( ) álcool }\end{array}$ & $\begin{array}{l}\text { ( ) Luvas } \\
\text { ( ) Avental } \\
\text { ( ) }\end{array}$ & $\frac{(\mathrm{I})}{\mathrm{BOX}}$ & $\begin{array}{l}\text { ( ) detergente } \\
\text { ( ) perezal } \\
\text { ( ) álcool }\end{array}$ & $\begin{array}{l}\text { ( ) Sim } \\
\text { ( ) Não } \\
\text { ( ) }\end{array}$ & $\begin{array}{l}\text { ( ) Sim } \\
\text { ( ) Não } \\
\text { ( ) }\end{array}$ \\
\hline & & & $\begin{array}{l}\text { ( ) concorrente } \\
\text { ( ) terminal }\end{array}$ & $\begin{array}{l}\text { ( ) leito } \\
\text { ( ) piso } \\
\text { ( ) parede } \\
\text { BOX }\end{array}$ & $\begin{array}{l}\text { ( ) detergente } \\
\text { ( ) perezal } \\
\text { ( ) álcool }\end{array}$ & $\begin{array}{l}\text { ( ) Luvas } \\
\text { ( ) Avental } \\
\text { ( ) }\end{array}$ & $\overline{\mathrm{BOX}}$ & $\begin{array}{l}\text { ( ) detergente } \\
\text { ( ) perezal } \\
\text { ( ) álcool }\end{array}$ & $\begin{array}{l}\text { ( ) Sim } \\
\text { ( ) Não } \\
\text { ( ) }\end{array}$ & $\begin{array}{l}\text { ( ) Sim } \\
\text { ( ) Não } \\
\text { ( ) }\end{array}$ \\
\hline & & & $\begin{array}{l}\text { ( ) concorrente } \\
\text { ( ) terminal }\end{array}$ & $\begin{array}{l}\text { ( ) leito } \\
\text { ( ) piso } \\
\text { ( ) parede } \\
\text { BOX }\end{array}$ & $\begin{array}{l}\text { ( ) detergente } \\
\text { ( ) perezal } \\
\text { ( ) álcool }\end{array}$ & $\begin{array}{l}\text { ( ) Luvas } \\
\text { ( ) Avental } \\
\text { ( ) }\end{array}$ & $\frac{(\mathrm{C})}{\mathrm{BOX}}$ & $\begin{array}{l}\text { ( ) detergente } \\
\text { ( ) perezal } \\
\text { ( ) álcool }\end{array}$ & $\begin{array}{l}\text { ( ) Sim } \\
\text { ( ) Não } \\
\text { ( ) }\end{array}$ & $\begin{array}{l}\text { ( ) Sim } \\
\text { ( ) Não } \\
\text { ( ) }\end{array}$ \\
\hline
\end{tabular}

OBSERVADOR:

LOCAL: 


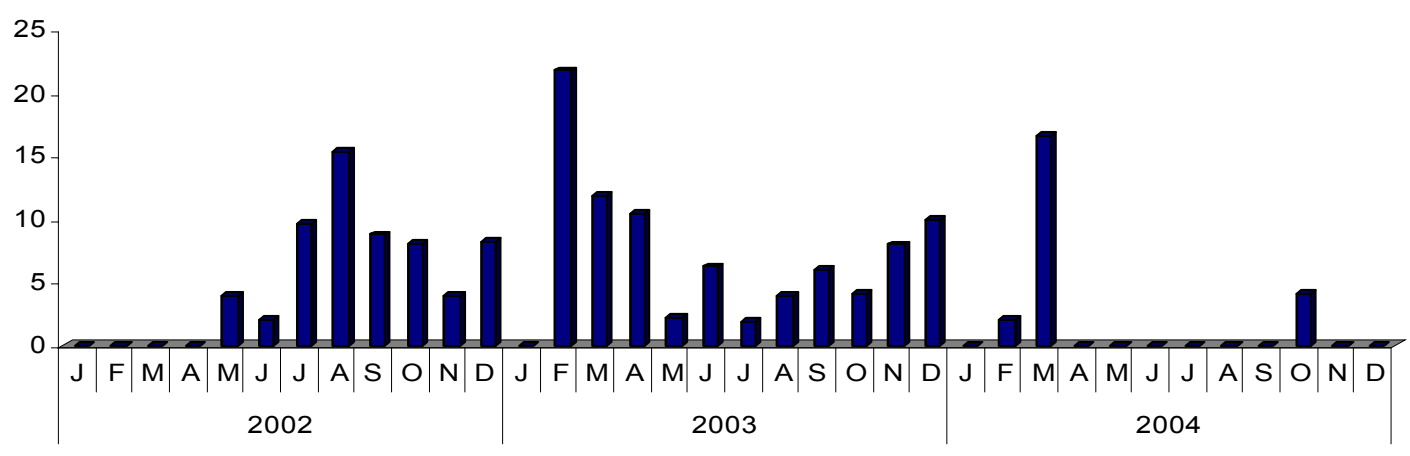

Anexo 7 - Curva de incidência de colonização por VRE por 1.000 pacientes-dia, nas UTIs Gerais do HU do ano 2002 a 2004, mês a mês. colocar no anexo

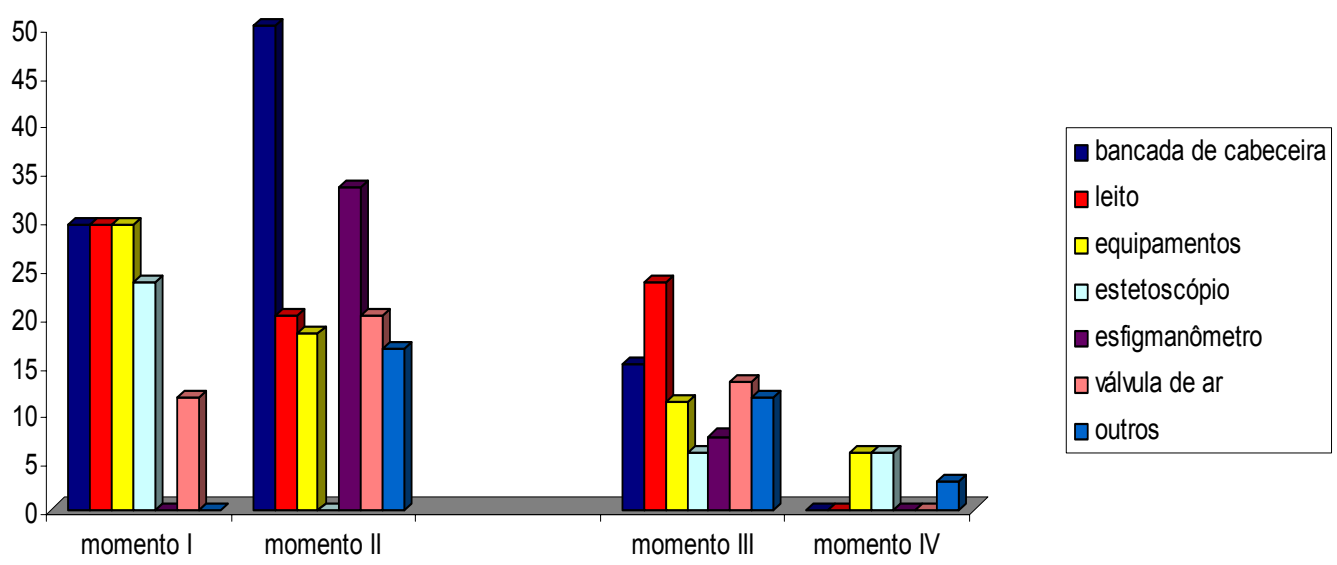

Anexo 9 - Percentual de culturas de ambiente positivas entre 91 culturas realizadas no mês de abril de 2006 (momento I), 75 em março de 2007 (momento II) do período pré-intervenção, 152 do mês de maiol de 2007 (momento III) e 121 em novembro de 2007 (momento IV) do período pós-intervenção, por material de isolamento. 


\section{Anexo 8 - Dados clinicos e demográficos dos pacientes com infecção por VRE}

\begin{tabular}{|c|c|c|c|c|c|c|c|c|c|c|c|c|c|c|}
\hline No & nome & sexo & idade & $\begin{array}{c}\text { data } \\
\text { coleta }\end{array}$ & $\begin{array}{c}\text { Col } \\
\text { previa }\end{array}$ & $\begin{array}{c}\text { Inter } \\
\text { Col } \\
\end{array}$ & $\begin{array}{l}\text { Inter } \\
\text { Inf }\end{array}$ & Amostra & Espécie & $\begin{array}{l}\text { Uso } \\
\text { glico }\end{array}$ & $\begin{array}{l}\text { Uso } \\
\text { cefal }\end{array}$ & trat & Õbito & $\begin{array}{c}\text { Padrão } \\
\text { PFGE }\end{array}$ \\
\hline 1 & JFS & M & 70 & $19 / 07 / 05$ & S & 24 & 55 & Urina & E. faecium & 14 & 10 & LINZ & S & $B$ \\
\hline 2 & EJA & M & 71 & $26 / 07 / 05$ & $\mathrm{~N}$ & $\mathrm{NI}$ & 20 & sec. purulenta & E. faecium & $\mathrm{N}$ & $\mathrm{N}$ & LINZ & $\mathrm{N}$ & B \\
\hline 3 & EM & M & 55 & 01/08/05 & $S$ & 5 & 20 & Sangue & E. faecium & $\mathrm{N}$ & $\mathrm{N}$ & $\mathrm{N}$ & $S$ & $B$ \\
\hline 4 & MLN & $\mathrm{F}$ & 71 & 02/09/05 & $\mathrm{S}$ & 18 & 28 & Secreção pe & E. faecium & $\mathrm{N}$ & $\mathrm{N}$ & $\mathrm{N}$ & $\mathrm{S}$ & B2 \\
\hline 5 & SM & M & 91 & 05/09/05 & $\mathrm{N}$ & 18 & 10 & Sangue & E. faecium & 20 & 3 & $\mathrm{~N}$ & $\mathrm{~N}$ & W1 \\
\hline 6 & AMS & $\mathrm{F}$ & 23 & $27 / 09 / 05$ & $\mathrm{~S}$ & $\mathrm{NI}$ & 24 & P. cateter & E. faecium & 5 & 1 & TIG & $\mathrm{S}$ & $B$ \\
\hline 7 & GSV & $\mathrm{F}$ & 81 & 05/10/05 & $S$ & 16 & 40 & Urina & E. faecium & 6 & 6 & $\mathrm{~N}$ & S & \\
\hline 8 & JMV & M & 32 & $30 / 11 / 05$ & $\mathrm{~S}$ & 55 & 56 & Sangue & E. faecalis & $\mathrm{N}$ & $\mathrm{N}$ & $\mathrm{N}$ & $\mathrm{N}$ & $B$ \\
\hline 9 & MCL & $\mathrm{F}$ & 73 & 02/03/06 & $S$ & 7 & 44 & Urina & E. faecium & $\mathrm{N}$ & $\mathrm{N}$ & $\mathrm{N}$ & $\mathrm{S}$ & $\mathrm{B}$ \\
\hline 10 & JHF & M & 65 & $11 / 04 / 06$ & $\mathrm{~S}$ & 6 & 20 & Sangue & E. faecalis & 5 & 5 & TIG & $\mathrm{S}$ & W \\
\hline 11 & JM & $M$ & 67 & $17 / 04 / 06$ & $S$ & 10 & 24 & Sangue & E. faecium & $\mathrm{N}$ & $\mathrm{N}$ & $\mathrm{N}$ & $\mathrm{N}$ & B2 \\
\hline 12 & NP & M & 66 & $17 / 04 / 06$ & $\mathrm{~S}$ & 4 & 63 & Urina & E. faecium & $\mathrm{N}$ & $\mathrm{N}$ & $\mathrm{N}$ & $\mathrm{S}$ & W \\
\hline 13 & $\mathrm{CC}$ & $M$ & 51 & 02/06/06 & $\mathrm{S}$ & 35 & 39 & Urina & E. faecium & $\mathrm{N}$ & $\mathrm{N}$ & $\mathrm{N}$ & $\mathrm{S}$ & \\
\hline 14 & JNO & M & 47 & 08/07/06 & $\mathrm{N}$ & $\mathrm{NI}$ & 54 & Sangue & E. faecium & $\mathrm{N}$ & $\mathrm{N}$ & $\mathrm{N}$ & $\mathrm{S}$ & \\
\hline 15 & FPC & $\mathrm{F}$ & 58 & $15 / 07 / 06$ & S & 15 & 34 & Sangue & E. faecium & 15 & 31 & AMP & $\mathrm{N}$ & \\
\hline 16 & FLB & $\mathrm{F}$ & 62 & $19 / 07 / 06$ & $\mathrm{~N}$ & $\mathrm{NI}$ & 28 & Urina & E. faecium & $\mathrm{N}$ & $\mathrm{N}$ & TIG & $\mathrm{S}$ & \\
\hline 17 & $\mathrm{JV}$ & M & 79 & $20 / 07 / 06$ & $\mathrm{~N}$ & 8 & 8 & Sangue & E. faecium & $\mathrm{N}$ & 7 & $\mathrm{~N}$ & $\mathrm{~S}$ & $\mathrm{~B}$ \\
\hline 18 & JMS & $\mathrm{F}$ & 74 & 05/08/06 & $\mathrm{S}$ & 12 & 10 & Urina & E. faecium & $\mathrm{N}$ & $\mathrm{N}$ & $\mathrm{N}$ & $\mathrm{N}$ & B7 \\
\hline 19 & SRO & $\mathrm{F}$ & 28 & $17 / 08 / 06$ & $\mathrm{~N}$ & $\mathrm{NI}$ & 7 & Sangue & E. faecium & 5 & $\mathrm{~N}$ & TIG & S & B2 \\
\hline 20 & FAL & $\mathrm{F}$ & 15 & 20/09/06 & $\mathrm{S}$ & $\mathrm{NI}$ & 24 & sec. purulenta & E. faecium & $\mathrm{N}$ & $\mathrm{N}$ & GEN & $\mathrm{S}$ & \\
\hline
\end{tabular}

Continua... 
Conclusão Anexo 7

\begin{tabular}{|c|c|c|c|c|c|c|c|c|c|c|c|c|c|c|}
\hline No & nome & sexo & idade & $\begin{array}{c}\text { data } \\
\text { coleta }\end{array}$ & $\begin{array}{c}\text { Col } \\
\text { previa }\end{array}$ & $\begin{array}{c}\text { Inter } \\
\text { Col }\end{array}$ & $\begin{array}{c}\text { Inter } \\
\text { Inf }\end{array}$ & Amostra & Espécie & $\begin{array}{c}\text { Uso } \\
\text { glico }\end{array}$ & $\begin{array}{l}\begin{array}{l}\text { Uso } \\
\text { cefal }\end{array} \\
\end{array}$ & trat & Õbito & $\begin{array}{c}\text { Padrão } \\
\text { PFGE }\end{array}$ \\
\hline 21 & $\mathrm{MCP}$ & $\mathrm{F}$ & 63 & 02/10/06 & $S$ & 34 & 55 & Urina & E. faecalis & 2 & 18 & $\mathrm{~N}$ & $S$ & \\
\hline 22 & MS & $\mathrm{F}$ & 63 & $25 / 10 / 06$ & $S$ & 12 & 56 & Sangue & E. faecium & 15 & 9 & $\mathrm{~N}$ & $\mathrm{~N}$ & B \\
\hline 23 & JRS & M & 63 & $03 / 11 / 06$ & S & 6 & 9 & sec. purulenta & E. faecium & $\mathrm{N}$ & $\mathrm{N}$ & $\mathrm{N}$ & S & B \\
\hline 24 & JBN & M & 65 & $10 / 11 / 06$ & $\mathrm{~N}$ & $\mathrm{NI}$ & 8 & Sangue & E. faecalis & 17 & 5 & LINZ & $\mathrm{N}$ & W \\
\hline 25 & JLN & $\mathrm{M}$ & 24 & $16 / 11 / 06$ & $S$ & IA & 1 & sec. purulenta & E. faecium & 17 & $\mathrm{~N}$ & $\mathrm{~N}$ & $S$ & B9 \\
\hline 26 & GCS & $\mathrm{F}$ & 47 & $30 / 11 / 06$ & $\mathrm{~N}$ & $\mathrm{NI}$ & 53 & Urina & E. faecalis & 17 & 10 & LINZ & $S$ & \\
\hline 27 & GLC & $\mathrm{M}$ & 38 & $04 / 12 / 06$ & $S$ & 7 & 180 & Sangue & E. faecium & $?$ & $?$ & $\mathrm{~N}$ & $\mathrm{~N}$ & \\
\hline 28 & $\mathrm{EMB}$ & $\mathrm{F}$ & 84 & $04 / 12 / 06$ & $\mathrm{~N}$ & 8 & 8 & Sangue & E. faecium & $\mathrm{N}$ & $\mathrm{N}$ & $\mathrm{N}$ & $S$ & \\
\hline 29 & MRP & $\mathrm{F}$ & 48 & $02 / 01 / 07$ & S & 23 & 125 & Sangue & E. faecium & 11 & 11 & $\mathrm{~N}$ & $\mathrm{~N}$ & B \\
\hline 30 & PMA & $\mathrm{M}$ & 75 & $20 / 03 / 07$ & $S$ & 24 & 35 & Urina & E. faecium & 16 & 20 & $\mathrm{~N}$ & $S$ & B \\
\hline 31 & MAL & $\mathrm{F}$ & 20 & $23 / 03 / 07$ & $S$ & 28 & 38 & Sangue & E. faecium & $\mathrm{N}$ & $\mathrm{N}$ & $\mathrm{N}$ & $S$ & B \\
\hline 32 & AMF & M & 71 & $26 / 03 / 07$ & $S$ & 10 & 42 & Urina & E. faecalis & $\mathrm{N}$ & $\mathrm{N}$ & $\mathrm{N}$ & $S$ & W \\
\hline 33 & BPA & $\mathrm{F}$ & 69 & $11 / 04 / 07$ & $s x$ & 2 & 16 & Sangue & E. faecium & $\mathrm{N}$ & $\mathrm{N}$ & $\mathrm{N}$ & $S$ & B \\
\hline 34 & JLS & $\mathrm{M}$ & 36 & $16 / 05 / 07$ & $S$ & 12 & 173 & Urina & E. faecium & 8 & $\mathrm{~N}$ & $\mathrm{~N}$ & $\mathrm{~N}$ & B \\
\hline 35 & JGC & $\mathrm{M}$ & 83 & $21 / 05 / 07$ & $\mathrm{~N}$ & $\mathrm{NI}$ & 36 & Urina & E. faecium & $\mathrm{N}$ & 20 & $\mathrm{~N}$ & $\mathrm{~N}$ & \\
\hline 36 & ATM & $\mathrm{M}$ & 58 & $28 / 06 / 07$ & $S$ & 12 & 30 & Sangue & E. faecium & 30 & 5 & TIG & $S$ & B7 \\
\hline
\end{tabular}

Legenda: Col previa- colonização prévia, Inter col- tempo em dias entre internação e colonização, Inter inf - tempo em dias entre internação e

infecção, uso glico- uso prévio de glicopeptídeos, uso cefal- uso prévio de cefalosporinas, trat- tratamento, M-masculino, F- feminino, S- sim, N-não,

$\mathrm{NI}$ - não investigado, IA-internação anterior, TIG- tigacil, LINZ- linezolida 


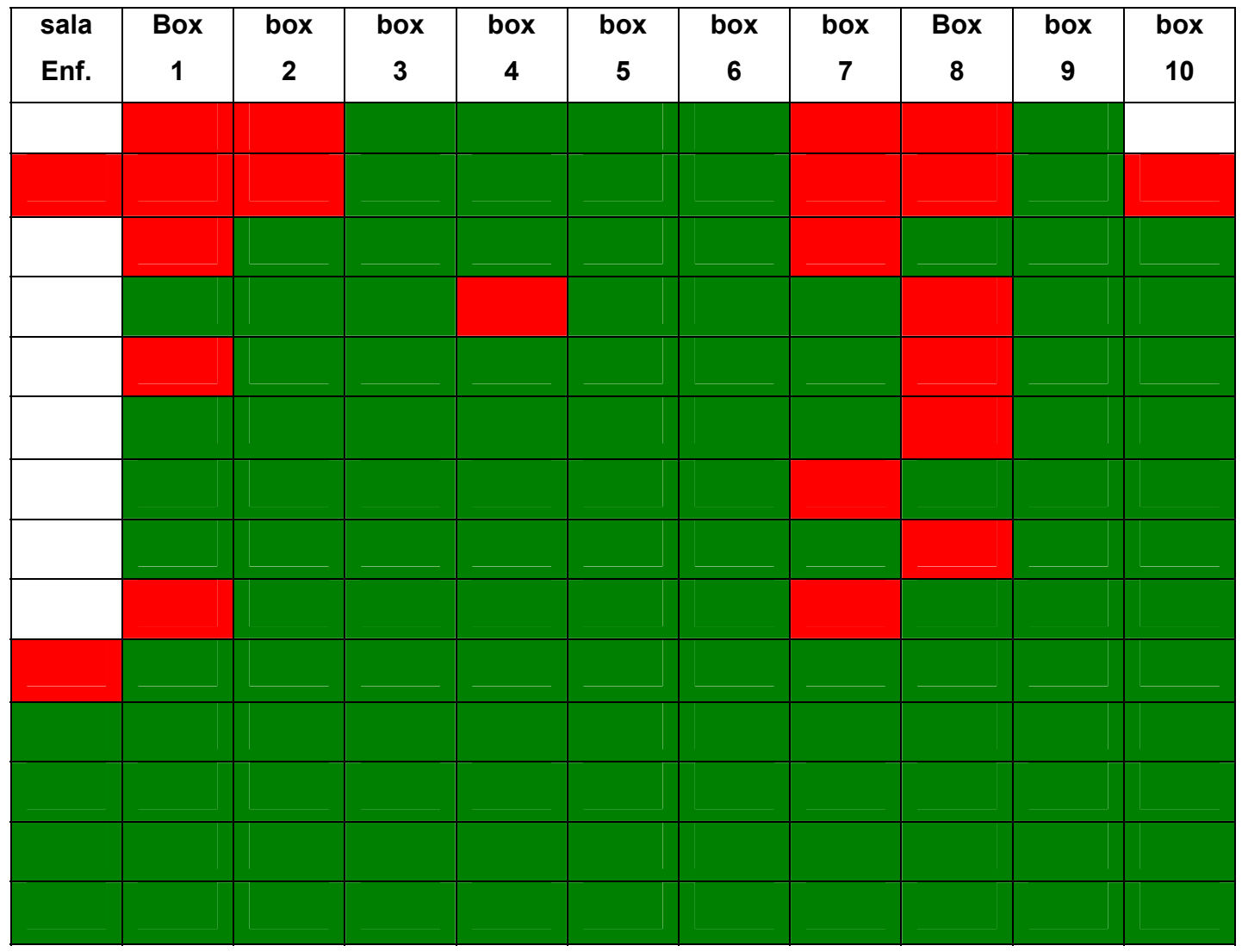

Anexo 10 - Distribuição de materiais positivos para VRE de acordo com a localização na UTI I e Posto de Enfermagem ,momento II (março de 2007) do período pré-intervenção. 


\begin{tabular}{|c|c|c|c|c|c|c|c|c|c|c|c|}
\hline & $\begin{array}{l}\text { Posto } \\
\text { Enferm }\end{array}$ & $\begin{array}{c}\text { box } \\
1\end{array}$ & $\begin{array}{c}\text { box } \\
2\end{array}$ & $\begin{array}{c}\text { box } \\
3\end{array}$ & $\begin{array}{c}\text { box } \\
4\end{array}$ & $\begin{array}{c}\text { box } \\
5\end{array}$ & $\begin{array}{c}\text { box } \\
6\end{array}$ & $\begin{array}{c}\text { box } \\
7\end{array}$ & $\begin{array}{c}\text { box } \\
8\end{array}$ & $\begin{array}{c}\text { box } \\
9\end{array}$ & $\begin{array}{c}\text { box } \\
10\end{array}$ \\
\hline swab retal & & & & & & & & & & & \\
\hline Bancada & & & & & & & & & & & \\
\hline Borda leito & & & & & & & & & & & \\
\hline equipamentos & & & & & & & & & & & \\
\hline Estetoscópio & & & & & & & & & & & \\
\hline esfigmanômetro & & & & & & & & & & & \\
\hline Válvula de ar & & & & & & & & & & & \\
\hline Termômetro & & & & & & & & & & & \\
\hline Otoscópio & & & & & & & & & & & \\
\hline Prancheta & & & & & & & & & & & \\
\hline Geladeira & & & & & & & & & & & \\
\hline Computador & & & & & & & & & & & \\
\hline Maçaneta & & & & & & & & & & & \\
\hline Telefone & & & & & & & & & & & \\
\hline ar ondicionado & & & & & & & & & & & \\
\hline
\end{tabular}

Anexo 11 - Distribuição de materiais positivos para VRE de acordo com a localização na UTI I e Posto de Enfermagem, período III (maio de 2007) do período pós-intervenção.

\begin{tabular}{|l|c|c|c|c|c|c|c|}
\hline & box & Box & box & box & box & box & box \\
\hline & 1 & 2 & 3 & 4 & 5 & 6 & 7 \\
\hline swab retal & & & & & & & \\
\hline Bancada & & & & & & & \\
\hline Borda leito & & & & & & & \\
\hline Equipamentos & & & & & & & \\
\hline Estetoscópio & & & & & & & \\
\hline válvula de ar & & & & & & & \\
\hline Esfigma & & & & & & & \\
\hline Oxímetro & & & & & & & \\
\hline Termômetro & & & & & & & \\
\hline Prancheta & & & & & & & \\
\hline
\end{tabular}

Anexo 12 - Distribuição de materiais positivos para VRE de acordo com a localização na UTI II momento período III (maio de 2007) do período pósintervenção. 
Anexo 13 - Dados clínicos e microbiológicos das amostras de VRE analisadas

\begin{tabular}{|c|c|c|c|c|c|c|c|c|c|}
\hline No & $\begin{array}{l}\text { nome do } \\
\text { paciente }\end{array}$ & Unid & $\begin{array}{c}\text { data } \\
\text { coleta }\end{array}$ & Amostra & Espécie & \begin{tabular}{|c|} 
Padrão \\
PFGE
\end{tabular} & Tenover & PCR & Fenótipo \\
\hline 1 & IPS & UT2 & $28 / 05 / 02$ & Esfigmanômetro & E. faecium & A & Dominante & $\operatorname{van} A$ & VanA \\
\hline 3 & IPS & UT2 & $28 / 05 / 02$ & Estetoscópio & E. faecium & A1 & Estreit relac. & $\operatorname{van} A$ & VanA \\
\hline 23 & JLAF & EM & 06/03/03 & Bancada & E. faecium & $\mathrm{K}$ & Não relac. & $\operatorname{van} \mathrm{A}$ & VanA \\
\hline 22 & JLAF & EM & 06/03/03 & Borda de Leito & E. faecium & A7 & Estreit relac. & $\operatorname{van} A$ & VanA \\
\hline 21 & CS & EM & $06 / 03 / 03$ & Esfigmanômetro & E. faecium & A & Dominante & $\operatorname{van} A$ & VanA \\
\hline 24 & CS & EM & $07 / 03 / 03$ & Bancada & E. faecium & A & Dominante & $\operatorname{van} \mathrm{A}$ & VanA \\
\hline 26 & JVJ & EM & $07 / 03 / 03$ & Bancada & E. faecium & A7 & Estreit relac. & $\operatorname{van} A$ & VanA \\
\hline 25 & CS & EM & 07/03/03 & Borda de Leito & E. faecium & A7 & Estreit relac. & $\operatorname{van} A$ & VanA \\
\hline 51 & EFL & UT2 & $23 / 05 / 05$ & Bancada & E. faecium & $\mathrm{B}$ & Dominante & $\mathrm{NI}$ & VanA \\
\hline 49 & ALS & UT2 & $23 / 05 / 05$ & Borda de Leito & E. faecium & $\mathrm{B}$ & Dominante & $\mathrm{NI}$ & VanA \\
\hline 52 & EFL & UT2 & $23 / 05 / 05$ & Equipamento & E. faecium & $B$ & Dominante & $\mathrm{NI}$ & VanA \\
\hline 50 & EFL & UT2 & $23 / 05 / 05$ & Válvula de ar & E. faecium & $\mathrm{B}$ & Dominante & $\mathrm{NI}$ & VanA \\
\hline 71 & Ambiente & UT2 & $16 / 08 / 05$ & ambu & E. faecium & 1 & Não relac. & $\mathrm{NI}$ & VanA \\
\hline 62 & Ambiente & UT2 & $16 / 08 / 05$ & Bancada & E. faecium & $\mathrm{B}$ & Dominante & $\operatorname{van} \mathrm{A}$ & VanA \\
\hline 68 & Ambiente & UD & $16 / 08 / 05$ & Bancada & E. faecium & $\mathrm{B}$ & Dominante & $\mathrm{NI}$ & VanA \\
\hline 69 & Ambiente & UT2 & $16 / 08 / 05$ & Bancada & E. faecium & B & Dominante & $\mathrm{NI}$ & VanA \\
\hline 66 & Ambiente & $\mathrm{EF}$ & $16 / 08 / 05$ & Borda de Leito & E. faecium & $\mathrm{B}$ & Dominante & $\mathrm{NI}$ & VanA \\
\hline 64 & Ambiente & UT2 & $16 / 08 / 05$ & Equipamento & E. faecium & $\mathrm{B}$ & Dominante & $\mathrm{NI}$ & VanA \\
\hline 70 & Ambiente & UT2 & $16 / 08 / 05$ & Equipamento & E. faecium & $B$ & Dominante & $\mathrm{NI}$ & VanA \\
\hline 65 & Ambiente & EM & $16 / 08 / 05$ & Equipo & E. faecium & B & Dominante & $\mathrm{NI}$ & VanA \\
\hline
\end{tabular}

Continua... 
Continuação Anexo 13

\begin{tabular}{|c|c|c|c|c|c|c|c|c|c|}
\hline No & $\begin{array}{l}\text { nome do } \\
\text { paciente }\end{array}$ & Unid & $\begin{array}{c}\text { data } \\
\text { coleta }\end{array}$ & Amostra & Espécie & \begin{tabular}{|c|} 
Padrão \\
PFGE \\
\end{tabular} & Tenover & PCR & Fenótipo \\
\hline 67 & Ambiente & EM & $16 / 08 / 05$ & Mascara de Oxigenio & E. faecium & $\mathrm{B}$ & Dominante & $\mathrm{NI}$ & VanA \\
\hline 63 & Ambiente & EM & $16 / 08 / 05$ & Tubo de Oxigenio & E. faecium & B & Dominante & $\operatorname{van} A$ & VanA \\
\hline 101 & FHD & UT1 & $27 / 12 / 05$ & Fragmento ósseo & E. faecalis & W & Dominante & $\operatorname{van} \mathrm{A}$ & VanA \\
\hline 113 & JM & UT2 & $10 / 04 / 06$ & Bancada & E. faecalis & W & Dominante & $\operatorname{van} A$ & VanA \\
\hline 121 & JDNMA & UT2 & $10 / 04 / 06$ & Bancada & E. faecalis & W & Dominante & $\mathrm{NI}$ & VanA \\
\hline 130 & LO & UT1 & $10 / 04 / 06$ & Bancada & E. faecalis & W & Dominante & $\mathrm{NI}$ & VanA \\
\hline 111 & CGA & UT2 & $10 / 04 / 06$ & Borda de Leito & E. faecalis & W & Dominante & $\operatorname{van} A$ & VanA \\
\hline 120 & JBS & UT1 & $10 / 04 / 06$ & Borda de Leito & E. faecalis & W & Dominante & $\mathrm{NI}$ & VanA \\
\hline 123 & JM & UT2 & $10 / 04 / 06$ & Borda de Leito & E. faecalis & W & Dominante & $\mathrm{NI}$ & VanA \\
\hline 127 & JSN & UT2 & $10 / 04 / 06$ & Borda de Leito & E. faecalis & W & Dominante & $\mathrm{NI}$ & VanA \\
\hline 125 & $\mathrm{JM}$ & UT2 & $10 / 04 / 06$ & Equipamento & E. faecalis & W & Dominante & $\mathrm{NI}$ & $\operatorname{Van} A$ \\
\hline 129 & LO & UT1 & $10 / 04 / 06$ & Equipamento & E. faecalis & W & Dominante & $\mathrm{NI}$ & VanA \\
\hline 117 & CGA & UT2 & $10 / 04 / 06$ & Estetoscópio & E. faecalis & W & Dominante & $\mathrm{NI}$ & $\operatorname{Van} A$ \\
\hline 124 & JM & UT2 & $10 / 04 / 06$ & Estetoscópio & E. faecalis & W & Dominante & $\mathrm{NI}$ & VanA \\
\hline 128 & LO & UT1 & $10 / 04 / 06$ & Estetoscópio & E. faecalis & W & Dominante & $\mathrm{NI}$ & VanA \\
\hline 118 & Ambiente & UT1 & $10 / 04 / 06$ & Máquina de $\mathrm{RX}$ & E. faecalis & W & Dominante & $\mathrm{NI}$ & VanA \\
\hline 122 & JCA & UT2 & $10 / 04 / 06$ & Válvula de ar & E. faecalis & W & Dominante & $\mathrm{NI}$ & VanA \\
\hline 126 & JSN & UT2 & $10 / 04 / 06$ & Válvula de ar & E. faecalis & W & Dominante & $\mathrm{NI}$ & VanA \\
\hline 131 & CGA & UT2 & $10 / 04 / 06$ & Bancada & E. faecium & $\mathrm{J}$ & Não relac. & $\mathrm{NI}$ & VanA \\
\hline 135 & JHF & UT1 & $10 / 04 / 06$ & Bancada & E. faecium & B2 & Estreit relac. & $\mathrm{NI}$ & VanA \\
\hline
\end{tabular}

Continua.. 
Continuação Anexo 13

\begin{tabular}{|c|c|c|c|c|c|c|c|c|c|}
\hline No & $\begin{array}{l}\text { nome do } \\
\text { paciente }\end{array}$ & Unid & $\begin{array}{c}\text { data } \\
\text { coleta }\end{array}$ & Amostra & Espécie & \begin{tabular}{|c|} 
Padrão \\
PFGE \\
\end{tabular} & Tenover & PCR & Fenótipo \\
\hline 114 & JHF & UT1 & $10 / 04 / 06$ & Borda de Leito & E. faecium & B2 & Estreit relac. & $\operatorname{van} A$ & VanA \\
\hline 132 & JBS & UT1 & $10 / 04 / 06$ & Equipamento & E. faecium & B2 & Estreit relac. & $\mathrm{NI}$ & VanA \\
\hline 134 & JHF & UT1 & $10 / 04 / 06$ & Estetoscópio & E. faecium & B2 & Estreit relac. & $\mathrm{NI}$ & VanA \\
\hline 178 & Ambiente & UT1 & $31 / 03 / 07$ & Aparelho & E. faecium & B7 & Estreit relac. & $\mathrm{NI}$ & VanA \\
\hline 174 & AP & UT1 & $31 / 03 / 07$ & aparelho & E. faecium & $B$ & Dominante & $\mathrm{NI}$ & VanA \\
\hline 184 & $M Z$ & UT1 & $31 / 03 / 07$ & Aparelho auricular & E. faecium & B7 & Estreit relac. & $\mathrm{NI}$ & VanA \\
\hline 175 & Ambiente & UT1 & $31 / 03 / 07$ & Bancada & E. faecium & $\mathrm{B}$ & Dominante & $\mathrm{NI}$ & VanA \\
\hline 176 & AP & UT1 & $31 / 03 / 07$ & Bancada & E. faecium & B7 & Estreit relac. & $\mathrm{NI}$ & VanA \\
\hline 182 & EMC & UT1 & $31 / 03 / 07$ & Bancada & E. faecium & B7 & Estreit relac. & $\mathrm{NI}$ & VanA \\
\hline 185 & $M Z$ & UT1 & $31 / 03 / 07$ & Bancada & E. faecium & B7 & Estreit relac. & $\mathrm{NI}$ & VanA \\
\hline 181 & EMC & UT1 & $31 / 03 / 07$ & Borda de Leito & E. faecium & B7 & Estreit relac. & $\mathrm{NI}$ & $\operatorname{Van} A$ \\
\hline 183 & $M Z$ & UT1 & $31 / 03 / 07$ & Borda de Leito & E. faecium & B7 & Estreit relac. & $\mathrm{NI}$ & VanA \\
\hline 177 & CSS & UT1 & $31 / 03 / 07$ & Oxímetro & E. faecium & B7 & Estreit relac. & $\mathrm{NI}$ & $\operatorname{Van} A$ \\
\hline 179 & Ambiente & UT1 & $31 / 03 / 07$ & Prancheta & E. faecium & B7 & Estreit relac. & $\mathrm{NI}$ & VanA \\
\hline 180 & EMC & UT1 & $31 / 03 / 07$ & Válvula de ar & E. faecium & B7 & Estreit relac. & $\mathrm{NI}$ & VanA \\
\hline 190 & MAS & UT1 & $24 / 04 / 07$ & Bancada & E. faecium & $\mathrm{H}$ & Não relac. & $\mathrm{NI}$ & VanA \\
\hline 196 & HMSO & UT1 & $25 / 04 / 07$ & Bancada & E. faecium & $\mathrm{L}$ & Não relac. & $\mathrm{NI}$ & VanA \\
\hline 195 & MAS & UT2 & $25 / 04 / 07$ & Equipamento & E. faecium & $\mathrm{H}$ & Não relac. & $\mathrm{NI}$ & VanA \\
\hline 192 & $\mathrm{JQ}$ & UT1 & $25 / 04 / 07$ & Oxímetro & E. faecium & $\mathrm{B}$ & Dominante & $\mathrm{NI}$ & VanA \\
\hline 194 & ERA & UT1 & $25 / 04 / 07$ & Termômetro & E. faecium & B7 & Estreit relac. & $\mathrm{NI}$ & VanA \\
\hline
\end{tabular}

Continua... 
Continuação Anexo 13

\begin{tabular}{|c|c|c|c|c|c|c|c|c|c|}
\hline No & $\begin{array}{l}\text { nome do } \\
\text { paciente }\end{array}$ & Unid & $\begin{array}{c}\text { data } \\
\text { coleta }\end{array}$ & Amostra & Espécie & \begin{tabular}{|c|} 
Padrão \\
PFGE \\
\end{tabular} & Tenover & PCR & Fenótipo \\
\hline 193 & BGGR & UT1 & $25 / 04 / 07$ & Válvula de ar & E. faecium & B7 & Estreit relac. & $\mathrm{NI}$ & VanA \\
\hline 201 & MSR & UT2 & $27 / 04 / 07$ & Borda de Leito & E. faecium & B & Dominante & $\mathrm{NI}$ & VanA \\
\hline 203 & MAS & UT2 & $27 / 04 / 07$ & Borda de Leito & E. faecium & B7 & Estreit relac. & $\mathrm{NI}$ & VanA \\
\hline 204 & MLMS & UT2 & $27 / 04 / 07$ & Borda de Leito & E. faecium & B9 & Estreit relac. & $\mathrm{NI}$ & VanA \\
\hline 197 & $A B J$ & UT2 & $27 / 04 / 07$ & Estetoscópio & E. faecium & $\mathrm{B}$ & Dominante & $\mathrm{NI}$ & VanA \\
\hline 200 & MSR & UT2 & $27 / 04 / 07$ & Oxímetro & E. faecium & $\mathrm{B}$ & Dominante & $\mathrm{NI}$ & $\operatorname{Van} A$ \\
\hline 199 & MAS & UT2 & $27 / 04 / 07$ & Termômetro & E. faecium & $B$ & Dominante & $\mathrm{NI}$ & VanA \\
\hline 205 & Ambiente & UT1 & $29 / 04 / 07$ & Prancheta & E. faecium & B2 & Estreit relac. & $\mathrm{NI}$ & VanA \\
\hline 224 & VVB & UT1 & $19 / 07 / 07$ & Borda de Leito & E. faecium & $\mathrm{B}$ & Dominante & $\mathrm{NI}$ & VanA \\
\hline 223 & PJ & UT1 & $19 / 07 / 07$ & Equipamento & E. faecium & $\mathrm{B}$ & Dominante & $\mathrm{NI}$ & VanA \\
\hline 222 & $\mathrm{MC}$ & UT1 & $19 / 07 / 07$ & Estetoscópio & E. faecium & B & Dominante & $\mathrm{NI}$ & $\operatorname{Van} A$ \\
\hline 221 & $\mathrm{MC}$ & UT1 & $19 / 07 / 07$ & Termômetro & E. faecium & $\mathrm{B}$ & Dominante & $\mathrm{NI}$ & VanA \\
\hline 2 & JAS & UT2 & $28 / 05 / 02$ & Swab Retal & E. faecium & A & Dominante & $\operatorname{van} A$ & VanA \\
\hline 4 & IPS & UT2 & $28 / 05 / 02$ & Swab Retal & E. faecium & A & Dominante & $\mathrm{NI}$ & VanA \\
\hline 5 & IPS & UT2 & $11 / 06 / 02$ & Swab Retal & E. faecium & A & Dominante & $\operatorname{van} A$ & VanA \\
\hline 6 & LOF & UT1 & $27 / 06 / 02$ & Swab Retal & E. faecium & A & Dominante & $\operatorname{van} A$ & $\operatorname{Van} A$ \\
\hline 7 & BS & UT2 & 01/07/02 & Swab Retal & E. faecium & A & Dominante & $\operatorname{van} A$ & VanA \\
\hline 8 & MPL & UT2 & 01/07/02 & Swab Retal & E. faecium & $\mathrm{A} 2$ & Estreit relac. & $\operatorname{Van} A$ & VanA \\
\hline 9 & IPS & UT2 & 01/07/02 & Swab Retal & E. faecium & A & Dominante & $\mathrm{NI}$ & VanA \\
\hline 10 & AJL & UT2 & 09/07/02 & Swab Retal & E. faecalis & $x$ & Não relac. & $\mathrm{NI}$ & VanA \\
\hline
\end{tabular}

Continua... 
Continuação Anexo 13

\begin{tabular}{|c|c|c|c|c|c|c|c|c|c|}
\hline No & $\begin{array}{l}\text { nome do } \\
\text { paciente }\end{array}$ & Unid & $\begin{array}{c}\text { data } \\
\text { coleta }\end{array}$ & Amostra & Espécie & \begin{tabular}{|c|} 
Padrão \\
PFGE \\
\end{tabular} & Tenover & PCR & Fenótipo \\
\hline 11 & IPS & UT2 & $15 / 07 / 02$ & Swab Retal & E. faecium & A & Dominante & $\operatorname{van} A$ & VanA \\
\hline 12 & AJL & UT2 & $15 / 07 / 02$ & Swab Retal & E. faecium & A & Estreit relac. & $\operatorname{van} A$ & VanA \\
\hline 13 & GMO & UD & $22 / 07 / 02$ & Swab Retal & E. faecium & A4 & Estreit relac. & $\mathrm{NI}$ & VanA \\
\hline 14 & IPS & UT2 & $22 / 07 / 02$ & Swab Retal & E. faecium & A5 & Estreit relac. & $\mathrm{NI}$ & $\operatorname{Van} A$ \\
\hline 15 & VFR & AMB & $26 / 07 / 02$ & Swab Retal & E. faecium & A & Dominante & $\mathrm{NI}$ & VanA \\
\hline 17 & MISA & UT2 & $17 / 02 / 03$ & Swab Retal & E. faecium & A & Estreit relac. & $\mathrm{NI}$ & VanA \\
\hline 18 & MTH & UT2 & $17 / 02 / 03$ & Swab Retal & E. faecium & A6 & Estreit relac. & $\mathrm{NI}$ & VanA \\
\hline 19 & OAS & UT2 & $24 / 02 / 03$ & Swab Retal & E. faecium & $\mathrm{D}$ & Não relac. & $\operatorname{van} A$ & VanA \\
\hline 20 & MISA & UT2 & $24 / 02 / 03$ & Swab Retal & E. faecium & A7 & Estreit relac. & $\mathrm{NI}$ & VanA \\
\hline 28 & $\mathrm{DC}$ & UT2 & $16 / 02 / 04$ & Swab Retal & E. faecium & A7 & Estreit relac. & $\mathrm{NI}$ & VanA \\
\hline 29 & OMZ & UT1 & $16 / 02 / 04$ & Swab Retal & E. faecium & A7 & Estreit relac. & $\mathrm{NI}$ & $\operatorname{Van} A$ \\
\hline 30 & AMR & UT2 & $01 / 03 / 04$ & Swab Retal & E. faecium & A9 & Não relac. & $\mathrm{NI}$ & VanA \\
\hline 31 & $\mathrm{DC}$ & UT2 & $01 / 03 / 04$ & Swab Retal & E. faecium & A8 & Estreit relac. & $\mathrm{NI}$ & $\operatorname{Van} A$ \\
\hline 32 & GMJ & UT2 & $01 / 03 / 04$ & Swab Retal & E. faecium & A9 & Estreit relac. & $\mathrm{NI}$ & VanA \\
\hline 33 & CDD & UD & $10 / 05 / 04$ & Swab Retal & E. faecalis & $Y$ & Não relac. & $\mathrm{NI}$ & VanA \\
\hline 34 & TCF & UT1 & $13 / 10 / 04$ & Swab Retal & E. faecalis & $\mathrm{A} 6$ & Não relac. & $\mathrm{NI}$ & VanA \\
\hline 35 & JFS & UT1 & $19 / 10 / 04$ & Swab Retal & E. faecalis & Y2 & Não relac. & $\mathrm{NI}$ & $\operatorname{Van} A$ \\
\hline 36 & OLF & UT1 & 03/01/05 & Swab Retal & E. faecalis & Y3 & Não relac. & $\mathrm{NI}$ & VanA \\
\hline 37 & GNG & UT2 & $01 / 02 / 05$ & Swab Retal & E. faecalis & Z & Não relac. & $\mathrm{NI}$ & VanA \\
\hline 38 & AAL & UT1 & 07/03/05 & Swab Retal & E. faecalis & Z & Não relac. & $\mathrm{NI}$ & VanA \\
\hline
\end{tabular}

Continua... 
Continuação Anexo 13

\begin{tabular}{|c|c|c|c|c|c|c|c|c|c|}
\hline No & $\begin{array}{l}\text { nome do } \\
\text { paciente }\end{array}$ & Unid & $\begin{array}{c}\text { data } \\
\text { coleta }\end{array}$ & Amostra & Espécie & \begin{tabular}{|c|} 
Padrão \\
PFGE \\
\end{tabular} & Tenover & PCR & Fenótipo \\
\hline 39 & AFR & UT1 & 07/03/05 & Swab Retal & E. faecalis & Z & Não relac. & $\mathrm{NI}$ & $\operatorname{Van} A$ \\
\hline 40 & LGN & UT2 & 07/03/05 & Swab Retal & E. faecalis & Z & Não relac. & $\mathrm{NI}$ & VanA \\
\hline 41 & JJS & EM & 09/03/05 & éc. Traqueal & E. faecalis & Z & Não relac. & $\mathrm{NI}$ & VanA \\
\hline 42 & JMS & UT1 & $14 / 03 / 05$ & Swab Retal & E. faecalis & Z & Não relac. & $\mathrm{NI}$ & $\operatorname{Van} A$ \\
\hline 43 & JRS & UT1 & $14 / 03 / 05$ & Swab Retal & E. faecalis & Z & Não relac. & $\mathrm{NI}$ & VanA \\
\hline 44 & OM & UT1 & $14 / 03 / 05$ & Swab Retal & E. faecalis & Z & Não relac. & $\mathrm{NI}$ & VanA \\
\hline 45 & OM & UT2 & $21 / 03 / 05$ & Swab Retal & E. faecalis & Z & Não relac. & $\mathrm{NI}$ & VanA \\
\hline 46 & EPF & UT1 & 28/03/05 & Swab Retal & E. faecalis & W & Dominante & $\mathrm{NI}$ & VanA \\
\hline 47 & MSL & UT1 & $28 / 03 / 05$ & Swab Retal & E. faecalis & W & Dominante & $\mathrm{NI}$ & VanA \\
\hline 48 & RLRF & UT1 & $28 / 03 / 05$ & Swab Retal & E. faecium & $\mathrm{B}$ & Dominante & $\mathrm{NI}$ & VanA \\
\hline 58 & $A C$ & UT2 & 07/08/05 & Swab Retal & E. faecium & B & Dominante & $\mathrm{NI}$ & $\operatorname{Van} A$ \\
\hline 61 & $A D$ & UT1 & 09/08/05 & Swab Retal & E. faecalis & Z & Não relac. & $\mathrm{NI}$ & VanA \\
\hline 59 & EM & UT2 & 09/08/05 & Swab Retal & E. faecium & $\mathrm{B}$ & Dominante & $\mathrm{NI}$ & VanA \\
\hline 60 & JM & UT2 & 09/08/05 & Swab Retal & E. faecium & $\mathrm{B}$ & Dominante & $\mathrm{NI}$ & VanA \\
\hline 73 & AFR & UT1 & $23 / 08 / 05$ & Swab Retal & E. faecalis & W & Dominante & $\mathrm{NI}$ & VanA \\
\hline 74 & $A C$ & UT2 & $23 / 08 / 05$ & Swab Retal & E. faecium & $\mathrm{B}$ & Dominante & $\mathrm{NI}$ & VanA \\
\hline 75 & MLN & UT1 & 23/08/05 & Swab Retal & E. faecium & B2 & Estreit relac. & Van A & $\operatorname{VanA}$ \\
\hline 77 & OM & UT1 & 29/08/05 & Swab Retal & E. faecalis & W & Dominante & $\mathrm{NI}$ & VanA \\
\hline 78 & OMP & UT1 & $30 / 08 / 05$ & Swab Retal & E. faecalis & W & Dominante & $\operatorname{van} A$ & VanA \\
\hline 79 & $\mathrm{CCM}$ & UT2 & $30 / 08 / 05$ & Swab Retal & E. faecium & $\mathrm{B}$ & Dominante & $\mathrm{NI}$ & VanA \\
\hline
\end{tabular}

Continua... 
Continuação Anexo 13

\begin{tabular}{|c|c|c|c|c|c|c|c|c|c|}
\hline No & $\begin{array}{l}\text { nome do } \\
\text { paciente }\end{array}$ & Unid & $\begin{array}{c}\text { data } \\
\text { coleta }\end{array}$ & Amostra & Espécie & \begin{tabular}{|c|} 
Padrão \\
PFGE \\
\end{tabular} & Tenover & PCR & Fenótipo \\
\hline 80 & MLN & UT2 & $30 / 08 / 05$ & Swab Retal & E. faecium & B2 & Estreit relac. & $\mathrm{NI}$ & $\operatorname{Van} A$ \\
\hline 96 & FHD & UT1 & $12 / 12 / 05$ & Swab Retal & E. faecium & $\mathrm{B}$ & Dominante & $\mathrm{NI}$ & VanA \\
\hline 110 & NP & UT2 & 03/04/06 & Swab Retal & E. faecium & $\mathrm{B}$ & Dominante & $\mathrm{NI}$ & VanA \\
\hline 112 & JDNMA & UT2 & $10 / 04 / 06$ & Swab Retal & E. faecium & $\mathrm{B}$ & Dominante & $\operatorname{van} A$ & $\operatorname{Van} A$ \\
\hline 115 & JM & UT2 & $10 / 04 / 06$ & Swab Retal & E. faecium & B2 & Estreit relac. & $\operatorname{van} A$ & VanA \\
\hline 116 & JSN & UT2 & $10 / 04 / 06$ & Swab Retal & E. faecium & B2 & Estreit relac. & $\operatorname{van} A$ & VanA \\
\hline 119 & GS & UT1 & $10 / 04 / 06$ & Swab Retal & E. faecium & $B$ & Dominante & $\mathrm{NI}$ & VanA \\
\hline 133 & JHF & UT1 & $10 / 04 / 06$ & Swab Retal & E. faecium & B2 & Estreit relac. & $\mathrm{NI}$ & VanA \\
\hline 136 & CPP & UT1 & $12 / 04 / 06$ & Swab Retal & E. faecium & $\mathrm{B}$ & Dominante & $\mathrm{NI}$ & VanA \\
\hline 138 & LO & UT2 & $17 / 04 / 06$ & Swab Retal & E. faecium & $\mathrm{B}$ & Dominante & $\mathrm{NI}$ & VanA \\
\hline 140 & JBS & UT1 & $17 / 04 / 06$ & Swab Retal & E. faecium & B2 & Estreit relac. & $\mathrm{NI}$ & $\operatorname{Van} A$ \\
\hline 141 & MIGN & UT1 & $24 / 04 / 06$ & Swab Retal & E. faecium & $\mathrm{B}$ & Dominante & $\mathrm{NI}$ & VanA \\
\hline 167 & AMF & UT2 & $26 / 03 / 07$ & Swab Retal & E. faecium & $\mathrm{B}$ & Dominante & $\mathrm{NI}$ & $\operatorname{Van} A$ \\
\hline 169 & CSS & UT1 & $26 / 03 / 07$ & Swab Retal & E. faecium & $\mathrm{B}$ & Dominante & $\mathrm{NI}$ & VanA \\
\hline 170 & LLO & UT2 & $26 / 03 / 07$ & Swab Retal & E. faecium & $\mathrm{B}$ & Dominante & $\mathrm{NI}$ & VanA \\
\hline 171 & $\mathrm{MZ}$ & UT1 & $26 / 03 / 07$ & Swab Retal & E. faecium & $\mathrm{B}$ & Dominante & $\mathrm{NI}$ & $\operatorname{Van} A$ \\
\hline 206 & JR & UT2 & $02 / 05 / 07$ & Swab Retal & E. faecium & B7 & Estreit relac. & $\mathrm{NI}$ & $\operatorname{VanA}$ \\
\hline 207 & MBP & PED & 03/05/07 & Swab Retal & E. avium & $\mathrm{L}$ & Não relac. & $\mathrm{NI}$ & $\operatorname{Van} A$ \\
\hline 213 & JR & UT2 & $28 / 05 / 07$ & Swab Retal & E. faecium & B7 & Estreit relac. & $\mathrm{NI}$ & VanA \\
\hline 215 & ASS & UT2 & $16 / 07 / 07$ & Swab Retal & E. faecium & B7 & Estreit relac. & $\mathrm{NI}$ & VanA \\
\hline
\end{tabular}

Continua... 
Continuação Anexo 13

\begin{tabular}{|c|c|c|c|c|c|c|c|c|c|}
\hline No & $\begin{array}{l}\text { nome do } \\
\text { paciente }\end{array}$ & Unid & $\begin{array}{c}\text { data } \\
\text { coleta }\end{array}$ & Amostra & Espécie & \begin{tabular}{|c|} 
Padrão \\
PFGE \\
\end{tabular} & Tenover & PCR & Fenótipo \\
\hline 216 & BVC & UT1 & $16 / 07 / 07$ & Swab Retal & E. faecium & B7 & Estreit relac. & $\mathrm{NI}$ & VanA \\
\hline 217 & BVC & UT1 & $16 / 07 / 07$ & Swab Retal & E. faecium & B7 & Estreit relac. & $\mathrm{NI}$ & VanA \\
\hline 218 & MAF & UT1 & $16 / 07 / 07$ & Swab Retal & E. faecium & B7 & Estreit relac. & $\mathrm{NI}$ & $\operatorname{VanA}$ \\
\hline 219 & $\mathrm{VH}$ & UT1 & $16 / 07 / 07$ & Swab Retal & E. faecium & B7 & Estreit relac. & $\mathrm{NI}$ & VanA \\
\hline 220 & ARSC & AMB & $18 / 07 / 07$ & Swab Retal & E. faecium & B7 & Estreit relac. & $\mathrm{NI}$ & VanA \\
\hline 230 & $\mathrm{CN}$ & UT2 & & Swab Retal & E. faecalis & W & Dominante & $\operatorname{van} \mathrm{A}$ & VanA \\
\hline 231 & MRPS & UT2 & & Swab Retal & E. faecalis & W & Dominante & $\mathrm{NI}$ & VanA \\
\hline 16 & CS & UT2 & $17 / 02 / 03$ & secr purulenta & E. faecium & A7 & Estreit relac. & Van A & VanA \\
\hline 27 & ALS & UT2 & 07/04/03 & Urina & E. durans / hirae & M & Não relac. & $\mathrm{NI}$ & VanA \\
\hline 53 & WGA & EM & 08/06/05 & Urina & E. faecium & $\mathrm{B}$ & Dominante & $\mathrm{NI}$ & VanA \\
\hline 54 & JPG & UT2 & $22 / 07 / 05$ & Urina & E. faecium & B6 & Estreit relac. & $\mathrm{NI}$ & $\operatorname{Van} A$ \\
\hline 55 & EJA & UT2 & $26 / 07 / 05$ & secr purulenta & E. faecium & B & Dominante & $\mathrm{NI}$ & VanA \\
\hline 56 & RGB & UT2 & $28 / 07 / 05$ & Urina & E. faecium & $\mathrm{B}$ & Dominante & $\mathrm{NI}$ & $\operatorname{Van} A$ \\
\hline 57 & MFM & OS & 02/08/05 & Sangue & E. faecium & $\mathrm{B}$ & Dominante & $\mathrm{NI}$ & VanA \\
\hline 72 & OAD & UD & $22 / 08 / 05$ & Secreção & E. faecium & $\mathrm{B}$ & Dominante & $\mathrm{NI}$ & VanA \\
\hline 76 & VS & EM & $24 / 08 / 05$ & Urina & E. faecalis & W & Dominante & $\mathrm{NI}$ & $\operatorname{Van} A$ \\
\hline 81 & MLN & UT2 & 02/09/05 & Secreção pe & E. faecium & B2 & Estreit relac. & $\operatorname{Van} A$ & VanA \\
\hline 82 & SM & UT1 & 05/09/05 & Sangue & E. faecalis & W1 & Estreit relac. & $\mathrm{NI}$ & VanA \\
\hline 83 & TMF & UT1 & 06/09/05 & Sangue & E. faecium & $\mathrm{B}$ & Dominante & $\mathrm{NI}$ & VanA \\
\hline 84 & RAA & EM & $13 / 09 / 05$ & secr purulenta & E. faecium & B2 & Estreit relac. & Van A & VanA \\
\hline
\end{tabular}

Continua... 
Continuação Anexo 13

\begin{tabular}{|c|c|c|c|c|c|c|c|c|c|}
\hline No & $\begin{array}{l}\text { nome do } \\
\text { paciente }\end{array}$ & Unid & $\begin{array}{c}\text { data } \\
\text { coleta }\end{array}$ & Amostra & Espécie & \begin{tabular}{|c|} 
Padrão \\
PFGE \\
\end{tabular} & Tenover & PCR & Fenótipo \\
\hline 85 & GMC & AMB & $26 / 09 / 05$ & Urina & E. faecium & $\mathrm{B}$ & Dominante & $\mathrm{NI}$ & VanA \\
\hline 86 & GMC & EF & 26/09/05 & Urina & E. faecium & $\mathrm{B}$ & Dominante & $\mathrm{NI}$ & VanA \\
\hline 87 & AAS & UT2 & $27 / 09 / 05$ & Ponta de Cateter & E. faecium & $\mathrm{B}$ & Dominante & $\mathrm{NI}$ & VanA \\
\hline 88 & AV & EM & $17 / 10 / 05$ & Urina & E. faecium & $\mathrm{B}$ & Dominante & $\mathrm{NI}$ & VanA \\
\hline 89 & $\mathrm{HB}$ & UT2 & $18 / 10 / 05$ & Urina & E. faecium & $\mathrm{B}$ & Dominante & $\mathrm{NI}$ & VanA \\
\hline 90 & GSV & UT2 & $31 / 10 / 05$ & Urina & E. faecium & B6 & Estreit relac. & $\operatorname{van} A$ & VanA \\
\hline 91 & MVS & UT2 & 09/11/05 & Urina & E. faecium & $\mathrm{B}$ & Dominante & $\mathrm{NI}$ & VanA \\
\hline 92 & AML & EF & $18 / 11 / 05$ & Urina & E. faecium & $\mathrm{B}$ & Dominante & $\mathrm{NI}$ & VanA \\
\hline 93 & CAF & UT1 & $23 / 11 / 05$ & Sangue & E. faecium & $\mathrm{B}$ & Dominante & $\mathrm{NI}$ & VanA \\
\hline 95 & JMV & UT2 & $30 / 11 / 05$ & Sangue & E. faecium & $\mathrm{B}$ & Dominante & $\mathrm{NI}$ & VanA \\
\hline 94 & JAA & EM & $30 / 11 / 05$ & Urina & E. faecium & B & Dominante & $\mathrm{NI}$ & $\operatorname{Van} A$ \\
\hline 97 & JMV & UT2 & $14 / 12 / 05$ & Sangue & E. faecalis & W & Dominante & $\operatorname{van} A$ & VanA \\
\hline 98 & $\mathrm{CRC}$ & UT2 & $15 / 12 / 05$ & Urina & E. faecium & $\mathrm{B}$ & Dominante & $\mathrm{NI}$ & VanA \\
\hline 99 & GB & EM & $20 / 12 / 05$ & Urina & E. faecium & B2 & Estreit relac. & $\mathrm{NI}$ & VanA \\
\hline 100 & GB & EM & $26 / 12 / 05$ & Urina & E. faecium & W & Dominante & $\mathrm{NI}$ & VanA \\
\hline 102 & JMV & EM & 03/01/06 & Sangue & E. faecium & $\mathrm{B}$ & Dominante & $\mathrm{NI}$ & VanA \\
\hline 103 & ANE & PS & 09/01/06 & Urina & E. faecium & B & Dominante & $\mathrm{NI}$ & VanA \\
\hline 104 & LS & $\mathrm{Ml}$ & $20 / 01 / 06$ & Urina & E. faecium & $\mathrm{B}$ & Dominante & $\mathrm{NI}$ & VanA \\
\hline 105 & ccs & EF & $23 / 01 / 06$ & Urina & E. faecium & $\mathrm{B}$ & Dominante & $\mathrm{NI}$ & VanA \\
\hline 106 & JDNMA & UT2 & $23 / 01 / 06$ & Urina & E. faecium & $\mathrm{B}$ & Dominante & $\mathrm{NI}$ & VanA \\
\hline
\end{tabular}

Continua... 
Continuação Anexo 13

\begin{tabular}{|c|c|c|c|c|c|c|c|c|c|}
\hline No & $\begin{array}{l}\text { nome do } \\
\text { paciente }\end{array}$ & Unid & $\begin{array}{c}\text { data } \\
\text { coleta }\end{array}$ & Amostra & Espécie & \begin{tabular}{|c|} 
Padrão \\
PFGE \\
\end{tabular} & Tenover & PCR & Fenótipo \\
\hline 108 & LLG & PS & $20 / 02 / 06$ & Urina & E. faecalis & W1 & Estreit relac. & $\mathrm{NI}$ & $\operatorname{Van} A$ \\
\hline 107 & LS & $\mathrm{Ml}$ & $20 / 02 / 06$ & Urina & E. faecium & $\mathrm{B}$ & Dominante & $\mathrm{NI}$ & VanA \\
\hline 109 & MCLA & EF & $02 / 03 / 06$ & Urina & E. faecium & $\mathrm{B}$ & Dominante & $\mathrm{NI}$ & VanA \\
\hline 137 & JM & UT2 & $17 / 04 / 06$ & Sangue & E. faecalis & W & Dominante & $\mathrm{NI}$ & VanA \\
\hline 139 & NP & UT1 & $17 / 04 / 06$ & Urina & E. faecium & $\mathrm{B}$ & Dominante & $\mathrm{NI}$ & VanA \\
\hline 142 & $\mathrm{CC}$ & UT2 & 02/06/06 & Urina & E. faecium & $\mathrm{B}$ & Dominante & $\mathrm{NI}$ & VanA \\
\hline 143 & DMM & UT1 & 07/07/06 & Urina & E. faecium & $B$ & Dominante & $\mathrm{NI}$ & VanA \\
\hline 144 & FPC & UT2 & $15 / 07 / 06$ & Sangue & E. faecalis & W & Dominante & $\mathrm{NI}$ & VanA \\
\hline 145 & FPC & EF & $18 / 07 / 06$ & Urina & E. faecium & B2 & Estreit relac. & $\mathrm{NI}$ & VanA \\
\hline 146 & FLB & UT1 & 19/07/06 & Urina & E. faecium & B3 & Estreit relac. & $\mathrm{NI}$ & VanA \\
\hline 147 & BM & UT2 & $20 / 07 / 06$ & Ponta de Cateter & E. faecium & $\mathrm{B}$ & Dominante & $\mathrm{NI}$ & $\operatorname{Van} A$ \\
\hline 148 & JV & UT2 & $20 / 07 / 06$ & Sangue & E. faecium & $\mathrm{B}$ & Dominante & $\mathrm{NI}$ & VanA \\
\hline 149 & FPC & UT2 & $26 / 07 / 06$ & Urina & E. faecium & $\mathrm{B}$ & Dominante & $\mathrm{NI}$ & $\operatorname{Van} A$ \\
\hline 150 & JMS & PS & $01 / 08 / 06$ & Urina & E. faecium & $\mathrm{B}$ & Dominante & $\mathrm{NI}$ & $\operatorname{Van} A$ \\
\hline 151 & MS & UT2 & $18 / 10 / 06$ & Urina & E. faecium & $\mathrm{B}$ & Dominante & $\mathrm{NI}$ & VanA \\
\hline 152 & MS & EF & $25 / 10 / 06$ & Sangue & E. faecium & $\mathrm{B}$ & Dominante & $\mathrm{NI}$ & $\operatorname{Van} A$ \\
\hline 153 & LAS & EF & $30 / 10 / 06$ & Urina & E. faecium & B2 & Estreit relac. & $\mathrm{NI}$ & VanA \\
\hline 154 & JRS & UT1 & $03 / 11 / 06$ & secr purulenta & E. faecium & B2 & Estreit relac. & $\mathrm{NI}$ & VanA \\
\hline 155 & AGV & EM & $20 / 11 / 06$ & Urina & E. faecium & G & Não relac. & $\mathrm{NI}$ & VanA \\
\hline 156 & GCS & EF & $30 / 11 / 06$ & Urina & E. faecium & B2 & Estreit relac. & $\mathrm{NI}$ & VanA \\
\hline
\end{tabular}

Continua... 
Continuação Anexo 13

\begin{tabular}{|c|c|c|c|c|c|c|c|c|c|}
\hline No & $\begin{array}{l}\text { nome do } \\
\text { paciente }\end{array}$ & Unid & $\begin{array}{c}\text { data } \\
\text { coleta }\end{array}$ & Amostra & Espécie & \begin{tabular}{|c|} 
Padrão \\
PFGE \\
\end{tabular} & Tenover & PCR & Fenótipo \\
\hline 157 & GLC & UT1 & $04 / 12 / 06$ & Sangue & E. faecalis & W & Dominante & $\mathrm{NI}$ & $\operatorname{Van} A$ \\
\hline 158 & os & UT1 & $04 / 12 / 06$ & Sangue & E. faecium & B4 & Estreit relac. & $\mathrm{NI}$ & VanA \\
\hline 159 & MRPS & MI & $01 / 01 / 07$ & Sangue & E. faecalis & W & Dominante & $\operatorname{van} A$ & VanA \\
\hline 160 & MRPS & MI & 02/01/07 & Sangue & E. faecalis & W & Dominante & $\mathrm{NI}$ & VanA \\
\hline 162 & MRPS & EF & 04/01/07 & Sangue & E. faecalis & W & Dominante & $\operatorname{van} A$ & VanA \\
\hline 161 & AMO & OS & 04/01/07 & Urina & E. faecium & $\mathrm{B}$ & Dominante & $\operatorname{van} A$ & VanA \\
\hline 163 & LMA & OS & $02 / 02 / 07$ & Urina & E. durans / hirae & M & Não relac. & $\mathrm{NI}$ & VanA \\
\hline 164 & MAS & EF & $05 / 02 / 07$ & Urina & E. faecium & B7 & Estreit relac. & Van A & VanA \\
\hline 165 & LRSF & AMB & $13 / 03 / 07$ & Urina & E. faecium & B7 & Estreit relac. & Van A & VanA \\
\hline 166 & PMA & EM & $16 / 03 / 07$ & Urina & E. faecium & B7 & Estreit relac. & $\operatorname{Van} A$ & VanA \\
\hline 168 & AMF & UT2 & $26 / 03 / 07$ & Urina & E. faecium & B7 & Estreit relac. & Van A & $\operatorname{Van} A$ \\
\hline 172 & MFBS & UT2 & $27 / 03 / 07$ & Urina & E. faecium & B7 & Estreit relac. & $\operatorname{Van} \mathrm{A}$ & $\operatorname{Van} A$ \\
\hline 173 & NVSS & PED & $29 / 03 / 07$ & Urina & E. faecium & B7 & Estreit relac. & Van A & VanA \\
\hline 186 & BPA & UT2 & $11 / 04 / 07$ & Sangue & E. faecium & $\mathrm{B}$ & Dominante & $\operatorname{van} A$ & VanA \\
\hline 187 & VS & AMB & $14 / 04 / 07$ & Urina & E. faecium & $\mathrm{B}$ & Dominante & $\operatorname{van} A$ & VanA \\
\hline 188 & PMA & EM & $17 / 04 / 07$ & Urina & E. faecium & $\mathrm{F}$ & Não relac. & $\mathrm{NI}$ & VanA \\
\hline 189 & PMA & EM & $24 / 04 / 07$ & Urina & E. faecium & B7 & Estreit relac. & Van A & VanA \\
\hline 191 & PMA & EM & $25 / 04 / 07$ & Urina & E. faecium & B7 & Estreit relac. & Van A & VanA \\
\hline 198 & MVPCB & AMB & $27 / 04 / 07$ & Urina & E. faecium & $E$ & Não relac. & Van A & VanA \\
\hline 202 & ERL & $\mathrm{Ml}$ & $27 / 04 / 07$ & Urina & E. faecium & B5 & Estreit relac. & $\mathrm{NI}$ & VanA \\
\hline
\end{tabular}

Continua... 
Conclusão Anexo 13

\begin{tabular}{|c|c|c|c|c|c|c|c|c|c|}
\hline No & $\begin{array}{l}\text { nome do } \\
\text { paciente }\end{array}$ & Unid & $\begin{array}{c}\text { data } \\
\text { coleta }\end{array}$ & Amostra & Espécie & \begin{tabular}{|c|} 
Padrão \\
PFGE \\
\end{tabular} & Tenover & PCR & Fenótipo \\
\hline 208 & JGC & EM & $15 / 05 / 07$ & Urina & E. faecium & B7 & Estreit relac. & $\operatorname{van} A$ & VanA \\
\hline 209 & JLAF & EM & $16 / 05 / 07$ & Urina & E. faecalis & W & Dominante & $\operatorname{van} A$ & VanA \\
\hline 210 & JGC & UT1 & $21 / 05 / 07$ & Urina & E. faecalis & W & Dominante & $\operatorname{van} \mathrm{A}$ & VanA \\
\hline 211 & JLAF & EM & $22 / 05 / 07$ & Urina & E. faecalis & W & Dominante & $\mathrm{NI}$ & VanA \\
\hline 212 & AAS & UT2 & $25 / 05 / 07$ & Urina & E. faecalis & W & Dominante & $\mathrm{NI}$ & VanA \\
\hline 214 & $\mathrm{CB}$ & EM & $29 / 05 / 07$ & Urina & E. faecium & $B$ & Dominante & $\operatorname{van} A$ & VanA \\
\hline 225 & PJ & UT1 & $30 / 07 / 07$ & Ponta de Cateter & E. faecium & B & Dominante & $\operatorname{van} A$ & VanA \\
\hline 226 & PAAD & EM & $31 / 07 / 07$ & Urina & E. faecium & B7 & Estreit relac. & $\operatorname{van} A$ & VanA \\
\hline 227 & JAF & PS & $07 / 08 / 07$ & Urina & E. faecium & B7 & Estreit relac. & $\operatorname{van} \mathrm{A}$ & VanA \\
\hline 228 & $\mathrm{JR}$ & PS & $14 / 08 / 07$ & Urina & E. faecium & $\mathrm{N}$ & Não relac. & $\operatorname{van} A$ & VanA \\
\hline 229 & $\mathrm{JM}$ & UT2 & $15 / 08 / 07$ & Sangue & E. faecium & B & Dominante & $\operatorname{van} A$ & VanA \\
\hline
\end{tabular}

Legenda: PS- Pronto Socorro, EM- Enfermaria Masculina, EF- Enfermaria Feminina, UT1- Unidade de Terapia Intensiva 1, UT2- Unidade de Terapia intensiva 2, NI- não investigado. Clone A: E.faecium, Clone B: E. faecium, Clone Z: E. faecalis, Clone W: E. faecalis, Critérios de Tenover: Dominante, Estritamente relacionado, Não relacionado. 
8. REFERÊNCIAS 
Almeida FP, Martino MDV, Silva JR M, Corrêa L, Silbert S. Surto de enterococo resistente a vancomicina (ERV) em uma unidade de terapia intensiva de adulto . VI Congresso Pan-Americano e X Congresso Brasileiro de Controle de Infecção e Epidemiologia Hospitalar. Porto Alegre; 2006. Res.522.

Almuneef MA, Baltimore RS, Farrel PA, Reagan-Cirincione P, Dembry LM. Molecular typing demonstrating transmission of gram-negative rods in a neonatal intensive care unit in the absence of a recognized epidemic. Clin Infect Dis. $2001 ; 32: 220-7$.

Armstrong-Evans M, Litt M, McArthur MA, Willey B, Cann D, Liska S, Nusinowitz S, Gould R, Blacklock A, Low D E. Control of transmission of vancomycin-resistant Enterococcus faecium in a long-term-care facility. Infect Control Hosp Epidemiol .1999;20:312-7.

Arthur M, Depardieu F, Cabanié L, Reynolds P, Courvalin P. Requirement of the VanY and VanX D,D-peptidases for glycopeptide resistance in enterococci. Mol Microbiol. 1998;30:819-30. 
Arthur M, Courvalin P.Genetics and mechanisms of glycopeptide resistance in enterococci. Antimicrob Agents Chemother. 1993 Aug;37:1563-71.

Austin DJ, Bonten MJ, Weinstein RA, Slaughter S, Anderson RM. Vancomycin-resistant enterococci in intensive-care hospital settings: transmission dynamics, persistence, and the impact of infection control programs. Proc Natl Acad Sci USA 1999; 96:6908-13.

Bhalla A, Pultz NJ, Gries DM, Ray AJ, Eckstein EC, Aron DC, Donskey CJ. Acquisition of nosocomial pathogens on hands after contact with environmental surfaces near hospitalized patients. Infect Control Hosp Epidemiol. 2004; 25:164-7.

Biendenbach DJ, Moet GJ, Jones RN. Occurrence and antimicrobial resistance pattern comparisons among bloodstream infection isolates from the SENTRY Antimicrobial Surveillance Program (1997-2002). Diagn Microbiol Infect Dis. 2004;50:59-69.

Bischoff WE, Reynolds TM, Sessler CN, Edmond MB, Wenzel RP. Handwashing compliance by health care workers: the impact of introducing an accessible, alcohol-based hand antiseptic. Arch Intern Med. 2000;160:1017-21. 
Bodnar UR, Noskin GA, SurianoT, Cooper, Isenberg BE, Peterson LR. Use of in-house studies of molecular epidemiology and full species identification for controlling spread of vancomycin-resistant Enterococcus faecalis isolates. J Clin Microbiol. 1996;34:2129-32.

Boisivon A, Thibault M, Leclerq R. Colonization by vancomycin-resistant enterococci of the intestinal tract of patients in intensive care units from French general hospitals. Clin Microbiol Infect. 1997;3:175-9.

Bonilla HF, Zervos MA, Lyons MJ, Bradley Sf, Hedderwick Sa, Ramsey MA, Paul LK, Kauffman CA. Colonization with vancomycin-resistant Enterococcus faecium: comparison of a long-term-care unit with an acute-care hospital. Infect Control Hosp Epidemiol 1997; 18:333-9.

Bonten MJM, Hayden MK, Nathan C, van Voorthis J, Matushek M, Slaughter S, Rice T, Weinstein RA. Epidemiology of colonisation of patients and environment with vancomycin-resistant enterococci. Lancet 1996;348(9042):1615-9.

Bonten MJM, Willems R, Weinstein RA. Vancomycin-resistant enterococci: why are they here and where do they come from? Lancet Infect Dis. $2001 ; 1: 314-25$ 
Boyce JM, Opal SM, Chow JW, Zervos MJ, Potter-Bynoe G, Sherman CB, Romulo RL, Fortna S, Medeiros AA. Outbreak of multidrug-resistant Enterococcus faecium with transferable vanB class vancomycin resistance. $J$ Clin Microbiol 1994;32:1148-53.

Boyce JM, Mermel LA, Zvreos MJ, Rice LB, Potter-Bynoe G, Giorgio C, Medeiros AA. Controlling vancomycin-resistant enterococci. Infection Control Hosp Epidemiol. 1995;16:634-7.

Boyce J.M. Vancomycin-resistant Enterococcus detection, epidemiology and control measures. Infect Dis Clin North Am.1997;11: 367-84.

Boyce JM. Environmental contamination makes an important contribution to hospital infection. J Hosp Infect. 2007; 65(S2):50-4.

Boyd DA, Du T, Hizon R, Kaplen B, Murphy T, Tyler S, Brown S, Jamieson F, Weiss K, Mulvey MR. VanG-type vancomycin-resistant Enterococcus faecalis strains isolated in Canada. Antimicrob Agents Chemother. 2006;50:2217-21.

Brinsley K, Srinivasan A, Sinkowitz-Cochran R, Lawton R, Mclntyre R, Kravitz G, Burke B, Shadowen R, Cardo D. Implementation of the campaign to prevent antimicrobial resistance in healthcare settings: 12 Steps to prevent antimicrobial resistance among hospitalized adults: experiences from 3 institutions. Am J Infect Control. 2005;33;53-4. 
Brown DF, Brown NM, Cookson BD, Duckworth G, Farrington M, French GL, King L, Lewis D, Livermore DM, Macrae B, Scott GM, Williams D, Woodford N. National glycopeptide-resistant enterococcal bacteraemia surveillance Working Group Report to the Department of Health - August 2004. J Hosp Infect. 2006;62 (Suppl 1):S1-27.

Byers KE, Anglim AM, Anneski CJ, Germanson TP, Simonton BM, Farr BM. A hospital epidemic of vancomicin-resistant Enterococcus: risk factors and control. Infect Control Hosp Epidemiol. 2001;22:140-7.

Byers KE, Anglim AM, Anneski CJ, Farr BM. Duration of colonization with vancomycin-resistant Enterococcus. Infect Control Hosp Epidemiol.2002;23:207-11.

Caiaffa Filho HH, Almeida GD, Oliveira GA, Sarahyba L, Mamizuka EM, Burattini MN. Caiaffa Filho H, Almeida G, Oliveira G, Sarahyba L, Mamizuka E, Burattini M. Molecular characterization of van genes found in vancomycinresistant Enterococcus spp. isolated from the Hospital das Clinicas, FMUSP, Sao Paulo, Brazil. Braz J Infect Dis. 2003;7:173-4.

Camargo II, Del Pelozo PF, Da Costa Leite CF, Goldman GH, Darini AL. Identification of an unusual VanA element in glycopeptide-resistant Enterococcus faecium in Brazil following international transfer of a bone marrow transplant patient. Can J Microbiol. 2004; 50:767-70. 
Camargo IL, Zanella RC, Brandileone MC, Pignatari AC, Goldman GH, Woodford N, Darini AL. Ocurrence of insertion sequences within the genomes and Tn1546-like elements of glycopeptide-resistant enterococci isolated in Brazil and identification of a novel element, ISZEfa5. Int J Microbiol. 2005;294:519-9.

Carias LL, Rudin SD, Donskey CJ, Rice LB. Genetic linkage and cotransfer of a novel, vanB-containing transposon (Tn5382) and a low-affinity penicillinbinding protein 5 gene in a clinical vancomycin-resistant Enterococcus faecium isolate. J Bacteriol. 1998;180:4426-34.

Carling PC, Von S, Kimc P, Woods C. Intensive care unit environmental cleaning: an evaluation in sixteen hospitals using a novel assessment tool. $J$ Hosp Infect. 2008;68:39-44.

Carmeli Y, Samore MH, Huskins $\mathrm{C}$. The association between antecedent vancomycin treatment and hospital-acquired vancomycin-resistant enterococci: a meta-analysis. Arch Intern Med.1999;159:2461-8.

Carter RJ, Sorenson G, Heffernan R, Kiehlbauch JA, Kornblum JS, Leggiadro R J, Nixon LJ, Wertheim WA, Whitney C G, Layton M. Infect failure to control an outbreak of multidrug-resistant Streptococcus pneumoniae in a long-termcare facility: emergence and ongoing transmission of a fluoroquinolone-resistant strain. Control Hosp Epidemiol. 2005;26:248-55. 
Centers for Disease Control and Prevention-CDC. Recommendations for preventing the spread of vancomycin resistance. Recommendations of the Hospital Infection Control Practices Advisory Committee (HICPAC). MMWR Recomm Rep. 1995;44 (RR12):1-13.

Centers for Disease Control and Prevention-CDC. Staphylococcus aureus with reduced susceptibility to vancomycin- United States, 1997. MMWR-Morb Mortal Wkly Rep. 1997;46:765-6.

Centers for Disease Control and Prevention-CDC. Staphylococcus aureus resistant to vancomycin-United States, 2002. MMWR-Morb Mortal Wkly Rep. 2002a;51:565-7.

Centers for Disease Control and Prevention-CDC. Staphylococcus aureus resistant to vancomycin-Pennsylvania, 2002. MMWR-Morb Mortal Wkly Rep. $2002 b ; 51: 902$.

Centers for Disease Control and Prevention-CDC. Guideline for Hand Hygiene in Health-Care Settings: recommendations of the Healthcare Infection Control Practices Advisory Committee and the HICPAC/SHEA/APIC/IDSA Hand Hygiene Task Force. MMWR-Morb Mortal Wkly Rep. 2002c; 51(RR-16):1-44. 
Centers for Disease Control and Prevention-CDC. Guidelines for Environmental Infection Control in Health-Care Facilities. Recommendations of CDC and the Health Care Infection Control Prectices. Advisory Committee (HICPAC). CDC MMWR-Morb Mortal Wkly Rep. 2003;52;(RR10):1-42.

Centers for Disease Control and Prevention-CDC. Vancomycin-resistant Staphylococcus aureus-New York, 2004. MMWR-Morb Mortal Wkly Rep. 2004a;53:322-3.

Cereda RF, Gales AC, Silbert S, Ones RN, Sader HS. Molecular typing and antimicrobial susceptibility of vancomycin-resistant Enterocccus faecalis in Brazil. Infect Control Hosp Epidemiol. 2002;23:19-22.

Cetinkaya Y, Falk P, Mayhall GC. Vancomycin-resistant Enterococci. Clin Microbial Rev. 2000;13:686-707.

Chavers LS, Moser SA, Benjamin WH, Banks SE, Steinhauer JR, Smith AM, Johnson CN, Funkhouser E, Chavers LP, Stamm AM, Waites KB. Vancomycin-resistant enterococci: 15 years and counting. J Hosp Infect. 2003;53:159-71.

Christiansen KJ, Tibbett PA, Beresford W, Pearman JW, Lee RC, Coombs GW, Kay ID, O'Brien FG, Palladino S, Douglas CR, Montgomery PD, Orrell T, Peterson AM, Kosaras FP, Flexman JP, Heath CH, McCullough CA. 
Eradication of a large outbreak of a single strain of vanB vancomycinresistant Enterococcus faecium at a major Australian teaching hospital. Infect Control Hosp Epidemiol. 2004;25:384-90

Clinical Laboratory Standards Institute. Performance standards for Antimicrobial susceptibility testing: Seventh Informational Supplement M100S17. CLSI, Wayne, Pennsylvania USA; 2007.

Colak D, Naas T, Gunseren F, Fortineau N, Ogunc D, Gultekin M, Nordmann P. First outbreak of vancomycin-resistant enterococci in a tertiary hospital in Turkey. J Antimicrob Chemother. 2002;50:397-401.

Cookson BD, Macrae MB, Barrett SP, Brown DF, Chadwick C, French GL, Hateley P, Hosein IK, Wade JJ; Combined Working Party of the Hospital Infection Society and Infection Control Nurses Association. Guidelines for the control of glycopeptide-resistant enterococci in hospitals.J Hosp Infect. 2006;62:6-21.

D`Azevedo, PA, Kacman SB, Schmalfuss T, Rodrigues LF. Primeiro caso de Enterococos resistente a vancomicina isolado de Porto alegre, RS. J Bras Patol Med Lab. 2000; 36:258.

de Bruin MA, Riley LW. Does vancomycin prescribing intervention affect vancomycin-resistant enterococcus infection and colonization in hospitals? A systematic review. BMC Infect Dis. 2007; 10:7:24. 
Dalla Costa, L.M, Souza DC, Martins LT, Zanella RC, Brandilone MC, Bokermann S, Sader HS, Souza HA. Vancomycin-Resistant Enterococcus faecium: first case in Brazil. Braz J Infect Dis . 1998;2:160-3.

DeLisle S, Perl TM. Vancomycin-resistant enterococci: a road map on how to prevent the emergence and transmission of antimicrobial resistance. Chest. 2003;123 Suppl 5:504-18.

Denton M, Wilcox MH, Parnell P, Green D, Keer V, Hawkey PM, Evans I, Murphy P. Role of environmental cleaning in controlling an outbreak of Acinetobacter baumannii on a neurosurgical intensive care unit. J Hosp Infect. 2004:56:106-10.

Deshpande LM, Fritsche TR, Moet GJ, Biendenbach DJ, Jones RN. Antimicrobial resistance and molecular epidemiology of vancomycin-resistant enterococci from North America and Europe: a report from the SENTRY antimicrobial surveillance program. Diagn Microbiol Infect Dis. 2000;58:163-70.

Depardieu F, Perichon B, Courvalin P. Detection of the van alphabet and identification of enterococci and staphylococci at the species level by multiplex PCR. J Clin Microbiol. 2004;42:5857-60

Donskey CJ, Hoyen CK, Das SM, Helfand MS, Hecker MT. Recurrence of vancomycin-resistant Enterococcus stool colonization during antibiotic therapy. Infect Control Hosp Epidemiol. 2002;23:436-40. 
Drees M, Snydman DR, Schmid CH, Barefoot L, Hansjosten K, Vue PM, Cronin M, Nasraway SA, Golan Y. Prior Environmental Contamination Increases the Risk of Acquisition of Vancomycin-Resistant Enterococci. Clin Infect Dis. 2008; 46:678-85.

Duckro AN, Blom DW, Lyle EA, Weinstein RA, Hayden MK.Transfer of vancomycin-resistant enterococci via health care worker hands. Arch Intern Med. 2005;165:302-7.

Dutka-Malen SS, Evers P. Courvalin. 1995. Detection of glycopeptide resistance genotypes and identification to the species level of clinically relevant enterococci by PCR. J Clin. Microbiol. 1995;33:24-7.

Eckstein BC, Adams DA, Eckstein EC, Rao A, Sethi AK, Yadavalli GK, Donskey CJ. Reduction of Clostridium difficile and vancomycin-resistant Enterococcus contamination of environmental surfaces after an intervention to improve cleaning methods. BMC Infect Dis. 2007;7:61.

Falk PS, Winnike J, Woodmansee C. Outbreak of vancomycin-resistant enterococci in a burn unit. Infect Control Hosp Epidemiol. 2000; 21:575-82.

Ferraz C.R, Santos LCG, Pérez MA, Moreira S. Prevalência de colonização/infecção por VRE em pacientes submetidos ao programa de terapia renal substitutiva. VI Congresso Pan-Americano e $X$ Congresso Brasileiro de Controle de Infecção e Epidemiologia Hospitalar, Porto Alegre; 2006. Res. 533 
Fines M, Perichon B, Reynolds P, Van E, A new type of acquired glycopeptide resistance in Enterococcus faecalis BM4405. Antimicrob. Agents Chemother 1999;43:2161-4.

Foca M, Jakob K, Whittier S, Della Latta P, Factor S, Rubenstein D, Saiman L. Endemic Pseudomonas aeruginosa infection in a neonatal intensive care unit. N Engl J Med. 2000;343:695-700.

Freitas MC, Pacheco-Silva A, Barbosa D. Silbert S, Sader H, Sesso R, Camargo LF. Prevalence of vancomycin-resistant Enterococcus fecal colonization among kidney transplant patients. BMC Infect Dis. 2006;6:133.

Fridkin SK, Lawton R, Edwards JR, Tenover FC, McGowan JE Jr, Gaynes RP. Monitoring antimicrobial use and resistance: comparison with a national benchmark on reducing vancomycin use and vancomycin-resistant enterococci. Emerg Infect Dis. 2002; 8:702-7.

Fry AM, Udeagu CC, Soriano-Gabarro M, Fridkin S, Musinski D, LaClaire L, Elliott J, Cook DJ, Kornblum J, Layton M. Persistence of fluoroquinoloneresistant, multidrug-resistant Streptococcus pneumoniae in a long-term-care facility: efforts to reduce intrafacility transmission. Infect Control Hosp Epidemiol.2005;26:239-47.

Furtado GHC, Martins ST, Coutinho AM. Wey SB, Medeiros EA. Prevalence and factors associated with rectal vancomycin-resistant enterococci Colonization in two intensive care units in São Paulo, Brazil. Braz J Infect Dis. 2005a;9:64-9. 
Furtado, GH, Martins, ST, Coutinho, AP, Soares, GM, Wey SB, Medeiros, EA. Incidence of vancomycin-resistant Enterococcus at a university hospital in Brazil. Rev Saude Publica. 2005b;39;41-6.

Garner JS. Guideline for isolation precautions in hospitals. The Hospital Infection Control Practices Advisory Committee. Infect Control Hosp Epidemiol 1996;17;53-80.

Gardner JS, Jarvis WR, Emori TG. CDC definitions for nosocomial infections. Am J Infect Control. 1988;16:128-40

Gordin FM, Schultz ME, Huber RA, Gill JA. Reduction in nosocomial transmission of drug-resistant bacteria after introduction of an alcohol-based handrub. Infect Control Hosp Epidemiol. 2005;26:650-3.

Guglielmo BJ, Dudas V, Maewal I, Young R, Hilts A, Villmann M, Gibbs L, Gropper M, Jacobs R: Impact of a series of interventions in vancomycin prescribing on use and prevalence of vancomycin- resistant enterococci. Jt Comm J Qual Patient Saf. 2005, 31:469-75.

Hachem R, Graviss L, Hanna H, Arbuckle R, Dvorak T, Hackett B, Gonzalez V, Perego C, Tarrand J, Raad I. Impact of surveillance for vancomycinresistant enterococci on controlling a bloodstream outbreak among patients with hematologic malignancy. Infect Control Hosp Epidemiol. 2004;25:391-4. 
Handwerger S, Raucher B, Altarac D. Nosocomial outbreak due to Enterococcus faecium highly resistant to vancomycin, penicillin, and gentamicin. Clin Infect Dis. 1993;16:750.

Harbarth S, Cosgrove S, Carmeli Y: Effects of antibiotics on nosocomial epidemiology of vancomycin-resistant enterococci. Antimicrob Agents Chemother. 2002;46:1619-28.

Hardy KJ, Oppenheim BA, Gossain S, Gao F, Hawkey PM. A study of the relationship between environmental contamination with methicillin-resistant Staphylococcus aureus (MRSA) and patients' acquisition of MRSA.Infect Control Hosp Epidemiol. 2006;27:127-32

Harstein Al, LeMonte AM, Iwamoto PK. DNA typing and control of methicillinresistant Staphylococcus aureus at two affiliated hospitals. Infect Control Hosp Epidemiol. 1997;18: 42-8.

Hayden MK, Trenholme GM, Schultz JE, Sahm DF. In vivo development of teicoplanin resistance in a VanB Enterococcus faecium isolate. J Infect Dis. 1993;167:1224-7.

Hayden MK, Bonten JM, Blom DW, Lyle EA, van de Vijver DA, Weinstein RA. Reduction in acquisition of vancomycin-resistant enterococcus after enforcement of routine environmental cleaning measures. Clin Infect Dis. $2006 ; 42: 1552-60$. 
Hayden MK, Blom DW, Lyle EA, Moore CG, Weinstein RA. Risk of hand or glove contamination after contact with patients colonized with vancomycinresistant enterococcus or the colonized patients' environment . Infect Control Hosp Epidemiol 2008;29:149-54.

Herman D J, Gerding DN. Screening and treatment of infections caused by resistant enterococci. Antimicrob. Agents Chemother. 1991;35:215-9.

Hota B. Contamination, disinfection, and cross-colonization: are hospital surfaces reservoirs for nosocomial infection? Clin Infect Dis. 2004;39:182-9.

Huang SS, Datta R, Platt R. Risk of acquiring antibiotic-resistant bacteria from prior room occupants. Arch Intern Med. 2006;166:1945-51.

Huskins WC. Interventions to prevent transmission of antimicrobial-resistant bacteria in the intensive care unit. Curr Opin Crit Care 2007;13:572.

Jochimsen EM, Fish L, Manning K. Young S, Singer DA, Baker R, Jarvis WR Control of vancomycin-resistant enterococci at a community hospital: efficacy of patient and staff cohorting. Infect Control Hosp Epidemiol. 1999;20:106-9.

Junior, MS; Correa, L.; Marra, A.R.; Camargo, L.F.A.; Pereira, C.A.P. Analysis of vancomycin use and associated risk factors in a university teaching hospital: a prospective cohort study BMC Infectious Diseases. 2007, 7:88 
Kalocheretis P, Baimakou E, Zerbala S, Papaparaskevas J, Makriniotou I, Tassios PT, latrou C, Kouskouni E, Zerva L. Dissemination of vancomycinresistant enterococci among haemodialysis patients in Athens, Greece..J Antimicrob Chemother. 2004;54:1031-4.

Kaufmann M E. Pulsed-field gel electrophoresis. In: Woodford N, Johnson AP. editors. Molecular bacteriology:: protocols and clinical application. Totowa: Humana Press; 1998. p. 33-50.

Kawalec M, Gniadkowski M, Zaleska M, Ozorowski T, Konopka L, Hryniewicz W. Outbreak of vancomycin-resistant Enterococcus faecium of the phenotype VanB in a hospital in Warsaw, Poland: probable transmission of the resistance determinants into an endemic vancomycin-susceptible strain. $J$ Clin Microbiol. 2001;39:1781-7.

Kaye KS, Engemann JJ, Mozaffari E, Carmeli Y. Reference group choice and antibiotic resistance outcomes. Emerg Infect Dis. 2004;10:1125.

Kearns AM, Freeman R, Lightfoot NF. Nosocomial enterococci to heat and sodium hypochloride. J Hosp Infect. 1995;3:193-9.

Kim PW, Roghmann MC. Perencevich EN, Harris AD. Rates of hand disinfection associated with glove use, patient isolation, and changes between exposure to various body sites. Am J Infect Control. 2003;31:97-103. 
Klare I, Konstabel C, Mueller-Bertling S, Werner G, Strommenger B, Kettlitz C, Borgmann S, Schulte B, Jonas D, Serr A, Fahr AM, Eigner U, Witte W. Spread of ampicillin/vancomycin-resistant Enterococcus faecium of the epidemic-virulent clonal complex-17 carrying the genes esp and hyl in German hospitals. Eur J Clin Microbiol Infect Dis. 2005;24:815-25.

Koc Y, Snydman DR, Schenkein DS, Miller KB.Vancomycin-resistant enterococcal infections in bone marrow transplant recipients. Bone Marrow Transplant. 1998;22:207-9

Koh TH, Hsu LY, Chiu LL, Lin RV. Emergence of epidemic clones of vancomycin-resistant Enterococcus faecium in Singapore. J Hosp Infect. 2006; 63:234-6

Kolar M, Pantucek R, Vagnerova I, Sauer P, Kesselova M, Cekanova L, Koukalova D, Doskar J, Ruzickova V. Prevalence of vancomycin-resistant enterococci in hospitalized patients and those living in the community in the Czech Republic. New Microbiol. 2006;29:121-5.

Kuriyama T, Williams D, Patel M, Lewis M, Jenkins L, Hill D. Hosein IK. Molecular characterization of clinical and environmental isolates of vancomycin-resistant Enterococcus faecium and Enterococcus faecalis from a teaching hospital in Wales. J Med Microbiol. 2003;52:821-7. 
Lai KK, Kelley AL, Melvin ZS, Belliveau PP, Fontecchio SA: Failure to eradicate vancomycin-resistant enterococci in a university hospital and the cost of barrier precautions. Infect Control Hosp Epidemiol 1998, 19:647-52.

Larson EL, Early E, Cloonan P, Sugrue S, Parides M. An organizational climate intervention associated with increased handwashing and decreased nosocomial infections. Behav Med. 2000;26:14-22.

Lautenbach E, LaRosa LA, Marr AM, Nachamkin I, Bilker WB, Fishman NO. Changes in the prevalence of vancomycin-resistant enterococci in response to antimicrobial formulary interventions: impact of progressive restrictions on use of vancomycin and third-generation cephalosporins. Clin Infect Dis. $2003 ; 36: 440-6$.

Leavis HL, Bonten MJ, Willems RJ. Identification of high-risk enterococcal clonal complexes: global dispersion and antibiotic resistance. Curr Opin Microbiol. 2006;9:454-60.

Leavis HL, Willems RJ, Top J, Spalburg E, Mascini EM, Fluit AC, Hoepelman A, de Neeling AJ, Bonten MJ. Epidemic and nonepidemic multidrug-resistant Enterococcus faecium. Emerg Infect Dis. 2003;9:1108-15

Leclercq R, Derlot E, Duval J. Plasmid-mediated resistance to vancomycin and teicoplanin in Enterococcus faecium. N Engl J Med.1988;319:157-61. 
Lemmen SW, Hafner H, Zolldann D, Stanzel S, Lutticken R. Distribution of multi-resistant Gram-negative versus Gram-positive bacteria in the hospital inanimate environment. J Hosp Infect; 2004;5:191-7.

Lin SW, Carver PL, DePestel, DD. Dalbavancina: a new option for the treatment of gram-positive infections. Ann Pharmacother. 2006;40:449-60.

Littvik AM, López TN, González SE, Fernández CM, Pavan JV. Colonization with vancomycin-resistant enterococci (VRE) in intensive care unit patients in Cordoba City, Argentina. Rev Argent Microbiol. 2006;38:28-30.

Livornese LL Jr, Dias S, Samel C. Hospital-acquired infection with vancomycin-resistant Enterococcus faecium transmitted by electronic thermometers. Ann Intern Med. 1992;117:112-6.

Loukil C, Saizou C, Doit C, Bidet P, Mariani-Kurkdjian P, Aujard Y, Beaufils F, Bingen E. Epidemiologic investigation of Burkholderia cepacia acquisition in two pediatric intensive care units. Infect Control Hosp Epidemiol. 2003;24:707-10.

Low DE, Keller N, Barth A, Jones RN. Clinical prevalence, antimicrobial susceptibility, and geographic resistance patterns of enterococci: results from the SENTRY antimicrobial surveillance program, 1997-1999. Clin Infect Dis.2001;32(Suppl 2):S133-45. 
Madaras-Kelly K J, Remington R E, Lewis PG, Stevens DL. Evaluation of an intervention designed to decrease the rate of nosocomial methicillin-resistant Staphylococcus aureus infection by encouraging decreased fluoroquinolone use. Infect Control Hosp Epidemiol. 2006;27:155-69.

Maki,DG, Alvarado CJ, Hassemer CA, Zilz MA. Relation of the inanimate hospital environmental to endemic nosocomial infection. New Engl J Med. $1982 ; 307: 1562-66$.

Marín ME, Mera JR, Arduino RC, Correa AP, Coque TM, Stamboulian D, Murray BE. First report of vancomycin-resistant Enterococcus faecium isolated in Argentina. Clin Infect Dis. 1998;26:235-6.

Martinez JA, Ruthazer R, Hansjosten K, Barefoot L, Snydman DR. Role of environmental contamination as a risk factor for acquisition of vancomycinresistant enterococci by inpatients treated in a medical intensive care unit. Arch Intern Med. 2003;163:1905-12.

Maschieto A, Martinez R, Palazzo ICV, Darini ALC. Antimicrobial resistance of Enterococcus spp. Isolated from the intestinal tract of patients from a University Hospital in Brazil. Mem. Inst.Oswaldo Cruz. 2004;99:763-67.

Mascini EM, Troelstra MB, Beitsma M. Genotypng and preemptive isolation to control an outbreak of vancomycin-resistant Enterococcus faecium, Clin Infect Dis. 2006;42:739-46. 
McKessar SJ, Berry AM, Bell JM, Turnidge JD, Paton JC. Genetic characterization of vanG, a novel vancomycin resistance locus of Enterococcus faecalis. . 2000;44:3224-8.

Mevius D, Devriese L, Butaye P, Vandamme P, Verschure M, Veldman K. Isolation of glycopeptide resistant Streptococcus gallolyticus strains with vanA, vanB, and both vanA and vanB genotypes from faecal samples of veal calves in The Netherlands. J Antimicrob Chemother. 1998 ;42:275-6.

Moellering RC. Emergence of Enterococcus as a significant pathogen. Clin Infect Dis. 1992;14:1173-8

Montecalvo MA, Jarvis WR, Uman J. Shay DK, Petrullo C, Rodney K, Gedris C, Horowitz HW, Wormser GP.Infection-control measures reduce transmission of vancomycin-resistant enterococci in an endemic setting. Ann Intern Med. 1999;131:269-72.

Moretti, MI; Bratfich, Oj; Stucchi, Rb; Levi, C E; Levin, As; Duboc, Gm; Vormittag, E; Blum-Menezes, D. Clonal dissemination of VanA-type glycopeptide-resistant Enterococcus faecalis between hospitals of two cities located 100 km apart. Braz J Med Biol Res. 2004; 37:1339-43.

Morris JG Jr, Shay DK, Hebden JN, McCarter RJ Jr, Perdue BE, Jarvis W, Johnson JA, Dowling TC, Polish LB, Schwalbe RS. Enterococci resistant to multiple antimicrobial agents, including vancomycin. Establishment of endemicity in a university medical center. Ann Intern Med. 1995;123:250-9. 
Murray BE. The life and times of the enterococcus. Clin Microbiol Rev. 1990;3:46-65.

Murray,B.E. Drug therapy: vancomycin-resistant Enterococcal Infections . The New Engl J Med. 2000;342:710-21.

Murray PR, Baron EJ, Pfaller MA, Tenover FC, Yolken RH. Manual of clinical microbiology. 8th ed. Washington DC: American Society for Microbiology, 2003.

Mutnick AH, Biendenbach DJ, Jones RN. Geographic variations and trends in antimicrobial resistance among Enterococcus faecalis and Enterococcus faecium in the SENTRY Antimicrobial Surveillance Program (1997-2000). Diagn Microbiol Infect Dis. 2003;46:63-8.

Muto CA, Sistrom MG, Farr BM. Hand hygiene rates unaffected by installation of dispensers of a rapidly acting hand antiseptic. Am J Infect Control. 2000;28:273-76.

Muto C, Jernigan J, Ostrowsky B, Richet M, Jarvis W, Boyce J. SHEA Guideline for preventing nosocomial transmission of multidrug-resistant strains of Staphylococcus aureus and Enterococcus. Infect Control Hosp Epidemiol 2003;24:362-86. 
Naas T, Fortineau N, Snanoudj R, Spicq C, Durrbach A, Nordmann P. First nosocomial outbreak of vancomycin-resistant Enterococcus faecium expressing a VanD-like phenotype associated with a vanA genotype. J Clin Microbiol. 2005;43:3642-9.

National Nosocomial Infections Surveillance System (NNIS) report: data summary from October 1986-April 1997, issued May 1997. A report from the NNIS System. Am J Infect Control. 1997;25:477-87.

National Nosocomial Infections Surveillance (NNIS). System Intensive care antimicrobial resistance epidemiology (ICARE) surveillance report, data summary from January 1996 through December 1997. Am J Infect Control.1999;27:279-84.

National Nosocomial Infections Surveillance (NNIS) System report, data summary from January 1992-June 2001, issued August 2001 [correction in Am J Infect Control. Am J Infect Control. 2001;29:400-21.

National Nosocomial Infections Surveillance (NNIS) system report, data summary from January 1992 to June 2003, issued August 2003. Am J Infect Control. 2003;31:481-98.

National Nosocomial Infections Surveillance (NNIS) System report, data summary from January 1992 through June 2004, issued October 2004. Am J Infect Control. 2004;32:470-85. 
Navarro F, Courvalin P. Analysis of genes encoding D-alanine-D-alanine ligase-related enzymes in Enterococcus casseliflavus and Enterococcus flavescens. Antimicrob Agents Chemother. 1994;38:1788-93.

Nicolle LE, Dyck B, Thompson G. Roman S, Kabani A, Plourde P, Fast M, Embil J Regional dissemination and control of epidemic methicillin-resistant Staphylococcus aureus. Infect Control Hosp Epidemiol. 1999;202-05.

Noskin GA, Stosor V, Cooper I. Peterson LR. Recovery of vancomycinresistant enterococci on fingertips and environmental surfaces. Infect Control Hosp Epidemiol. 1995; 16:577-81.

Noskin GA, Bednarz P, Suriano T, Reiner S, Peterson LR. Persistent contamination of fabric-covered furniture by vancomycin-resistant enterococci: implications for upholstery selection in hospitals. Am J Infect Control. 2000;28:311-3.

Ofner-Agostini M, Varia M, Johnston L., Green K, M. A. S. et al RN,a the Canadian Nosocomial Infection Surveillance Program, Am J Infect Control. $2007 ; 35: 563-8$

Oliveira,OL; Jardim,OS. Controle do Enterococcus resistente a vancomicina (VRE) em um hospital de reabilitação. VI Congresso Pan-Americano e $X$ Congresso Brasileiro de Controle de Infecção e Epidemiologia Hospitalar, Porto Alegre, 2006, Res 109. 
Oprea , S F , Zaid, N, Donabedian, S M, Balasubramaniam, M, Hershberger E, Zervos, M J Molecular and clinical epidemiology of vancomycin-resistant Enterococcus faecalis. J. Antimicr Chemothe. 2004;53:626-30.

Ostrowsky BE, Trick WE, Sohn AH, Quirk SB, Holt S, Carson LA, Hill BC, Arduino MJ, Kuehnert MJ, Jarvis WR. Control of vancomycin-resistant enterococcus in health care facilities in a region. $N$ Engl $\mathrm{J}$ Med. 2001;344:1427-33.

Patel R. Clinical impact of vancomycin-resistant enterococci. J. Antimicr Chemothe. 2003; 51(Suppl 3):iii13-21.

Pearman JW. 2004 Lowbury Lecture: the Western Australian experience with vancomycin-resistant enterococci - from disaster to ongoing control. J Hosp Infect. 2006;63:14-26.

Perencevich EN, Fisman DN, Lipsitch M, Harris AD, Morris JG Jr, Smith DL. Projected benefits of active surveillance for vancomycin-resistant enterococci in intensive care units. Clin Infect Dis. 2004;38:1108-15.

Palmer, S. M., and M. J. Rybak. Vancomycin-resistant enterococci. Pharmacotherapy. 1996; 16:819-29. 
Peta M, Carretto E, Barbarini D, Zamperoni A, Carnevale L, Perversi L, Pagani M, Bonora MG, Fontana R, Marone P, Langer M.Outbreak of vancomycin-resistant Enterococcus spp. in an Italian general intensive care unit. Clin Microbiol Infect. 2006;12:163-9.

Petrich AK, Luinstra KE, Groves D, Chernesky MA, Mahony JB. Direct detection of vanA and vanB genes in clinical specimens for rapid identification of vancomycin resistant enterococci (VRE) using multiplex PCR. Mol Cell Probes. 1999;13:275-81.

Pfaller, M.A. ; Hollis, R.J.; Sader, H.S. Molecular Biology - PFGE Analysis of Chromossomal Restriction Fragments. In: Isenberg, H.D. Clinical Microbiology Procedures Handbook. Washington, ASM Press, 1992; P.p.10.5.c.11.

Porwancher R, Sheth A, Remphrey S, Taylor E, Hinkle C, Zervos M. Epidemiological study of hospital-acquired infection with vancomycinresistant Enterococcus faecium: possible transmission by an electronic earprobe thermometer. Infect Control Hosp Epidemiol. 1997;18:771-3.

Puzniak LA, Leet T, Mayfield J, Kollef M, Mundy LM.To gown or not to gown: the effect on acquisition of vancomycin-resistant enterococci. Clin Infect Dis. 2002;35:18-25. 
Quale, J. M., Landman, D., Bradford, P. A., Visalli, M., Ravishankar, J., Flores, C., Mayorga, Molecular epidemiology of a citywide outbreak of extended-spectrum beta-lactamase-producing Klebsiella pneumoniae infection. Clin Infect Dis. 2002;35:834-41.

Ray AJ, Hoyen CK, Das SM, Eckstein EC, Donskey CJ. Undetected vancomycin-resistant Enterococcus stool colonization in a Veterans Affairs Hospital using a Clostridium difficile-focused surveillance strategy. Infect Control Hosp Epidemiol. 2002; 23:474-7.

Rahal JJ, Urban C, Segal-Maurer S. Nosocomial antibiotic resistance in multiple gram-negative species: experience at one hospital with squeezing the resistance balloon at multiple sites. Clin Infect Dis. 2002;34;499-503.

Reinert RR, Conrads G, Schlaeger JJ, Werner G, Witte W, Lütticken R, Klare I. Survey of antibiotic resistance among enterococci in North RhineWestphalia, Germany. J Clin Microbiol. 1999;37:1638-41.

Reis AO; Cordeiro JC, Machado AM, Sader HS. In vitro antimicrobial activity of linezolid tested against vancomycin-resistant enterococci isolated in Brazilian hospitals. Brazilian J Infec Dis. 2001;5:243-51.

Rice LB, Eckstein, EC, DeVente J, Shlaes DM. Ceftazidime-resistant Klebsiella pneumoniae isolates recovered at the Cleveland Department of Veterans Affairs Medical Center. Clin Infect Dis.1996;23:118-24. 
Rice LB. Emergence of vancomycin-resistant enterococci. Emerg. Infect. Dis. 2001;7:183-87.

Rice LB, Hutton-Thomas R, Lakticova V. Beta-lactam antibiotics and gastrointestinal colonization with vancomycin-resistant enterococci. J Infect Dis. 2004;189:1113-18.

Rippere K, Patel R, Uhl JR, Piper KE, Steckelberg JM, Kline BC, Cockerill FR 3rd, Yousten AA. DNA sequence resembling vanA and vanB in the vancomycin-resistant biopesticide Bacillus popilliae. J Infect Dis. 1998;178:584-88.

Rodrigues, A.C.A.R., Máximo C., Cavalcanti R., Ribeiro M. D. E Carvalho S.M.F. Investigação epidemiológica de um surto de Enterococcus faecium Resistente à vancomicina (VRE) em um hospital de onco-hematologia. VI Congresso Pan-Americano e X Congresso Brasileiro de Controle de Infecção e Epidemiol Hosp, Porto Alegre 2006, Res302.

Rubin LG, Tucci V, Cercenado E, Eliopoulos G, Isenberg HD: Vancomycinresistant Enterococcus faecium in hospitalized children. Infect Control Hosp Epidemiol. 1992;13:700-5.

Rupp ME, Marion N, Fey PD. Outbreak of vancomycin-resistant Enterococcus faecium in a neonatal intensive care unit. Infect Control Hosp Epidemiol. 2001;22:301-3. 
Rutala, W.A.; Katz, E.B.; Sherertz, R.J.; Sarubbi, Jr, F.A. Environmental study of methicillin-resistant Staphylococcus aureus epidemic in a burn unit. J Clin Microbi. 1983:18:306-9.

Ryan MA, Akinbi HT, Serrano AG, Perez-Gil J, Wu H, McCormack FX, Weaver TE.Antimicrobial activity of native and synthetic surfactant protein B peptides.J Immunol. 2006;176:416-25.

Schultsz C, Meester HH, Kranenburg AM, Savelkoul PH, Boeijen-Donkers LE, Kaiser AM, de Bree R, Snow GB, Vandenbroucke-Grauls CJ. Ultra-sonic nebulizers as a potential source of methicillin-resistant Staphylococcus aureus causing an outbreak in a university tertiary care hospital. $J$ Hosp Infect. 2003; 55:269-75.

Severin A, Tabei, Tenover F, Chung M, Clarke N, Tomasz A. High level oxacillin and vancomycin resistance and altered cell wall composition in Staphylococcus aureus carrying the staphylococcal mecA and the enterococcal vanA gene complex. J Biol Chem. 2004;279:3398-407.

Shonekan D, Mildvan D, Handwerger S. Comparative in vitro activities of teicoplanin, daptomycin, ramoplanin, vancomycin, and PD 127,391 against blood isolates of gram-positive cocci. Antimicrob Agents Chemother.1992;36:1570-72. 
Sielfeld MAE, Costa SF, Gomes, LMB, Rossi F, Medeiros EAS. Emergência de Enterococcus faecium resistentes a vancomicina em unidades de terapia intensiva e imunodeprimidos de um hospital terciário de ensino. VI Congresso Pan-Americano e X Congresso Brasileiro de Controle de Infecção e Epidemiologia Hospitalar Porto Alegre. 2006, Res 522.

Siegel JD, Rhinehart E, Jackson M, Chiarello L. The Healthcare Infection Control Advisory Committee. Management of multi-resistant organisms in healthcare settings, 2006. Atlanta : Centers for Disease Control and Prevention; 2006.

Siegel JN, Rhinehart E, Jackson M, Chiarello L. Guideline for isolation precautions: preventing transmission of ilnfectious agents in Healthcare. 2007; Disponível em http://www.cdc.gov/ncidod/dhqp/pdf/isolation2007.pdf, acesso em 07 de abril de 2008 .

Simor, A. E. The role of the laboratory in infection prevention and control programs in long-term-care facilities for the elderly. Infect Control Hosp Epidemiol. 2001;22, 459-463.

Slaughter S, Hayden MK, Nathan C, Hu TC, Rice T, Van Voorhis J, Matushek M, Franklin C, Weinstein RA. A comparison of the effect of universal use of gloves and gowns with that of glove use alone on acquisition of vancomycin-resistant enterococci in a medical intensive care unit. Ann Intern Med 1996;125:448-56. 
Smith TL, Pearson LM, Wilcox KR, Cruz C, Lancaster MV, Robinson-Dunn B, Tenover FC, Zervos MJ, Band JD, White E, Jarvis WR. Emergence of Vancomycin resistance in Staphylococcus aureus. Glycopeptide-Intermediate Staphylococcus aureus Working Group. N Engl J Med. 1999;340:493-501.

Smith DL, Dushoff J, Perencevich EN, Harris AD, Levin SA Persistent colonization and the spread of antibiotic resistance in nosocomial pathogens: resistance is a regional problem. Proc Natl Acad Sci U S A 2004 101, 3709-14.

Stampone L, Del Grosso M, Boccia D, Pantostli A. Clonal spread of a vancomycin- Clonal spread of a vancomycin-resistant Enterococcus faecium strain among bloodstream-infecting isolates in Italy J Clin Microbiol. 2005;43:1575-80.

Stosor V, Kruszynski J, Suriano T, Noskin GA, Peterson LR Molecular epidemiology of vancomycin-resistant enterococci: a 2-year perspective. Infect Control Hosp Epidemiol. 1999;20:653-9.

Srinivasan A, Song X, Ross T, Merz W, Brower R, Perl TM. A prospective study to determine whether cover gowns in addition to gloves decrease nosocomial transmission of vancomycin-resistant enterococci in an intensive care unit. Infect Control Hosp Epidemiol. 2002;23:424-28. 
Tenorio AR, Badri SM, Sahgal NB, Hota B, Matushek M, Hayden MK, Trenholme GM, Weinstein RA. Effectiveness of gloves in the prevention of hand carriage of vancomycin-resistant Enterococcus species by health care orkers after patient care. Clin Infect Dis. 2001;32:826-29.

Tenover FC, Arbeit RD, Goering RV. How to select and interpret molecular strain typing methods for epidemiological studies of bacterial infections: a review for healthcare epidemiologists. Molecular Typing Working Group of the Society for Healthcare Epidemiology of America. Infect Control Hosp Epidemiol. 1997; 18:426-39.

Tenover, FC, Mcdonald, C. Vancomycin-resistant staphylococci and enterococci: epidemiology and control. Curr Opin Infect Dis. 2005; 18:300-5.

Tenover FC, Weigel LM, Appelbaum PC, et al. Vancomycin-resistant Staphylococcus aureus isolate from a patient in Pennsylvania. Antimicrob Agents Chemother. 2004;48: 275-80.

Titze-de-Almeida R, Rollo Filho M, Nogueira CA, Rodrigues IP, Eudes Filho J, Nascimento RS, Ferreira RF 2nd, Moraes LM, Boelens H, Van Belkum A, Felipe MS. Molecular epidemiology and antimicrobial susceptibility of Enterococci recovered from Brazilian intensive care units. Braz J Infect Dis. 2004;8:197-205. 
Tiwari HK, Sen MR. Emergence of vancomycin resistant Staphylococcus aureus (VRSA) from a tertiary care hospital from northern part of India. BMC Infect Dis. 2006;6:156.

Togneri AM, Corso A, González J, Lopardo H, Podesta LB, Gagetti P, et al. Clinical and epidemiologic analysis of intestinal tract colonization with vancomycin-resistant enterococci in an intensive care unit. Rev Argent Microbiol. 2005;37:26-33.

Tresoldi AT, Cardoso LG, Castilho GV, Dantas SR, von Nowakonski A, Pereira RM,Trabasso P. Low prevalence of vancomycin resistant enterococci colonization in intensive care patients in a Brazilian teaching hospital. Braz $J$ Infect Dis. 2006;10:239-41.

Trick WE, Vernon MO, Welbel SF, Demarais P, Hayden MK, Weinstein RA Multicenter intervention program to increase adherence to hand hygiene recommendations and glove use and to reduce the incidence of antimicrobial resistance. Infect Control Hosp Epidemiol. 2007;28:42-9.

Tsigrelis C, Singh KV, Coutinho TD, Murray BE, Baddour LM. Vancomycinresistant Enterococcus faecalis endocarditis: linezolid failure and strain characterization of virulence factors. J Clin Microbiol. 2007;45:631-5. 
Tucci V.; Haran M. A.;Isenberg, H. Epidemiology and control of vancomycinresistant enterococci in an adult and children's hospital. American Journal of Infection Contro., 1997;25:371-76.

Uttley $\mathrm{AH}$, Collins $\mathrm{CH}$, Naidoo J, George RC. Vancomycin-resistant enterococci. Lancet. 1988;1:57-58.

van den Bogard AE, Jensen LB, Stobberingh EE. Vancomycin-resistant enterococci in turkeys and farmers. N Engl J Med. 1997; 337:1558-59.

van den Braak N., Ott A., van Belkum A., Kluytmans JA, Koeleman JG, Spanjaard L, Voss A, Weersink AJ, Vandenbroucke-Grauls CM, Buiting AG, Verbrugh HA, Endtz HP.. Prevalence and determinants of fecal colonization with vancomycin-resistant enterococci in hospitalized patients in The Netherlands. Infect Control Hosp Epidemiol. 2000;21:520-4.

Vernon MO, Hayden MK, Trick WE, Hayes RA, Blom DW, Weinstein RA. Chlorhexidine gluconate to cleanse patients in a medical intensive care unit. Arch Intern Méd. 2006;166:306-12.

Vilela MA, Souza SL, Palazzo ICV, Ferreira JC, Morais Jr MA, Darini ALC, Morais MMC. Identification and molecular characterization of Van A-type vancomycin-resistant Enterococcus faecalis in Northeast of Brazil / BMC Infectious Diseases. 2007,7:88-92. 
Wade J, Baille L, Rolando N, Casewell M. Pristinamycin for Enterococcus faecium resistant to vancomycin and gentamicin. Lancet. 1992;339:312-3.

Wade JJ, Desai N, Casewell MW. Hygienic hands desinfection for the removal of epidemic vancomycin resistant Enterococcus faecium and gentamicin-resistant Enterobacter cloacae. J Hosp Infect. 1991;18:211-8.

Weber, D.J.; Rutala, W.A. Role of environmental contamination in the transmission of vancomyci-resistant enterococci. Infection Control Hospital Epidemiology. 1997;18:306-309.

Wendt C, Wiesenthal B, Dietz E, Ruden H. Survival of vancomycin-resistant and vancomycin-susceptible enterococci on dry surfaces. J Clin Microbiol. 1998;36:3734-6.

Werner, G.; Klare, I.; Fleige’ C.; Witte, W. Increasing rates of vancomycin resistance among Enterococcus faecium isolated from German hospitals between 2004 and 2006 are due to wide clonal dissemination of vancomycinresistant enterococci and horizontal spread of vanA clusters. Int $\mathrm{J}$ Med Microbiol. 2007 Oct 29 [Epub ahead of print].

Westenfelder, G. O., P. Y. Paterson, B. E. Reisberg, and G. M. Carlson. Vancomycin-streptomycin synergism in enterococcal endocarditis. JAMA. 1973;223:37-40. 
Whitener CJ, Park SY, Browne FA, Parent LJ, Julian K, Bozdogan B, Appelbaum PC, Chaitram J, Weigel LM, Jernigan J, McDougal LK, Tenover FC, Fridkin SK.Vancomycin-resistant Staphylococcus aureus in the absence of vancomycin exposure. Clin Infect Dis. 2004;38:1049-55.

Wilks, M; Wilson, A; Warwick,S; Price, E; Kennedy, D; Ely, A; Millar,MR. Control of an Outbreak of Multidrug-Resistant Acinetobacter baumanniicalcoaceticus Colonization and Infection in an Intensive Care Unit (ICU) Without Closing the ICU or Placing Patients in Isolation. Infect Control and Hosp Epidemiol. 2006;27:654-58.

Willems R, Homan W, Top J, van Santen-Verheuvel M, Tribe D, Manzioros X, Gaillard C, Vandenbroucke-Grauls CM, Mascini EM, van Kregten E, van Embden JD, Bonten MJ. Variant esp gene as a marker of a distinct genetic lineage of vancomycin-resistant Enterococcus faecium spreading in hospitals. Lancet 2001;357:853-55.

Willems RJ, Top J, van Santen M, Robinson DA, Coque TM, Baquero F, Grundmann H, Bonten MJ. Global spread of vancomycin-resistant Enterococcus faecium from distinct nosocomial genetic complex. Emerg Infect Dis. 2005;11: 821-28. 
Zanella RC, Valdetaro F, Lovgren M, Tyrrel GJ, Bokermann S, Almeida SC, Vieira VS, Brandileone MC. First confirmed case of a vancomycin-resistant Enterococcus faecium with vanA phenotype from Brazil: isolation from a meningitis case in Sao Paulo. Microb Drug Resist 1999;5:159-62.

Zárate, M S , Gales, A.; Jordá-Vargasa,L.; Yahnic,D.; Relloso, S.; Bonvehi,P.; Monteiro,J.; Pignatari , AC; Smayevsky, J. Contaminación ambiental durante un brote de enterococo resistente a vancomicina en un hospital de Argentina. Enferm Infecc Microbiol Clin. 2007;25:508-12. 